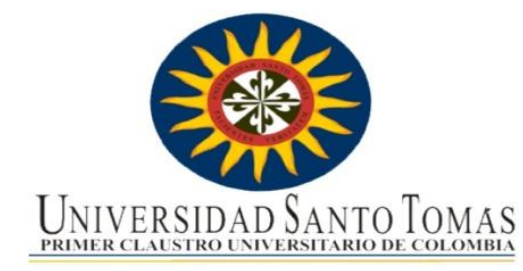

\title{
Emisoras comunitarias del sur del Tolima y Política pública de radiodifusión comunitaria en Colombia. Un escenario en tensión
}

\author{
Mónica del Pilar Álvarez Bustos
}

Universidad Santo Tomás

Maestría en Comunicación, Desarrollo y Cambio Social

Bogotá, Colombia

2018 



\section{Emisoras comunitarias del sur del Tolima y la Política Pública de radiodifusión comunitaria en \\ Colombia. Un escenario en tensión.}

\section{Mónica del Pilar Álvarez Bustos}

Trabajo de investigación presentado como requisito parcial para optar al título de:

Magister en Comunicación, Desarrollo y Cambio Social

Director (a):

Magister Carlos Durán

Línea de Investigación:

Comunicación gobierno y ciudadanía

Universidad Santo Tomás

Facultad de Comunicación Social

Bogotá, Colombia

2018 



\begin{abstract}
A mi familia, especialmente a mis soles de primavera, mi hijo Gabriel y mi hermana Alexandra.
\end{abstract}

A Jesús y Juan Ramos por ser incondicionales y por librarme de APA, Icontec y otros demonios

A mi tutor Carlos Durán por su confianza, su enorme paciencia y sus valiosos aportes

A mi equipo PyR por ser quienes son en mi vida

A todas las comunidades que hacen posible la radiodifusión comunitaria y que diariamente nos dan razones para la esperanza. 



\section{Resumen}

El objetivo del estudio fue Identificar y describir las tensiones que se presentan entre el funcionamiento de las emisoras comunitarias y los lineamientos de la Política Nacional de Radiodifusión Sonora Comunitaria, mediante el análisis de cuatro emisoras del sur del Tolima con el propósito de generar referentes de reflexión que sirvan para proyectar las políticas públicas nacionales y revisar la Política Pública vigente. La metodología es cualitativa, especialmente porque en esta tradición se sitúan los procesos de caracterización. La identificación de las tensiones entre el estado de las emisoras implica, de un lado, la caracterización de las emisoras comunitarias y por otro, la revisión documental de la política pública de comunicación comunitaria.

El diálogo e incidencia en lo público que se logra en cada contexto refleja la cultura política, el grado de participación cívica de los ciudadanos, la capacidad de las emisoras comunitarias para ser accesibles a la gente. Refleja también quiénes son los individuos y las instituciones más respetados, cuáles son considerados confiables y cuáles no, qué papel cumplen los actores en la comunidad y qué deudas tienen individuos e instituciones para con la sociedad.

Palabras clave: Radio comunitaria, Políticas públicas, Tensión, Participación ciudadana, Espacios públicos. 


\section{Contenido}

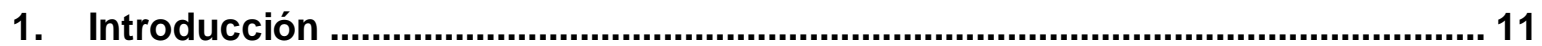

2. Capítulo 1. Planteamiento de la investigación ......................................................14

2.1 Identificación general del proyecto ………….............................................. 14

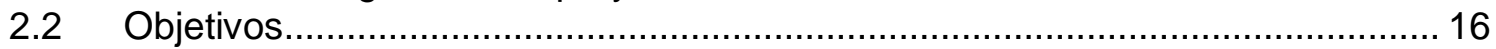

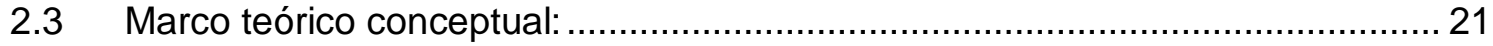

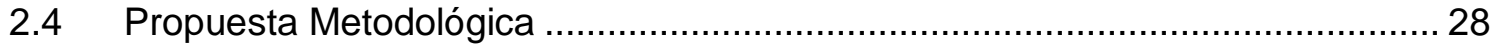

3. Capítulo 2. Política de Radiodifusión Sonora comunitaria en Colombia: pistas para entenderla....................................................................................................33

3.1 Marco normativo de la Radiodifusión Sonora Comunitaria en Colombia ............ 35

4. Capítulo 3. Breve marco histórico de las emisoras comunitarias del sur del

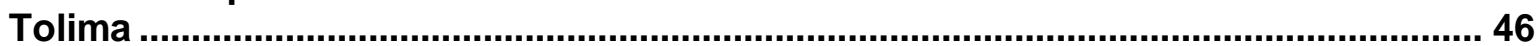

4.1 Natagaima: Emisora Haca Yu Macu 106.0 FM ........................................... 46

4.2 Alpujarra: Samán estéreo 102.5 F.M...................................................... 48

4.3 Rioblanco: Rioblanco estéreo 95.0 FM ..................................................51

4.4 San Antonio: Tetúan estéreo ……………………................................ 52

5. Capítulo 4: La tensión como encuentro .............................................................54

5.1 Tensión 1. El prisma de la participación ...................................................... 56

5.2 Tensión 2. La construcción de lo público: Un juego con muchas caras .............. 68

5.3 Tensión 3. La radio comunitaria como experiencia política ……………............ 75

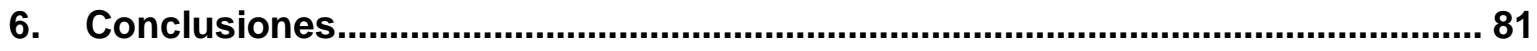

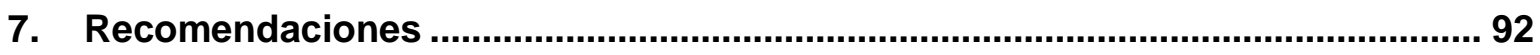

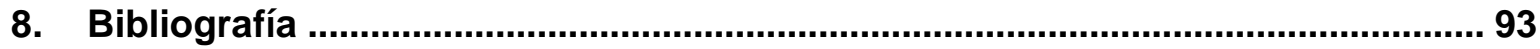

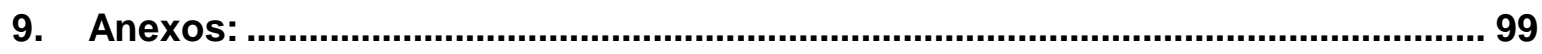




\section{Lista de Figuras}

Figura 1: Ubicación geográfica de las emisoras comunitarias consideradas en el estudio 56

\section{Lista de Tablas}

Tabla 1: Tabla №1. Objetivos, estrategias y herramientas de la Política Pública de Radiodifusión sonora comunitaria. 



\section{Introducción}

“La comunicación es la columna vertebral de la humanidad. Ésta ha sido ejercida desde que nuestros pueblos comenzaron a caminar en la Madre Tierra.

Estamos llamados a recuperar la palabra propia, a descolonizarla, a retomar la tarea de caminar la palabra juntos, unidos en nuestra diversidad, y a comunicar desde la visión de nuestros pueblos construyendo medios de comunicación que expresen realmente lo que somos."

(Declaración de Puno, Mesa de Comunicación, Mayo 2009)

En el mundo contemporáneo convergen las más variadas tensiones políticas, sociales, económicas y culturales. Dichas tensiones se caracterizan, en la mayoría de los casos, por tener límites difusos y ser puntos de encuentro y desencuentro de conflictos de poder e intereses, que se legitiman en el plano material y también, incluso con más fuerza, en un plano simbólico. En este contexto, todos los campos del saber están llamados a reinventarse y a trabajar juntos.

Aún prevalece en el imaginario social, aunque quizás con menos frecuencia que hace algunos años, la idea de un mundo compartimentado, dividido en pedacitos que deben repartirse entre distintas disciplinas. La fragmentación de los saberes dificulta el abordaje de la realidad desde la complejidad que le es inherente y sirve de caldo de cultivo para la incomprensión de lo que pasa en el mundo y de los cambios por los que atraviesa la sociedad.

En medio de un panorama que no siempre es el más alentador, por los vestigios que las violencias han dejado en las regiones colombianas y por el daño que el olvido y el silencio han causado a tantas personas, emerge una fuerza renovada que promete la reivindicación de la dignidad y el bienestar humano, este contexto, ha implicado cambios sustanciales y nuevos retos para todos los saberes, pero especialmente, para el campo de la comunicación.

La comunicación es una fuerza potente. En el diálogo abierto, en la recuperación y expresión abierta y colectiva de la palabra, permite la construcción de otros mundos posibles y allí, en lo que muchas veces se considera marginal, iletrado, ignorante y pobre, florece el espíritu transformador y sabio que tanto necesita el mundo. Este trabajo es el resultado de un camino recorrido en esa dirección, contiene historias reales de cuatro emisoras comunitarias del sur del Tolima que, como diría Gumucio en la introducción al libro "Pensar desde la Experiencia", no miran solo al pasado, sino que dan cuenta de itinerarios presentes y futuros. 
El objetivo del estudio fue Identificar y describir las tensiones que se presentan entre el funcionamiento de las emisoras comunitarias y los lineamientos de la Política Nacional de Radiodifusión Sonora Comunitaria, mediante el análisis de cuatro emisoras del sur del Tolima con el propósito de generar referentes de reflexión que sirvan para proyectar las políticas públicas nacionales y revisar la Política Pública vigente. Al respecto se entiende la tensión no como un conflicto que debe resolverse, sino como una relación que se configura diariamente entre las emisoras y la Política Pública a partir de diferencias de contexto y de la creación permanente de campos de interlocución e interpelación.

Se entiende en ese sentido que las emisoras comunitarias recrean su funcionamiento en el seno de comunidades cambiantes ubicadas en contextos sociohistóricos de complejidad creciente, la Política, por su parte, intenta trazarles una ruta de trabajo. De acuerdo a esto, el principal aporte de este estudio es el planteamiento de referentes concretos de reflexión a partir de los que la Política Pública de Radiodifusión sonora comunitaria podría proponer una toma de decisiones más pertinente.

En el marco de este trabajo se reconoce que las emisoras comunitarias constituyen espacios donde las comunidades han recuperado la voz y la palabra en términos de su origen y su memoria, y de esta manera avanzan hacia un horizonte de participación y construcción colectiva. Para el estudio se tuvieron en cuenta cuatro emisoras comunitarias del sur del departamento del Tolima, la emisora Haca Yu Macu del municipio de Natagaima, Samán estéreo del municipio de Alpujarra, Rioblanco Estéreo del municipio de Rioblanco y Tetuán estéreo del municipio de San Antonio.

El documento se divide en cinco apartados. El primer apartado desarrolla el planteamiento del estudio, en función de ello, se presentan los objetivos, antecedentes, así como el marco conceptual y metodológico. La metodología corresponde al enfoque cualitativo, la recolección de información se llevó a cabo a partir de entrevistas ${ }^{1}$ con los líderes y representantes de las emisoras, talleres en los que también participaron actores de la comunidad de los municipios. De igual manera, se efectuó una revisión general de los principales referentes normativos de la radio comunitaria en Colombia, así como de la Política de Radiodifusión Sonora Comunitaria y se planteó una reflexión a la luz de un marco conceptual sobre políticas de comunicación y comunicación para el desarrollo.

El segundo apartado consiste en un marco histórico general de las cuatro emisoras comunitarias involucradas en el estudio. Por cada una de ellas se realiza una descripción que incluye información sobre el origen del medio, las rutinas de producción de contenidos, programación, proyecto comunicativo y niveles de participación de la comunidad, de forma paralela se consideran aspectos relacionados con la gestión del medio desde el punto de vista técnico y financiero.

En el tercer apartado se plantea un marco general que incluye los referentes normativos principales que regulan la radiodifusión comunitaria en Colombia y se presenta una descripción de la actual Política de Radiodifusión Sonora Comunitaria. En el cuarto apartado, de acuerdo con la información recolectada, se analizan y plantean tres tensiones entre la Política de

\footnotetext{
${ }^{1}$ Las entrevistas se llevaron a cabo entre los años 2016 y 2017
} 
Radiodifusión Sonora Comunitaria y la puesta en escena cotidiana de las emisoras comunitarias en función de las categorías de participación, construcción de lo público y comunicación política.

Por último, se plantean las conclusiones, siendo una de las principales que la Política de Radiodifusión Sonora Comunitaria pasa de un diagnóstico muy general del estado de las emisoras comunitarias en Colombia a la acción, sin detenerse en el patrimonio colectivo de respuestas, en el acervo de soluciones y los problemas sentidos de estos medios. De acuerdo con ello, se proponen líneas de reflexión que deberían considerarse en un ejercicio de actualización o construcción de Política Pública en el contexto nacional o regional.

Las dudas y las contradicciones que se gestan en el seno de las emisoras comunitarias deben servir para fundar un escenario sólido de construcción de Política Pública capaz de soportar las más variadas discusiones sociales sobre los rumbos que debe tomar la gestión comunitaria de estos medios.

Para lograr lo anterior, no basta con tomar distancia de un paradigma instrumental de la comunicación, es necesario promover la entrada en escena de cuestionamientos acerca de cuál debe ser el rol de las emisoras y los medios comunitarios en general para que las sociedades lideren procesos propios, en el marco de los cuales sea posible construir ese tejido social y cultural tan necesario para jalonar las transformaciones sociales y el bienestar.

Entonces, ¿para qué fue este trabajo? Fue hecho no sólo para cumplir con un requisito académico, sino para reconocer al otro, para soñar, para imaginar y construir otros futuros posibles; para empoderar al hombre, a la mujer, al niño, al campesino, al marginado y propiciar el entendimiento mutuo y acuerdos para la acción en escenarios en los que, en otros casos, sólo se vería conflicto.

Finalmente, es importante generar investigaciones sobre cómo se construye la política sobre medios comunitarios en Colombia, quiénes participan, de qué mecanismos se disponen para la discusión de problemáticas específicas, cómo y quiénes definen las agendas de política públicas y cómo la academia y lo líderes comunitarios pueden contribuir al conocimiento de dichas problemáticas. 


\section{Capítulo 1. Planteamiento de la investigación}

\subsection{Identificación general del proyecto}

Título del proyecto: Tensiones de las emisoras comunitarias del sur del Tolima y la política púbica de radiodifusión comunitaria en Colombia

Tema de investigación: Radios comunitarias del sur del Tolima y política pública de radiodifusión comunitaria en Colombia

\section{Línea de investigación a la que se articula}

Este trabajo se articula a la línea de investigación Comunicación, gobierno y ciudadanía toda vez que busca, en primer lugar, consolidar una lectura de las tensiones entre el estado actual de las emisoras comunitarias del sur del Tolima y la política pública de comunicación comunitaria en Colombia, a partir de la caracterización de cuatro emisoras comunitarias del sur del Tolima y la revisión de la propuesta de la política pública en materia de comunicación comunitaria. De esta manera, se espera que el estudio genere insumos a partir de los cuales los actores que participan en estos medios de comunicación puedan consolidar una propuesta para participar en un posible escenario de construcción de política pública en materia de comunicación comunitaria en el departamento del Tolima.

\section{Pertinencia de la investigación}

El ejercicio de las radios comunitarias requiere de una política pública activa que la soporte, por esta razón, el acceso de las comunidades de base para pensar, proponer y participar en la toma de decisiones del Estado frente a este tema debe ser visto en clave de problema político. El éxito de una política pública tiene que ver, por un lado, con los grados de participación de la sociedad y los mecanismos de participación del Estado y la sociedad civil que se articulan para producir acciones gubernamentales más pertinentes, y por otro, con el nivel de correspondencia con respecto a las características del contexto donde ésta se implementa.

De acuerdo a lo anterior, el presente estudio es pertinente toda vez que busca rastrear las tensiones entre el estado actual de cuatro emisoras comunitarias del sur del Tolima y la propuesta de la política de radiodifusión comunitaria en el marco nacional, y a la luz de dichas tensiones plantear una reflexión, no sólo acerca de lo impertinente que puede resultar la acción estatal cuando desconoce los contextos locales en los que cobrará vigencia, sino también, acerca de aquellos elementos o aspectos que deberían incorporarse en un posible escenario de construcción de política pública de comunicación comunitaria en el departamento.

Pensar en un escenario de construcción de política pública en el Tolima capaz de recomponer la trama de lo comunitario y lo participativo de las emisoras, y en general de los medios comunitarios, que aliente su fuerza transformadora, exige reconocer los puntos de encuentro y desencuentro que existen actualmente entre la Política y el ejercicio de las emisoras comunitarias en los contextos dentro de los cuales se ubican, es decir, las asimetrías, las formas de dominación y las lógicas que amenazan con su extinción. Desde dicho análisis es 
posible generar referentes concretos que ayuden a tender un puente entre la Política del marco nacional y las exigencias del contexto, específicamente, del departamento del Tolima.

\section{Problema de investigación}

La radiodifusión comunitaria es un tema que ha quedado por fuera de las agendas políticas del Tolima a pesar de la existencia de nueve (9) emisoras comunitarias ${ }^{2}$. Es decir, no se han adelantado ejercicios locales ni regionales de deliberación sobre este tema que aporten en alguna medida a la construcción de una política regional. Desde el ámbito nacional, las políticas públicas, si bien contienen planteamientos pertinentes, asumen una homogeneidad de los territorios que no existe, conduciendo a que el marco de acción propuesto no siempre sea coherente con la realidad de los contextos en los que se instaura, en este sentido, la no existencia de estudios de caracterización integrales de las realidades sobre las que se desea decidir, esto es, una fase sólida de identificación del problema, resulta un obstáculo que debilita el proceso de diseño de la política, por cuanto el componente deliberativo y reflexivo que implica su construcción, deja por fuera referentes específicos de los contextos, cuya incorporación resultaría importante para asegurar la pertinencia de la Política Pública.

Las Políticas públicas deben avanzar hacia una lógica que supere los procesos jerarquizados, centralistas y unidireccionales de planteamiento de políticas públicas. Pensar en el planteamiento de política pública con una amplia participación de la ciudadanía, como ocurrió, por ejemplo, en el distrito bogotano en el tema de la comunicación comunitaria, implica, no sólo la apertura de espacios para la participación de los actores involucrados, sino también, la existencia de una caracterización integral sobre los temas que son de interés y sobre los cuales se pretende decidir, que hagan posible que se cualifiquen los procesos de deliberación y toma de decisiones.

Situaciones como el cierre de emisoras, su cooptación por parte de lógicas empresariales, asuntos que se dan en la cotidianidad de los escenarios locales, plantean la necesidad de revisar estas situaciones en los contextos donde tienen lugar, así como su nivel o no de correspondencia con la propuesta de la política pública en materia de radiodifusión comunitaria. El cierre de una emisora, su cooptación por parte de una lógica comercial, la réplica de formatos comerciales, son cuestiones que conducen, no sólo al estancamiento del medio en sí mismo, sino que también hacen que el proyecto político, cultural y comunicacional que estos representan, y muchas veces soportan, quede huérfano.

\section{Preguntas de investigación:}

¿Cuáles son los elementos que se deberían considerar en un ejercicio de construcción de política pública de radiodifusión comunitaria en el Tolima?

\footnotetext{
${ }^{2}$ En la coyuntura de los diálogos de paz y la firma del Acuerdo con las FARC EP, la radiodifusión comunitaria volvió a estar en el orden del día. En todo el proceso de diálogo las FARC como movimiento político exigió el máximo de garantías para la labor divulgativa de su movimiento y para el ejercicio de la oposición al convertirse en alternativa de poder (punto2.2.1, p. 32). Atendiendo a esta exigencia y a la experiencia en radiodifusión que tiene este movimiento, el Acuerdo plantea la adjudicación de 31 licencias para emisoras comunitarias para este grupo por parte del Ministerio de la TIC (Acuerdo Final p 32 Participación Política) (Página 191 de 2976.5 herramientas de difusión y comunicación). La financiación del Sistema, será asumido en su totalidad por el Gobierno Nacional.
} 


\section{Preguntas específicas:}

1. ¿Qué elementos caracterizan el funcionamiento de las emisoras comunitarias del sur del Tolima respecto a procesos de gestión, producción de contenidos y participación?

2. ¿Cuál es la propuesta de la Política Pública de radiodifusión sonora comunitaria en el marco nacional?

3. ¿Cuáles son los problemas de las emisoras comunitarias del sur del Tolima a los que debería responder una política pública de comunicación comunitaria en el departamento?

\subsection{Objetivos}

\section{Objetivo general}

Identificar y describir las tensiones que se presentan entre el funcionamiento de las emisoras comunitarias y los lineamientos de la Política Nacional de Radiodifusión Sonora Comunitaria, mediante el análisis de cuatro emisoras del sur del Tolima con el propósito de generar referentes de reflexión que sirvan para proyectar las políticas públicas nacionales y revisar la Política Pública vigente.

\section{Objetivos específicos:}

1. Identificar las características de cuatro emisoras comunitarias del sur del Tolima respecto a procesos de gestión, rutinas cotidianas de producción de contenidos y niveles de participación.

2. Describir y analizar la propuesta de Política Pública de Radiodifusión Sonora Comunitaria, a la luz del marco conceptual existente sobre políticas de comunicación y comunicación para el desarrollo.

3. Identificar y analizar los problemas de las emisoras comunitarias del sur del Tolima a los que debería responder una Política Pública de Radiodifusión comunitaria en el departamento

\section{Delimitación espacial del estudio}

Sobre la delimitación espacial, el sur del Tolima comprende nueve municipios: Planadas, Ataco, Rioblanco, Chaparral, San Antonio, Rovira, Natagaima, Coyaima y Purificación. Estos municipios están ubicados en el centro del territorio nacional, de modo que su ubicación les confiere un valor estratégico en la medida en que desde la colonia constituye un corredor natural entre varias regiones del país. Esta particularidad ha marcado el devenir histórico de esta zona, en especial, porque distintos intereses económicos y políticos importantes para el país, se han visto confrontados en esta región.

En el sur del Tolima se han venido desarrollando diferentes programas dirigidos por organizaciones del ámbito nacional e internacional, en todos los casos se reconoce el sur del departamento como un territorio sui generis, en el que convergen intereses y voluntades políticas e institucionales a partir de una historia común. Esta zona del departamento se ha asumido como un escenario de consolidación para el desarrollo regional y la construcción de tejido social, de ahí que se considere pertinente priorizar las emisoras comunitarias de esta zona. Este estudio tomará en cuenta las siguientes emisoras: 


\begin{tabular}{|c|c|}
\hline MUNICIPIO & EMISORA \\
\hline SAN ANTONIO & TETUAN FM STEREO 106.0 \\
\hline RIOBLANCO & RIOBLANCO ESTEREO 95.0 \\
\hline NATAGAIMA & HACA YU MACU 106.0 FM \\
\hline ALPUJARRA & SAMAN STEREO 102.5 \\
\hline
\end{tabular}

\section{Antecedentes:}

Podría pensarse que las políticas públicas son un asunto que sólo interesa a abogados o a las instancias de los gobiernos que se encargan de su formulación, implementación y evaluación en la medida en que estas se refieren a la construcción de normatividades a propósito de aspectos de la vida pública que afectan a todos. Si se analiza en detalle, esta mirada sobre la política pública es reducida, en especial, si se considera la apertura de concepciones sobre el Estado y sobre lo que significa gobernar mediante estrategias de regulación particulares a cada Nación.

El creciente interés en estudiar las políticas públicas encuentra sustento en uno de los planteamientos de Roth: "los científicos sociales, politólogos, sociólogos y economistas se interesaron por el estudio de la acción pública debido al crecimiento del intervencionismo del Estado en muchos aspectos de la vida social de nuestras sociedades, independientemente de sus niveles de desarrollo" (Roth, 2002, pág. 11).

Para el caso de este trabajo si bien el eje de indagación principal no es la política pública de radiodifusión comunitaria, sino las tensiones que se hacen visibles entre las rutinas de funcionamiento de las emisoras comunitarias y los lineamientos que al respecto se plantean en la Política, es necesario reconocer algunos de los hitos más importantes sobre la producción de conocimiento a propósito de los medios de comunicación y las políticas públicas.

En lo que respecta a los tipos de documentos revisados sobresalen los libros, de igual manera, se encuentra casi un igual número de capítulos de libro, artículos de revista y otros como ponencias, foros, seminarios y entre otros que fueron publicados. Llama la atención la baja cantidad de trabajos de grado que abordan los dos temas, al respecto sólo se identificaron dos los cuales se enuncian a continuación.

De acuerdo al rastreo efectuado, se encontraron dos trabajos que se acercan a este interés, el primero de ellos, corresponde a un trabajo de grado de la Universidad Nacional Abierta y a Distancia UNAD, Escuela de Ciencias Sociales, Artes y Humanidades CEAD José Acevedo y 
Gómez, del año 2010, denominado "Estado del arte de los medios de comunicación comunitaria en Bogotá, Cundinamarca y Tolima". Para el caso de Tolima el trabajo presenta un mapeo de 42 medios comunitarios, dentro de los cuales sólo 13 fueron medios radiales. Con base en el mapeo realizado, el trabajo se orientó en un primer momento a indagar con las audiencias de los medios identificados sobre su impacto, y en un segundo momento, a plantear una propuesta para la conformación de una red de medios comunitarios en Bogotá, Cundinamarca y Tolima.

Con respecto al mapeo realizado específicamente para el caso del departamento del Tolima, llaman la atención varios aspectos. Primero, a pesar de que el mapeo y el proceso de indagación tomaron en cuenta los municipios de Armero-Guayabal, Fresno, Guamo, Honda, Ibagué, Lérida, Mariquita, Ortega y Purificación, la mayoría de los medios reseñados fueron de Ibagué, capital del departamento; para el caso de las emisoras, se identificaron ocho, cuatro de ellas en lbagué. Segundo, en el trabajo se usa de manera indistinta el término medio de comunicación comunitario para nombrar medios que no lo son, muestra de ello, es que en el mapeo de medios impresos incluyen el diario Q'hubo, que es un diario comercial, y en el de radio incluyen a la Emisora Cultural del Tolima, que es la emisora pública del departamento y la emisora la Voz del Tolima, que es comercial y la emisora de la Policía Nacional. Tercero, si bien se hicieron explícitas algunas dificultades de sostenibilidad de estos medios, el proceso de indagación se concentró más en las audiencias, de modo que no se llega a un estado de la cuestión en sentido estricto.

El segundo documento que se encontró corresponde a un trabajo de grado de la Fundación Universitaria Católica del Norte, denominado "Estado de funcionamiento de siete emisoras comunitarias del departamento del Tolima, Colombia". El trabajo tuvo en cuenta los municipios de Líbano, Espinal, Purificación, Rioblanco, Prado, Fresno y Guamo y se ocupó de indagar por el funcionamiento de las emisoras comunitarias de los municipios a partir de visitas, aplicación de cuestionarios y evaluación de equipos e instalaciones. De forma general, se concluye que, si bien, la radio comunitaria cumple una función social y comunitaria, en los contextos donde tuvo lugar la indagación, las emisoras se encuentran subutilizadas en lo que a programación se refiere y carecen de equipos técnicos. A diferencia del anterior trabajo, en este sí se plantean algunas conclusiones acerca del estado de las emisoras, no obstante, no se consolida una caracterización, ni incorpora la política de comunicación como eje analítico.

A pesar de que existe la Corporación "Radio Red Pijao Miguel Marín" que agrupa a las emisoras comunitarias y públicas de la región, desde allí, tampoco se ha avanzado en la construcción de una descripción o análisis de los elementos que actualmente caracterizan el funcionamiento de las emisoras. De esta manera, el levantamiento de una caracterización enmarcado en el concepto de política de comunicación resulta pertinente, si se piensa como insumo en un escenario de política pública en el Tolima en materia de comunicación comunitaria.

Ahora bien, sobre la producción de conocimiento frente a políticas públicas y medios de comunicación se hacen evidentes dos enfoques principalmente: uno que se orienta a la evaluación y el análisis de políticas públicas, el segundo a la identificación y descripción de problemáticas. A continuación, se describirán con mayor precisión los dos enfoques, en cada caso se citarán algunos ejemplos que permiten ilustrarlos.

\section{Los enfoques}


Los trabajos que se inscriben en el primer enfoque se enmarcan en una perspectiva jurídica. En general se observa que el propósito de estos trabajos es relacionar en una secuencia lógica el marco normativo que regula la conformación, propiedad y control de los medios, así como los derechos relacionados con la información, la libertad de expresión, las responsabilidades que se atribuyen a los medios de comunicación y las políticas que al respecto se han implementado en algunos gobiernos. Frente a este enfoque se identifican dos tendencias: en primer lugar una que se orienta al análisis del marco normativo y en segundo lugar, una tendencia más amplia en la que los trabajos intentan dar cuenta de los contextos y dinámicas en el marco de los cuales se originó la normatividad.

Para el primer caso, la relación de normativa suele tener como fin el planteamiento de una secuencia histórica en la que, desde una perspectiva jurídica, se cuestiona su alcance, su claridad, o las posibles imprecisiones, en ocasiones se establecen comparativos entre reglamentaciones anteriores y reglamentaciones más vigentes; a la luz de estas comparaciones se explica la emergencia de conceptos. En este punto, es posible mencionar algunos trabajos: los estudios sobre legislación de prensa de serrano cuyos resultados se encuentran en el libro "Legislación sobre prensa. Prensa escrita, radiodifundida y televisada" (Serrano A, 1983), también el de Felipe Piquero "Aspectos jurídicos de la prensa en Colombia" (Piquero V, 1995). En estos dos casos, los trabajos tienen como objeto de estudio las normatividades y lo abordan desde una mirada descriptiva y explicativa, pero sin precisar características de los contextos ni del proceso de implementación de dicho marco normativo. Siguiendo con esta línea, se identifica el trabajo de Oswaldo Alvarado a propósito de los canales de televisión regional de Colombia y de las líneas de regulación emanadas desde la Comisión Nacional de Televisión, en este caso se tomó el caso de tres canales regionales y se efectuó una descripción de su funcionamiento en el marco de las regulaciones de la CNTV (Alvarado, 1998).

De forma paralela, Milciades Vizcaíno en su artículo "La legislación sobre televisión en Colombia: del Estado al mercado", plantea una reflexión acerca de cómo la legislación sobre tv termina siendo una norma para el Estado, al respecto plantea que esto se debe a las tensiones que se originan en grupos sociales que, al disputarse mercados publicitarios, empiezan a tener acceso a la toma de decisiones sobre el funcionamiento del medio independientemente de si es comercial, cultural o educativa. Para ello el autor establece dos periodizaciones una para un marco normativo de carácter más general y otra para decisiones de política sobre el medio (Vizcaíno, 2005).

De otra parte, se revisaron trabajos de un carácter menos general que en su contenido abordan el análisis de una ley en particular o un periodo de gobierno en lo que respecta a un marco normativo. En las siguientes líneas se hará mención a algunos de ellos. Por ejemplo, Víctor Guerrero, en su artículo Coyuntura legal y uso de la comunicación" se enfoca en la Ley 72 de 1989 por la cual se estableces nuevos conceptos y principios sobre la organización de las telecomunicaciones, y plantea la importancia de la democratización de la información y de la comunicación en Colombia (Guerrero, 1990). De igual forma, José Sánchez en su intervención para el Foro de 1995 sobre la Nueva Ley de televisión en Colombia, señala en el documento presentado que se hace evidente un intento por modernizar el sector ante los cambios del mercado del momento, la inyección de capital que requirió dicha modernización tuvo como efecto una mayor censura en tanto existían claras filiaciones políticas de los medios con los gobiernos de turno y oligopolios económicos, un segundo efecto fue una mayor incertidumbre para la financiación de la televisión pública, para este análisis Sánchez tuvo como referente la Ley 182 de 1995 (Sánchez, 1995). En esta misma línea Armando Benedetti, retomando 
también la Ley 182 del 95 describe y explica el contexto del debate que dio origen a esta Ley (Benedetti, 1995).

Es de resaltar que algunos de estos estudios hacen comparativos de políticas a nivel interno entre varios gobiernos, o con marcos normativos de otros países. Aquí se resalta un trabajo adelantado por la Unesco en el que se hace una recopilación de la legislación cultural de los siete países que hacen parte del Convenio Andrés Bello. Además de contener una documentación completa, plantea una reflexión acerca de la importancia de establecer sinergias transnacionales especialmente en lo que concierne a la conservación del patrimonio cultural (Harvey, 2000). De otra parte, hay trabajos que van más allá de la revisión documental y que incorporan en sus reflexiones conceptos como participación siendo el medio más explorado la televisión.

Por su parte, el segundo enfoque ${ }^{3}$ está más orientado en reflexionar acerca de problemáticas que deben ser consideradas por las políticas. El marco conceptual es de carácter cultural pues se establece una relación entre esta categoría y los medios de comunicación, en igual medida se establece la relación entre medios de comunicación $^{4}$ y educación. Aquí un autor fundamental que ilumina esa reflexión es Jesús Martín Barbero quien aborda de manera muy crítica e histórica la noción de cultura y al respecto plantea cómo los medios incorporan la cultura desde una dimensión industrializada y cómo es de alguna manera transforma las ciudadanías y las identidades (Barbero, Rey, \& Rincón, 2002).

Otro trabajo que se encontró es el de López Roche, en el marco del Seminario de Políticas Culturales para Santafé de Bogotá, en donde plantea que es necesario de comprender que los medios de comunicación inevitablemente están insertos en la cultura y que por eso las Políticas Públicas para medios deben ser coherentes a las políticas culturales (López de la Roche, 1999).

Se identifica que uno de los temas que se explora desde esta perspectiva cultural es la de los medios comunitarios, y canales regionales. Principalmente se describe su función como agentes de cambio con una función educativa y de promoción del desarrollo a partir de categorías como democracia y participación. Un trabajo en esa línea es el de Foz y Anzola en su artículo "Política y televisión regional en Colombia" que hacen un recorrido histórico por los conflictos entre gobiernos para emitir una legislación que favoreciera los canales regionales de televisión. En el estudio se presentan los intereses políticos y económicos que estuvieron involucrados en los cambios de la televisión colombiana y que permitieron la transición del total control gubernamental a la participación de mesas regionales (Fox \& Anzola, 1989).

Por su parte Jorge Londoño Londoño presenta y reflexiona sobre los elementos legales que han influido en la conformación de las emisoras comunitarias y la radiodifusión sonora comunitaria en Colombia, en su trabajo dan cuenta de la trayectoria de la Red Reccorra (Red colombiana de radios comunitarias) (Londoño, 1999). Por el contrario, en el trabajo de Ricardo Gómez, publicado en la Revista Signo y Pensamiento se propone una crítica a los intentos por regular los medios locales y comunitarios y plantea que el Estado no comprende con precisión qué significa e implica el funcionamiento de los medios comunitarios (Gómez, 1994).

\footnotetext{
${ }^{3}$ Aquí el número de trabajos encontrados fue menor

${ }^{4}$ El principal medio objeto de reflexión en este enfoque es la televisión
} 
Se evidenció una ausencia de investigación con respecto a políticas sobre radio comunitaria en Colombia. En ese sentido es necesario superar este vacío en la producción de conocimiento de manera que se promueva una mayor contribución a la democratización de la comunicación y la participación de las comunidades que confluyen en los territorios donde existen medios comunitarios.

\subsection{Marco teórico conceptual:}

A continuación, se abordarán las categorías que resultan pertinentes de acuerdo a la naturaleza e interés del presente estudio. En un primer momento se abordará el concepto de Política Pública así como el de Política de comunicación en términos de gobernanza de la comunicación, esto es, la toma sistemática de decisiones respecto a dicho tema, en un segundo momento, se abordan las categorías de medios comunitarios y radio comunitaria, para lo cual se mencionan algunas consideraciones a propósito del contexto en el que tuvo lugar la emergencia de dichos medios de comunicación.

En primer lugar, es preciso establecer la diferenciación entre los términos del inglés politics y policy, en español, ambos términos, aunque también significan e implican cosas distintas, se traducen al término política. El término politics, hace referencia a la acción de lo público, enfocada principalmente en lo electoral y en los elementos básicos de la representación (Surel, 2006, pág. 45). Por su parte, el término policies, se refiere a la acción concreta del Estado, o de un gobierno en particular, para responder a una situación considerada como problema, dichas respuestas, implican la articulación de unos actores y mecanismos para la ejecución de políticas públicas y otros procesos de regulación social (Surel, 2006, pág. 45).

Ahora bien, se han elaborado diferentes definiciones acerca de lo que es e implica la política pública. Lasswell citado en (Califano, 2011, pág. 4), señala que esta se refiere a "las opciones más importantes hechas tanto en la vida organizada como en la privada", de acuerdo a esto, es posible hablar de una "política gubernamental", "política empresarial" o una política propia (p.4).

Por su parte Dye citado en (Califano, 2011, pág. 5), define que las políticas públicas son "cualquier cosa que los gobiernos decidan hacer o no hacer" (p.5) y, en ese mismo sentido, Thoening citado en (Califano, 2011, pág. 5) plantea que las políticas públicas consisten en "lo que los gobiernos deciden realizar o no realizar" (p.5). De acuerdo a esto, se entiende que la decisión de no actuar ante un problema o situación particular también puede conformar una política pública, lo cual no equivale a decir que la no actuación sobre un tema implique la existencia de una política pública. Al respecto, Kauffer citado en (Califano, 2011, pág. 5), señala que una política pública no necesariamente expresa una acción concreta, también puede contemplar lo simbólico "las políticas públicas se refieren a actividades materiales o simbólicas que gestionan las autoridades públicas". En este punto, se llama la atención sobre el hecho de que las políticas públicas implican decisiones y ponen en juego la distribución de recursos, que pueden beneficiar o afectar a ciertos sectores sociales.

De acuerdo a Thoening, citado en (Espinel Torres, 2011, pág. 41) para que una política pública sea considerada como tal, debe tener cinco elementos: debe expresarse a través de un conjunto de reglamentaciones, acciones e instituciones; debe implicar la asignación de recursos; debe constituir un marco de acción concreto; debe orientarse a uno o varios sectores sociales y debe conducir a que se definan normas específicas (p.41). Además de esto, el 
diseño de una política pública comprende cinco momentos: la planeación (identificación del problema), el desarrollo del programa (construcción), puesta en marcha (implementación), evaluación del programa (medición de impacto y funcionamiento y cierre del programa Charles o Jones citado en (Espinel Torres, 2011, pág. 44) .

De acuerdo a lo anterior, las políticas públicas implican distintos elementos relevantes: las acciones y omisiones del Estado o de un gobierno en particular en relación con un tema particular, las decisiones de gobierno, las causas de su actividad, los recursos en juego y los actores que se benefician o afectan de dichas decisiones. La comunicación, es un tema que no ha escapado a los procesos de diseño de política pública.

El informe MacBride, en su momento, significó un intento de gobernanza ${ }^{5}$ democrática de la comunicación, ya a partir de los 90 han aumentado los escenarios en los que se aborda el tema de la regulación de la comunicación y que cuentan con la participación de la sociedad civil: la conferencia mundial sobre derechos humanos (Viena, 1993), el encuentro Latinoamericano de Medios de Comunicación Alternativa y Popular (Quito), la Campaña Continental por los Derechos de la Comunicación (Quito, 2004 en adelante), son algunos ejemplos.

Para hablar de una gobernanza y de una política de la comunicación, resulta necesario entender que los medios de comunicación han devenido un elemento fundamental de la esfera de lo público y que, en ese sentido, se ha considerado que la democratización política genuina, difícilmente se logra sin la democratización de la comunicación y los medios. La democratización de los medios, no se refiere a su expansión en la lógica del mercado, sino a su constitución como espacios democráticos abiertos a todos los sectores de la sociedad civil.

La regulación en el campo de políticas de comunicación empezó desde el siglo XIX, cuando se dictaron normas para la regulación de las tecnologías de comunicación que nacieron en la época. Desde que esta práctica se dio por primera vez, los Estados han vivido distintas transformaciones en los ámbitos social, económico, político y tecnológico, que a su vez han conducido a que se reconfiguren los mapas mediáticos en el mundo y a que se generen nuevos desafíos para el diseño y establecimiento de políticas de comunicación. Las políticas públicas en el campo de la comunicación comunitaria constituyen un marco de acción en lo que respecta al acceso de información, derechos y actividad ciudadana en pro de flujos y difusión de información diversa y plural, y acceso a espacios de participación Sierra Caballero citado en (Espinel Torres, 2011, pág. 47).

Entender la importancia de las políticas públicas en el campo de la comunicación comunitaria implica considerar que las emisoras comunitarias proponen una comunicación horizontal, dialógica a partir de la cual se promueve la participación y la transformación social. Su riqueza reside en la articulación con los movimientos sociales y los colectivos que le otorgan sentido, al respecto, cobra especial relevancia la descentralización de la capacidad de comunicarse y, por tanto, la descentralización de la esfera de lo público. De acuerdo a esto, resulta necesario un recorrido por los cambios en las maneras de entender la comunicación y los medios.

${ }^{5}$ El concepto de gobernanza tiene un sentido evolutivo y variable según la época histórica y el escenario político. En este caso se entiende como la "gestión imparcial y transparente de los asuntos públicos, a través de la creación de un sistema de reglas aceptadas como constitutivas de la autoridad legítima, con el objetivo de promover y valorizar valores deseados por los individuos y los grupos de la sociedad (World Bank, 1992). 
Para la época de 1970 en América Latina se dio un proceso de cambio en distintos sentidos que buscaba la reivindicación de los sectores sociales más desfavorecidos, en ese momento, no sólo se empezaron a diversificar los formatos comunicativos, sino que estudiosos de la comunicación propusieron cambios al modelo de desarrollo e hicieron importantes contribuciones para renovar la teoría sobre comunicación (Beltrán, 2005).

En efecto, para esa década se produjo importante literatura de protesta acerca de la dependencia latinoamericana de potencias extranjeras y la dominación interna de los pobres por las minorías enriquecidas, así como propuestas para promover cambios profundos en las dinámicas del desarrollo y la comunicación. Por entonces, se fijaron las bases conceptuales para la formulación de Políticas Nacionales de Comunicación que fueran coherentes con la nueva trama social que se venía tejiendo desde hacía varios años como resultado de una creciente hibridación cultural y del desdibujamiento de las fronteras entre lo rural y lo urbano, lo global y lo local.

En el anterior contexto, se dio un cambio en la manera de concebir la comunicación. Dejó de tratarse de un recurso para producir efectos sociales masivos y empezó a asumirse como un agente de mediación, llamado a jugar un rol protagónico en el cambio social y el desarrollo, pero no de cualquier desarrollo, sino de uno que le apuesta al bienestar colectivo, la dignidad humana y la inclusión social (Milán, 2006: 273).

El concepto de comunicación se amplió y tomó nuevos rumbos. El contenido de los mensajes y los medios ya no era lo más importante, sino, las personas, los pueblos, las comunidades y el reconocimiento de sus orígenes, sus costumbres, sus necesidades, sus sueños, su cultura. Surgieron nuevos interrogantes y conceptos que humanizaron el discurso e hicieron que el cómo se tornara relevante.

Hablar de otra comunicación implicó, no sólo el distanciamiento de un paradigma instrumental, sino que supuso la entrada en escena de cuestionamientos acerca de cuál debía ser el rol de la comunicación para hacer que las sociedades se involucraran en procesos que les fueran propios, para construir desde allí ese tejido social y cultural tan necesario para hacer posible las transformaciones sociales y el desarrollo. Si bien, se han efectuado importantes aportes al respecto, no todo está dicho y aún hay mucho sobre qué reflexionar, en especial, porque se trata de un campo vivo acerca del cual siempre habrá mucho que pensar y aprehender.

\section{Aproximación: medios alternativos, medios comunitarios}

La comunicación alternativa tuvo sus inicios entre los años 40 y 50 en América Latina, jalonando un modelo que revierte el esquema de comunicación tradicional (Silva, 1990). En este marco, surgieron los medios alternativos, orientados principalmente al uso de la radio por ser un medio económico y de fácil acceso. Los medios comunitarios promueven una dinámica que permite que las comunidades participen y se involucren, no sólo en la producción de mensajes, sino, en la definición y construcción de la identidad del medio.

Jesús Martín Barbero plantea que la comunicación alternativa está en estrecha relación con el tránsito de un modelo hegemónico, sustentado no sólo en lo económico, sino en el adoctrinamiento cultural y político, a uno que emerge con la puesta en escena de nuevos actores sociales e identidades culturales regionales y locales, que ponen de relevo una comunicación popular que se convierte en espacio estratégico para pensar el desarrollo y los 
valores de la cultura (Barbero J. , 1987, pág. 45). Esta reubicación de la comunicación no ocurrió de manera lineal, por el contrario, su trayectoria se nutrió de diferentes hitos históricos, especialmente del contexto Latinoamericano, así como de gran diversidad de campos de pensamiento.

Lo que en un primer momento señala Barbero implica, por un lado, un cambio en el paradigma para comprender la comunicación, ya no desde la propuesta lineal de Lasswel, sino desde una perspectiva orientada a la crítica política sobre los efectos que la ideología dominante ejerce sobre los receptores de los mensajes que circulaban en los medios. Por otro lado, da cuenta de un giro epistemológico de lo psicológico -conductista, a la semiótica estructuralista (Barbero J. , 1987, pág. 48).

En correspondencia a lo anterior, la denuncia política que se empezó a hacer desde la comunicación, dio lugar a una esquizofrenia sobre los medios de comunicación por el hecho de considerarlos multiplicadores de la ideología de un emisor dominante y culpable de los efectos que dichos mensajes tenían en los receptores dominados. Sobre este asunto, Barbero enfatiza en que el modelo semiótico carecía de un entramado conceptual que diera cuenta de lo colectivo, del análisis de las condiciones sociales de producción del sentido, los conflictos en la lucha por la información (Barbero J. , 1987, pág. 49).

En el marco de este vacío conceptual, el esquema emisor-mensaje-receptor se agota, y a mediados de los años 70 se da paso al redescubrimiento de lo popular y con ello a la revalorización de las mediaciones de la sociedad civil, el sentido social de los conflictos y de las experiencias culturales enmarcadas en contextos particulares. Se resalta en esta perspectiva el especial valor que cobra lo cultural desde la formación de nuevos sujetos y experiencias de rebeldía y resistencia. La reconceptualización de la cultura permitió que se legitimara lo popular como experiencia cultural diversa.

Así, se evidencia la necesidad de pensar los procesos comunicacionales desde la cultura y las mediaciones y no sólo desde las disciplinas o los medios. En este contexto, la comunicación alternativa $^{6}$ da cuenta de la participación, el diálogo y la reciprocidad que tiene cabida en los procesos comunicativos, sin dejar de lado la trama histórica, los mestizajes, complicidades y contradicciones que componen las experiencias colectivas, en otras palabras, se trata de la resignificación de la relación comunicación-cultura.

Gabriel Kaplún plantea que a partir de los años 60 "la comunicación se ha poblado de una constelación de apellidos emparentados entre sí: comunicación alternativa, popular, educativa, para el desarrollo comunitario, ciudadana" (Kaplún G. , 2007, pág. 311). En general, señala Gabriel Kaplún, se trata de experiencias comunicacionales ligadas a los movimientos populares.

Si bien, las nomenclaturas son diversas, se destaca en concepto de comunicación comunitaria. Para la brasileña Raquel Paiva, lo que hace que un medio de comunicación sea comunitario, no es su capacidad para prestar servicios, sino su propuesta social para la movilización

\footnotetext{
${ }^{6}$ En este punto es necesario considerar las reflexiones teóricas que contribuyeron al desarrollo epistemológico de la comunicación comunitaria: el marxismo desde la Escuela de Frankfurt, los estudios culturales, los estudios de recepción, la teología de la liberación y las teorías pedagógicas de educación popular.
} 
vinculada al ejercicio de la ciudadanía (Paiva, 2003, pág. 140). Al respecto, Paiva propone seis pilares de la comunicación comunitaria: 1) constituye una fuerza contrahegemónica, 2) tiene una estructura polifónica, 3) producción de nuevos lenguajes, 4) incidencia en los modos de producción de la comunicación y la información, 5) integración entre emisores y receptores de los mensajes, 6) se constituyen en lugares privilegiados para reflexionar sobre la comunicación (Paiva, 2003, pág. 143).

Para Mario Kaplún, esa otra comunicación se trata de una comunicación liberadora, participativa, concientizadora, problematizante, con otros principios, bases y técnicas que permiten una educación transformadora hecha por el pueblo. Así, todos son emisores y receptores y los mensajes son espacios de negociación e intercambio de diferentes valores culturales y políticos (Kaplún M. , 1987).

En relación con lo popular Canclini plantea que "lo popular no corresponde con precisión a un referente empírico, a sujetos o situaciones sociales nítidamente identificados en la realidad. Es una construcción ideológica, cuya consistencia teórica está aún por alcanzarse (Canclini, 1987). Canclini no sólo propone una reflexión sobre lo popular, sino sobre la categoría de ciudadanía. Sobre este tema señala que la ciudadanía no se agota en el ejercicio de los derechos reconocidos por una maquinaria estatal, sino que tiene que ver con las prácticas sociales y culturales que son referentes en la construcción de lo colectivo, es decir, lo ciudadano, es un concepto político.

Las anteriores consideraciones fueron fundamentales pues ya en la década de los 90 , las aproximaciones teóricas, definían a los medios alternativos o comunitarios más por lo que no eran que por lo que eran. En este sentido, se afirmaba que a diferencia de los grandes medios masivos que se caracterizaban por su verticalidad, los medios alternativos eran horizontales de manera que se nutrían de un alto nivel de participación de las comunidades de los contextos en los cuales se insertaban, de forma paralela, mientras que los medios masivos, comerciales, eran hegemónicos, los medios alternativos y comunitarios en su discurso y contenidos eran contestatarios, es decir, retoman en su lógica de funcionamiento el cuestionamiento a asuntos de la vida púbica y del contexto cercano que empiezan a formar parte de una agenda de interés para el medio.

Pese la trayectoria teórica conceptual de los términos, los medios comunitarios suponen una ampliación de los espacios, los temas, los problemas, del pensamiento y de las prácticas de la comunicación a partir del reconocimiento de actores, usualmente invisibilizados en la esfera de lo público. De acuerdo a esto, pensar los medios comunitarios implica que los medios narren las historias de los sujetos desde un marco de pluralidad y diversidad construido por los actores del tejido social. Estas características, se pueden sustentar desde el paradigma crítico de la comunicación, en que se plantea que los procesos de diálogo y argumentación que derivan en consensos o disensos deben constituir la esencia cotidiana de la comunicación. Desde este paradigma, la comunicación tiene las funciones de transformar, liberar, emancipar al ser humano del sistema dominante de comunicación que no le permite tener voz y que no le reconoce en su contexto cotidiano. En coherencia con esto, plantea Navarro (2008), los medios comunitarios de comunicación se conciben como ejercicios de interlocución y construcción de sentidos que posibilitan una comprensión enriquecida de las relaciones sociales, no hay entonces, una ruptura entre el pensar y el actuar de los sujetos toda vez que la comunicación es propia de la interacción social y la construcción de sentido. 
En este contexto, los medios comunitarios se visualizan como pilares capaces de producir una comunicación que le apunta al cambio, a la transformación, a partir del diálogo y el reconocimiento del otro, aun cuando ese sujeto sea totalmente diferente de los otros sujetos. Así se gesta una transición de una comunicación instrumentalizada pensada desde el funcionalismo, a una que aboga por el cambio y la resignificación de los sujetos como actores protagónicos de su construcción.

Los medios de comunicación locales juegan un papel importante en el desarrollo de sus comunidades. Es por ello que, desde las últimas décadas del siglo pasado, los gobiernos de América Latina, África y Asia han emprendido una promoción masiva para la creación de medios comunitarios de comunicación que les permita a las comunidades apartadas contar con canales propios para su reconocimiento y la promoción de sus tradiciones, culturas y prácticas ciudadanas.

La radio en particular es considerada la herramienta comunicacional más extendida en el mundo y el medio ideal para provocar cambios sociales (Gumucio, 2001). El hecho de ser un medio de comunicación por tradición de la sociedad, que siempre se encuentra en los hogares y que acompaña las labores del hogar y el campo, ha facilitado su posicionamiento.

En Colombia, desde las épocas de Radio Sutatenza se identificó el papel que cumplen las radios comunitarias en el desarrollo de sus poblaciones. Desde mediados de la década de los noventa, el gobierno nacional ha promovido una serie de decretos cuyo propósito es reglamentar el uso y los servicios que deben cumplir las emisoras comunitarias. Y en el año 2008 el Consejo Nacional de Política Económica y Social, CONPES, generó el documento 3506, en el que establece los Lineamientos de Política para el Fortalecimiento del Servicio de Radiodifusión Sonora en el país con el fin de promover el desarrollo de las emisoras comunitarias a través de distintas acciones desde la institucionalidad. De acuerdo con dicho documento, en la nación operan 534 emisoras comunitarias, en 30 departamentos. El departamento del Tolima cuenta con 9 emisoras comunitarias legalmente constituidas, según el informe (CONPES 3506, 2008).

Así pues, las radios comunitarias junto con las de interés público asignadas a comunidades indígenas, se han convertido en alternativas para la preservación de las tradiciones, costumbres y culturas de distintas organizaciones y comunidades. La creación de medios de comunicación comunitarios en los territorios abre una serie de posibilidades de reconocimiento y hacen visibles ante el país y el mundo a comunidades históricamente olvidadas por sus deficiencias en comunicaciones terrestres y las distancias que las separan de las áreas de desarrollo.

En este contexto, los medios de comunicación comunitarios están llamados a jugar un rol protagónico en el desarrollo local. Por una parte, constituyen importantes canales de participación y de ejercicio plural del poder y, por otra, la experiencia ha mostrado que los medios comunitarios son una oportunidad para transformar las experiencias individuales en visiones compartidas de mejores posibilidades de vida $y$, en ese sentido, potencian la construcción de comunidad y refuerzan los lazos sociales.

De acuerdo con lo anterior, los medios comunitarios se proponen defender los intereses de la mayoría partiendo del reconocimiento de la realidad local, e impactar de manera positiva en los procesos de construcción ciudadana, fomentando la convivencia y fortaleciendo el sentido de pertenencia a una comunidad en particular. En este sentido, ofrecen una alternativa para que 
los sectores de la sociedad que han quedado excluidos del diálogo público sean escuchados, manifiesten sus ideas, problemas, consoliden identidades, construyan narrativas, formen ciudadanía, desarrollen capacidades y recursos para mejorar su calidad de vida y transformar su entorno de acuerdo con sus aspiraciones como comunidad.

En ningún caso se busca rentabilidad económica, pero sí rentabilidad social; es decir, que la comunidad se convierta en el punto de referencia y de partida para la construcción de cursos de acción compartidos, con respecto a temas que resultan relevantes en el contexto cercano y que, normalmente, son dejados por fuera de las agendas de los principales medios de comunicación.

Además de lo anterior, las radios comunitarias han mostrado su capacidad para intervenir en la política desde el campo cultural, generando discursos, relatos y proponiendo maneras de narrar con las que es posible cuestionar lo negado, lo excluido. Al respecto, la radio comunitaria se construye cotidianamente, se fortalece o debilita de acuerdo a relaciones de fuerza de las que se es parte y no sólo víctima (Mata, 2009). A través de estudios llevados a cabo en el contexto latinoamericano, se ha observado que, en la mayoría de los casos, los medios de comunicación tradicionales excluyen a los sectores marginados, sus intereses, su imaginario, anulando toda posibilidad de interlocución. García Canclini (2002), señala que: "Los medios tradicionales permiten que se desarrolle un proceso de homogenización cultural reflejada en la cultura masiva y contextos de hibridación cultural en los que las culturas populares readaptan y resignifican estas pautas y prácticas".

Contrario a lo que ocurre con los medios tradicionales, los medios comunitarios permiten que los actores de una comunidad conozcan situaciones de interés para su contexto, recuperen su memoria, su imaginario y desarrollen un discurso propio a partir del cual pueden, no sólo contar, sino recrear su realidad. Silva (1990), plantea que las radios comunitarias: "cumplen la función de cambiar las relaciones de dependencia y entregar espacios y posibilidades de comunicación a sectores que están excluidos". Es precisamente esta característica de apertura e inclusión, la que posibilita que la radio comunitaria sea una fuente potenciadora del empoderamiento de las comunidades de base, así como de la participación y la construcción de identidad (Camacho, 2007).

El espíritu de los medios de comunicación comunitarios es la participación activa de sus beneficiarios. Sin la participación de la ciudadanía pierden su sentido y esencia. En este contexto, es indispensable que la comunidad tenga claro el papel que ella juega en el desarrollo y proyección de su emisora, canal de televisión o periódico comunitario. Esta situación hace necesario que las comunidades hagan parte de procesos de formación que garanticen, por un lado, su participación activa en los distintos espacios con que cuenta el medio de comunicación de su comunidad, y por otro, su dominio del lenguaje de producción del medio.

Así pues, los medios de comunicación comunitarios adquieren sentido cuando la participación activa de la ciudadanía trasciende las agendas informativas tradicionales de los medios de comunicación comerciales, abriendo espacio a las informaciones que se generan desde las organizaciones, grupos informales, "parches" de barrio, combos deportivos, que contribuyen con sus acciones a fortalecer un ambiente de paz y convivencia en los distintos territorios de la nación. 
En este orden de ideas, los medios comunitarios de comunicación no sólo buscan una apuesta comunicativa distinta, sino que, además, en su estructura funcional deben lograr superar la reproducción de modelos de gestión propios de organizaciones liberales y neoliberales basados en lógicas de rentabilidad, para que se propicie la convivencia de distintas formas culturales, de lecturas y maneras de comprender la realidad.

\subsection{Propuesta Metodológica}

A continuación, se plantea la propuesta metodológica para la recolección de información del proyecto en mención.

\section{Postura epistemológica:}

La identificación de las tensiones entre el estado de las emisoras implica, de un lado, la caracterización de las emisoras comunitarias y por otro, la revisión documental de la política pública de comunicación comunitaria. En este sentido, la presente investigación se ubica en un enfoque cualitativo. De acuerdo con esto, se considera importante aclarar la perspectiva epistemológica desde la que se abordará el proceso de indagación. La postura epistemológica no sólo direcciona la indagación, sino que además inciden en la definición del tipo de instrumentos a utilizar.

De acuerdo con Sánchez Upegui (2010), desde la investigación, la caracterización corresponde a un proceso descriptivo que se adelanta con el propósito de identificar los aspectos, componentes, acontecimientos (hitos), actores y procesos involucrados en el contexto de una experiencia, hecho o proceso, en este caso, el objeto de caracterización son las emisoras comunitarias de los municipios que se han priorizado en el marco del proyecto de investigación.

Al respecto, Bonilla, Hurtado y Jaramillo (2009), plantean que la caracterización busca principalmente consolidar una descripción cualitativa, que en ocasiones puede nutrirse de datos cuantitativos, con el fin de conocer de manera profunda algún aspecto de la realidad. Dicha descripción implica la identificación y organización de los datos para posteriormente lograr una descripción estructurada que sea susceptible de sistematización crítica.

Citando a Strauss \& Corbin (2002), Sánchez Upegui indica que la caracterización, además de obedecer a un orden descriptivo, también necesita de una reflexión conceptual previa que permita definir con claridad cuáles son aquellos elementos que se deben considerar en el proceso de indagación. Adicional a esto, la descripción debe tener una perspectiva histórica que permita documentar el pasado y el presente de un fenómeno.

De acuerdo a las implicaciones de la caracterización y al proceso de revisión documental que debe adelantarse para la descripción de la propuesta de la política pública, la perspectiva epistemológica de este estudio corresponde a una postura hermenéutica interpretativa, por cuanto lo que interesa es la interpretación de un fenómeno en un contexto particular, esto no quiere decir que no se considere la participación de actores de la comunidad, así como de las personas que participan de manera directa en las dinámicas de funcionamiento del medio en el proceso de caracterización, pues se reconoce que son las personas quienes desde lo individual y lo colectivo producen ideas y concepciones sobre sus contextos y que, en tanto, el conocimiento que se produce sobre la realidad se da en la relación de las personas con su contexto-mundo. 
En lo que respecta a la participación de los actores, en el proceso de abordaje del objeto que se va a caracterizar, es importante tomar en consideración que su aproximación para generar conocimiento sobre el medio, estará mediado por sus experiencias tanto individuales como colectivas, así como preconceptos frente al tema de interés.

Así, la postura interpretativa invita a lograr una mirada holística del escenario y el objeto de estudio, dese una relación que les es compleja e incluso contradictoria, en este sentido, el investigador debe estar abierto a reconocer el influjo del contexto sobre el objeto que es de interés en el marco de su estudio, de ahí que se legitima una visión intersubjetiva de la actividad investigativa.

\section{Metodología:}

La metodología es cualitativa, especialmente porque en esta tradición se sitúan los procesos de caracterización.

La metodología cualitativa se sustenta en las ideas que surgieron con las epistemologías pos positivistas y tiene diferentes enfoques. De acuerdo con Martínez (2004:8), la investigación cualitativa es "[...] descriptiva, inductiva, fenomenológica, holista, sistémica, humanista, de diseño flexible y destaca más la validez que la replicabilidad de los resultados".

Los resultados en una investigación de este corte no están previstos, ni tampoco parten de una certeza previa, por el contrario,

"lo cualitativo es un discurso, un ensayo prolongado de un camino que se piensa, es un viaje, un desafío, una travesía, una estrategia que se ensaya para llegar a un final pensado e imaginado y al mismo tiempo insólito, imprevisto y errante [...] es una búsqueda que se inventa y se reconstruye continuamente" (Morin, Ciurana y Motta, 2006:17).

La metodología cualitativa, también supone una relación distinta con el conocimiento y los modos de conocer pues se pasa de considerar el conocimiento como un reflejo o copia de la realidad a una desde la que el conocimiento se produce en la relación sujeto cognoscente y objeto cognoscible. (Martínez, 2004):25). En este sentido, no interesa tanto la generalización, las conclusiones; sino las particularidades del fenómeno que se estudia, es decir, se reconoce al investigador como un sujeto que se inserta en la realidad para comprenderla, no sólo desde su observación, sino también, desde sus interacciones con otros.

Así pues, los medios comunitarios de comunicación se corresponden con una realidad compleja y diversa que se construye con el tiempo, en perspectiva de memoria y de construcción de sentido por parte de actores sociales. Para adentrarse en su contexto, se requiere un método participativo que permita su comprensión e interpretación y que constituya un punto de partida para su transformación desde los cursos de acción que desde ellos mismos emerjan, fruto de una comprensión crítica y contextualizada que reconoce sus actores y su trayectoria histórica.

Por lo anterior, es posible afirmar que el objeto de la investigación cualitativa es la realidad en su propio contexto, por esto, Rodríguez et al (1999:33), citando a Taylor y Bodgan indican que "la investigación cualitativa se caracteriza por producir datos descriptivos, con las propias palabras de las personas, sus métodos son humanistas, es inductiva, el escenario y las personas son vistos de forma holística, [...] es un arte". 
Así, este tipo de investigación va más allá de la recolección de datos, descubre hechos, genera análisis críticos, contextualizados, permitiendo la búsqueda constante de acciones que favorezcan la transformación de la realidad, pero una transformación con memoria y que adquiere sentido en el contexto social. Por esta razón, la orientación cualitativa se mueve entre lo difuso y los entramados de las interacciones.

III. Método: Participativo

Para consolidar la caracterización de los medios comunitarios se contempla un método participativo, que involucre actores de la comunidad en la construcción de conocimiento acerca de estos medios en su propio contexto. En este sentido, se proponen técnicas que favorezcan la reflexión colectiva en torno a una realidad común.

Documental: en lo concerniente a la revisión de Política Pública de radiodifusión comunitaria de Colombia

\section{Técnicas:}

La rutina de caracterización de cada medio incluye las siguientes técnicas:

-Entrevista semiestructurada con los actores que participan directamente en la dinámica de funcionamiento del medio. Esta entrevista se ha diseñado pensando en tres componentes: la perspectiva histórica del medio, el proyecto comunicativo y, en tercer lugar, los procesos de producción.

-Taller con actores de la comunidad y actores del medio. El taller se ha pensado desde cuatro momentos: Reconocimiento del contexto, identificación de los relatos ausentes, reflexión en torno al papel de los medios y diálogo sobre los medios locales. Si bien el taller no tiene por objetivo que las personas de la comunidad caractericen su medio, éste generará insumos importantes para avanzar en dicho sentido, desde el reconocimiento de los múltiples elementos que allí se ven involucrados por parte de los participantes.

A continuación, se relacionan la guía de entrevista, así como la guía del taller, el cual incluyó un momento introductorio y de preparación para que los participantes comprendieran el alcance del trabajo y se relacionaran con la noción de Política Pública.

\section{Guía entrevista semiestructrurada con actores de los municipios del Tolima}

\section{Perspectiva histórica:}

1. ¿Quiénes fueron los pioneros, y qué motivó el surgimiento del medio de comunicación?

2. ¿Cuál es la historia de los primeros años del medio? (indagar por los hitos que permitieron el nacimiento del medio, participantes etc.)

3. ¿Cómo fue el acompañamiento que recibieron en el proceso de creación del medio? (particulares, instituciones, otros)

\section{Proyecto Comunicativo:}

1. ¿Cuál es el enfoque del medio de comunicación? (Se está haciendo referencia en esta pregunta al proyecto comunicativo)

2. ¿Cómo se ve reflejado en la parrilla de programación este enfoque? 
3. ¿De qué manera la comunidad y las organizaciones locales participan en la producción de contenidos y a qué tipo de públicos van dirigidos? (Es importante profundizar en el tipo de formatos y contenidos que se privilegian en el medio de comunicación)

4. ¿Existe un documento en el que esté consignada la información que define la identidad del medio de comunicación? ¿Las personas vinculadas conocen el documentoparticularidades? ¿Cómo se llevó a cabo la construcción de este documento? ¿Quiénes participaron? ¿Qué dificultades se han presentado en el desarrollo del proyecto comunicativo, como se podrían superar?

\section{Procesos de producción:}

1- ¿Quiénes están vinculados a la producción técnica del medio y con qué experiencia cuentan?

2- ¿Qué dificultades técnicas presenta el medio de comunicación y cuáles son las debilidades en el proceso de producción de contenidos?

3- ¿Qué espacios de capacitación existen quienes están vinculados en la producción?

4- ¿De qué manera se da a conocer el medio de comunicación?

\section{Cierre:}

¿Cuáles son los aportes que genera el medio de comunicación al contexto local a nivel económico, político, social?

\section{Taller de caracterización de medios}

El objetivo del taller es promover un escenario de reflexión que permita a diferentes actores del medio de comunicación reconocer el contexto local del medio, su dinámica de funcionamiento, el rol que en ese marco ha tenido la comunidad, así como el papel que juega o puede jugar el medio frente a temas como la participación, el empoderamiento y la construcción de paz.

El taller se piensa desde cuatro grandes momentos

Momento 1. Reconocimiento del contexto

Momento 2. Identificación de los relatos ausentes

Momento 3. Reflexión en torno al papel de los medios locales

Momento 4. Diálogo para el cierre

En el anexo B se describen las actividades previstas en el desarrollo de cada uno de estos momentos. 



\section{Capítulo 2. Política de Radiodifusión Sonora comunitaria en Colombia: pistas para entenderla}

El propósito de este apartado es describir de manera general los componentes de la actual Política Pública de Radiodifusión Sonora comunitaria de Colombia a la luz de un marco conceptual sobre políticas de comunicación y comunicación para el desarrollo. Se aclara que no se efectuará un análisis ni una evaluación de la Política, pues esto implicaría revisar la interacción de los tres sistemas que le son propios: el social, el político y el administrativo ${ }^{7}$. Además, para hacer un análisis de política pública en sentido estricto, sería necesario revisar sus planteamientos a la luz de las condiciones económicas y políticas del país y de acuerdo a ello construir una mirada crítica particular y de conjunto.

Como se mencionó en un apartado anterior, las políticas públicas constituyen un flujo del régimen político hacia la sociedad, es decir, se consideran productos del sistema político. Sobre esto, Manuel Alcántara plantea que las políticas públicas no deben entenderse como elementos accesorios del sistema político, sino como "parte constitutiva de las acciones o de los resultados de las actuaciones de los elementos formalmente institucionalizados del sistema político adscritos al ámbito del Estado" (Alcántara Sáez, 2004, pág. 106).

En este sentido, una política pública se refiere al conjunto de actividades y decisiones del gobierno que se realizan de manera directa o con la mediación de algún agente para influir sobre un tema particular que afecta la vida de los ciudadanos, en este caso, la Política de Radiodifusión Sonora Comunitaria, está dirigida a orientar programáticamente y promover el trabajo de las emisoras comunitarias.

Aunque existen distintos desarrollos conceptuales sobre política pública, es posible distinguir rasgos comunes en todas las definiciones. Primero, una política pública implica un trabajo gubernamental que conduce a resultados concretos, en segundo lugar, incorpora elementos de decisión por parte del Estado, al respecto constituye una regla destinada a guiar los comportamientos institucionales y ciudadanos frente a determinado tema. Tercero, las políticas públicas representan un panorama de acción general, esto puede explicarse en la medida en que no siempre se basan en necesidades definidas de forma específica.

${ }^{7}$ El sistema social se refiere al hecho de que la Política pretende ser una respuesta del Gobierno a problemas, demandas o necesidades de la sociedad. El sistema político, se refiere al ámbito institucional donde se toman las decisiones. $Y$ finalmente el sistema administrativo, se refiere a los elementos que intervienen en su ejecución. 
La radiodifusión sonora constituye uno de los ámbitos de las telecomunicaciones más importantes de un país, usualmente reviste aspectos tecnológicos y comerciales importantes. No obstante, como lo recuerda la Convención sobre la Protección y Promoción de la Diversidad de las expresiones culturales, es deber de los Estados adelantar acciones para promover y proteger diferentes expresiones culturales propias de sus territorios a partir de políticas de comunicación y cultura sin importar "el valor comercial que puedan tener" (Unesco, 2005, pág. 5).

Sobre esta premisa es fundamental considerar que el derecho a la cultura no puede abordarse de manera independiente al derecho de la comunicación, de ahí que se plantea: "sólo se podrá proteger y promover la diversidad cultural si se garantizan los derechos humanos y las libertades fundamentales como la libertad de expresión, información y comunicación" (Unesco, 2005, pág. 2). De acuerdo a esta concepción, el derecho a la cultura está atravesado por el acceso a los procesos de creación cultural, lo que debe conducir a la promoción de la diversidad de medios de comunicación incluyendo los de servicio público y comunitario (Unesco, 2005, pág. 6). En función de lo anterior, es posible afirmar que el ciudadano no es sólo sujeto de derecho en el ámbito socioeconómico, sino también en los ámbitos de la comunicación y la cultura.

En el anterior contexto, el papel de las políticas de comunicación es fundamental en tanto generan pautas y regulan el funcionamiento de este sector. Para hablar de políticas de comunicación es necesario entender primero la relación entre el sistema político y el sistema de medios. Para ello, resulta pertinente mencionar la propuesta de Bresnahan cuando se refiere al papel que cumplen los medios de comunicación en los procesos de democratización: "en la medida que los medios se han convertido crecientemente en la primera arena de la esfera pública, la democratización de los media ha sido reconocida como un componente fundamental de una democratización política completa" (Bresnahan, 2003, pág. 40).

La anterior relación lleva a pensar también en una distinción entre teoría democrática y teoría neoliberal de los medios. En la primera perspectiva se conceptualiza a los destinatarios de los medios como ciudadanos, mientras que en la segunda se les asume como consumidores, lo que hace que la expansión mediática quede condicionada exclusivamente por las opciones del mercado (Bresnahan, 2003, pág. 42).

Ahora bien, las políticas públicas en el ámbito de la comunicación se refieren a los "principios, estrategias y prácticas de organización, regulación, administración, financiamiento y esbozo de planes y predicciones relacionadas con las actividades de comunicación, participación ciudadana e información" ${ }^{8}$ (Becerra, 2008, pág. 120). Así por ejemplo, las emisoras comunitarias cuentan con un marco normativo y una Política Pública propia.

Las políticas públicas de comunicación para medios comunitarios deben representar unos principios, valores y objetivo que, en teoría, fortalezcan la democracia desde el ámbito de la equidad comunicativa, la participación ciudadana y el desarrollo social (Mc Bride, 1980). En otras palabras, las políticas de comunicación consideran "la integración de objetivos para la organización de medios, tecnologías y contenidos de la comunicación pública, integrando

\footnotetext{
${ }^{8}$ Traducción propia
} 
diversos actores, niveles de análisis y formas de intervención distintos así como problemas políticos, económicos y culturales relacionados con el proceso general del desarrollo de los estados y la gestión social de las comunidades. Es decir, las políticas públicas en comunicación conciernen al mundo de lo estatal y del ciudadano, a los espacios de participación y conflicto social y las relaciones de poder materializadas en una desigual distribución de los recursos materiales, de saberes e información" (Sierra, 2005, pág. 45).

Las emisoras comunitarias se definen como medios vinculados con sus comunidades de referencia, que fomentan su participación en la producción de contenidos comunicativos y en el desarrollo de un pensamiento crítico y que no tienen interés de lucrativo. De acuerdo al principio 13 de la Carta de Radios Comunitarias, lo que define a la radio comunitaria es su rentabilidad sociocultural, esta se sustenta en la promoción de la participación y en el reconocimiento de los oyentes como ciudadanos y no como simples receptores (Unesco, 2003, pág. 6).

\subsection{Marco normativo de la Radiodifusión Sonora Comunitaria en Colombia}

A continuación, se presentan los principales referentes legales ${ }^{9}$ de la radiodifusión sonora comunitaria en Colombia y se describen los componentes de la actual Política Pública.

En primer lugar, es posible mencionar el Decreto-ley 1901 de 1990 por el cual se reconoce el papel de la participación comunitaria en el desarrollo de las comunicaciones sin que se atribuya como rasgo propio de la radiodifusión comunitaria. Se considera un hito importante en tanto generó una apertura para que las comunidades participaran en la gestión de los servicios de comunicación. De igual forma, se hace referencia a la importancia de que el servicio de radiodifusión comunitaria llegue al sector rural y contribuya al desarrollo social, económico y cultural (Presidencia de la República, 1990).

De igual forma el Decreto 1445 de 1995, con un cariz mucho más técnico adopta los Planes Técnicos Nacionales de Radiodifusión Sonora en A.M y en F.M. los cuales integraron en su momento el Plan General de Radiodifusión Sonora, en ese momento, las emisoras comunitarias se acogían a los lineamientos establecidos para la frecuencia modulada (Presidencia de la República, 1995). En el mismo año, el Decreto 1446 reconoció legalmente las emisoras comunitarias como un tercer tipo de servicio de radiodifusión, aparte del servicio público y comercial, este reconocimiento estuvo acompañado de una desventaja, que en su momento fue motivo de controversia entre los sectores sociales, la prohibición para conformar cadenas.

Uno de los desarrollos normativos más importantes para las emisoras comunitarias también tuvo lugar en el 95 con el Decreto 1447 que en su capítulo $V$ reglamenta el servicio de radiodifusión comunitaria y delega al Ministerio de Comunicaciones, la tarea de velar por el cumplimiento de los objetivos que se propusieron para estas emisoras en términos de pluralismo, participación y respeto por la diversidad. Este decreto define la radiodifusión comunitaria como un servicio público sin ánimo de lucro a cargo del Estado en gestión

\footnotetext{
9 Los referentes legales considerados en esta revisión comprenden el periodo entre el año 1995 y 2000. Algunos de ellos se refieren de manera directa a las emisoras comunitarias y otros constituyen antecedentes importantes desde el punto de vista normativo.
} 
indirecta a través de comunidades organizadas (Presidencia de la República, 1995) .Por su parte, el Decreto 1439 modifica algunas disposiciones del 1447 entre ellos, amplía los plazos para la puesta en funcionamiento de las emisoras comunitarias.

Otro desarrollo normativo fundamental para el funcionamiento de la radio comunitaria en Colombia fue el Decreto 1981 del 2003 que establece como requisito para la integración de las juntas de programación que los participantes acrediten liderazgo social y que exista representación de diferentes sectores.

A diferencia de otros países, en Colombia es posible identificar un desarrollo legal importantes para las emisoras comunitarias, incluso, es reconocido por la Unesco como un país "propulsor de los derechos de las radios comunitarias" (Unesco, 2003, pág. 35). Llama la atención el hecho de que a pesar de que desde 1990 se reconoció la importancia de la participación comunitaria en la gestión de los servicios de comunicaciones, las emisoras comunitarias sólo gozaron de reconocimiento legal hasta 1995.

Un aspecto positivo a resaltar es que en el país se reconoce a las emisoras comunitarias como un tercer tipo de servicio independiente del comercial y el público, este hecho ha dado lugar a la existencia de una Política específica que legitima la radio comunitaria como un elemento constitutivo del sistema de radiodifusión ${ }^{10}$ y que reconoce su rol social y existencia legal.

\section{Radio y pluralismo: la Política Pública de Radiodifusión Sonora Comunitaria}

La Política pública de radiodifusión sonora comunitaria en Colombia fue expedida en el 2007, esta se realizó con el liderazgo de Jeanine El Gazi y funcionarios del Ministerio de Comunicaciones. El 20 de septiembre de ese mismo año se llevó a cabo un evento para presentarla formalmente con la participación de 26 representantes de diferentes Redes de Radio Comunitaria del país, representantes de emisoras y académicos para un total de 86 asistentes.

En el documento se asume que la Política de Radiodifusión Sonora Comunitaria constituye "un compromiso para promover la comunicación local con la participación plural democrática directa" (Ministerio de Comunicaciones República de Colombia, 2007, pág. 5). En ese sentido se plantea que el desarrollo de las emisoras comunitarias contribuye al enriquecimiento creativo y responsable de las condiciones de vida colectiva.

La Política cuenta con 6 componentes: una descripción de los fundamentos conceptuales, un diagnóstico sobre la situación de la radio comunitaria en Colombia, los principios y los objetivos de la Política, por último, se plantean las estrategias y herramientas para la implementación de la propuesta. A continuación, se presentarán de manera general cada uno de estos componentes con especial énfasis en el diagnóstico y las estrategias.

Son ocho los principios que fundamentan la propuesta: Comunicación y construcción de lo cultural; Comunicación pluralismo y democracia; Articulación en torno a propuestas comunes; Corresponsabilidad y compromiso frente a la Política; Reconocimiento de derechos constitucionales; Responsabilidad social de los medios; Promoción de estilos de

\footnotetext{
${ }^{10}$ El no reconocimiento de la radio comunitaria como un tercer sector ha conducido en algunos países a que estas radios funcionen bajo el régimen jurídico de la radiodifusión privada, tal es el caso de India y el Salvador.
} 
vida saludables; Educación cultura y comunicación. De forma general estos principios dan cuenta de los retos que el Estado reconoce de cara la radiodifusión comunitaria en materia de inclusión y creación de contenidos coherentes con los propósitos constitucionales. De igual manera, dejan ver que se reconoce en las emisoras comunitarias la capacidad para promover la diversidad y la cohesión regional en torno a la educación, la cultura, la convivencia, la identidad nacional, la calidad de vida y el patrimonio ambiental. Estratégicamente se plantea una oportunidad para que las comunidades construyan un diálogo social y político mediado por la comunicación y la cultura como el contexto que determina los modos de estar juntos en sociedad.

El diagnóstico por su parte se centró en los ejes de participación, programación y gestión. Para su desarrolló se realizó una consulta por Internet a actores estratégicos del sector para conocer sus apreciaciones sobre la situación de las emisoras. En total se obtuvieron respuestas de 20 personas que aportaron información sobre más de 259 emisoras comunitarias del país (Ministerio de Comunicaciones República de Colombia, 2007, pág. 13). Se identifica el abordaje general que tuvo el proceso de recolección de información, así como la poca participación que tuvieron las comunidades que se implican directamente en el funcionamiento de estos medios, este aspecto se refleja en el alto nivel de mediación que tuvo la información (20 personas que suministran información de 259 emisoras).

Respecto a lo anterior, el documento abiertamente plantea que uno de los problemas que se tuvo para la formulación de la Política fue la falta de información sistematizada sobre el estado de las emisoras comunitarias, en especial, en lo relacionado con el cumplimiento de los fines del servicio y la calidad de la programación. De acuerdo a esto, se planteó como reto para el $2010^{11}$ consolidar un banco de información y base de datos actualizada para asegurar la pertinencia de la intervención, se entiende que la consulta por Internet fue la estrategia a partir de la que se intentó subsanar este vacío en la información (Ministerio de Comunicaciones República de Colombia, 2007, pág. 7).

Frente al eje de participación el diagnóstico concluye que las parrillas de programación no siempre responden de manera coherente a los intereses y necesidades de comunicación de las comunidades locales, situación que limita la capacidad del medio para convocar la participación de diferentes sectores poblacionales, adicionalmente, se indica que el trabajo de las juntas de programación es poco conocido y que estas no realizan procesos de rendición de cuentas a la ciudadanía. Estas situaciones se atribuyen a que en el contexto nacional las discusiones y participación en la esfera pública están mediadas por formas clientelistas de hacer política.

De otra parte, el diagnóstico señala que una de las principales razones para que el servicio de radiodifusión comunitaria no cumpla con los objetivos que se le han trazado desde la participación, obedece a que los beneficios que de ellos se derivan no se perciben de manera rápida ni en el plano colectivo ni en el plano individual, sino que operan más en un plano simbólico y cultural que suele ser poco valorado por la ciudadanía. A lo anterior, se suma el hecho de que en la asignación de licencias termina por tener más peso el componente técnico de regulación del espectro que la evaluación de los proyectos comunicativos (Ministerio de Comunicaciones República de Colombia, 2007, pág. 17).

\footnotetext{
${ }^{11}$ De acuerdo a la búsqueda efectuada, no se encontró información que dé cuenta del avance en ese reto.
} 
El segundo eje considerado en el diagnóstico es el de la producción y la programación, elementos donde se concreta el proyecto comunicativo y se aporta a la ampliación y profundización de la participación democrática. Al respecto, se plantea que las emisoras comunitarias en su mayoría no cuentan con proyectos comunicativos ni manuales de estilo y que en otros casos estos no se asumen como cartas de navegación para su labor diaria, es decir, no pasan de ser un requisito que se presenta al momento de la adjudicación de la licencia.

De forma paralela, se indica que, si bien es posible encontrar programas propios, en muchos casos las emisoras transmiten contenidos de fuera, producen contenidos inspirados en estilos comerciales o se orientan por una programación musical. Se asume que de esta manera se reducen costos y se requiere menor dedicación de tiempo (Ministerio de Comunicaciones República de Colombia, 2007, pág. 17). Se concluye que hay una falta de conocimiento de los contextos locales y de las audiencias, así como de evaluaciones de impacto que favorezcan la toma de decisiones en los procesos de producción. En el caso de las zonas de conflicto armado se estima que la existencia de estos actores limita la capacidad de expresión y creación en los medios comunitarios (p.20).

Frente a la gestión, que es el último eje tomado en cuenta, el diagnóstico señala que en general las emisoras no logran llevar a la práctica procesos eficientes de planeación de modo que suelen trabajar de manera improvisada lo que les dificulta consolidarse como empresas sociales sostenibles. Sumado a lo anterior, se enfatiza en la ausencia de criterios administrativos y financieros que conducen a la falta de presupuestos para asumir el pago de compra o reposición de equipos, servicios públicos, mantenimiento de estudios, etc. El diagnóstico reconoce que las deficientes operaciones económicas han llevado incluso al cierre de emisoras incapaces de pagar los derechos de concesión (Ministerio de Comunicaciones República de Colombia, 2007, pág. 21).

Además, se indica que al ser la pauta local la principal fuente de financiamiento que contempla el marco normativo para las emisoras comunitarias y al existir pocas posibilidades de pauta en el contexto local, las emisoras comunitarias en ocasiones terminan por sucumbir a intereses privados o comerciales. Sobre este mismo asunto se plantea que la sostenibilidad financiera muchas veces representa un doble trabajo en tanto se deben recurrir a actividades no radiofónicas como rifas, bingos, entre otros.

En este punto se señala que las direcciones territoriales del Ministerio brillan por su ausencia y que no existe un acompañamiento oportuno que permita velar por el cumplimiento de los fines del servicio de radiodifusión comunitaria en el país.

Es posible afirmar que el diagnóstico es acertado y coherente en sus planteamientos, no obstante, es muy general, lo que limita la pertinencia de las estrategias propuestas. Se considera necesario involucrar de primera mano a los actores que participan del funcionamiento cotidiano de las emisoras comunitarias, que es lo que se propone en este trabajo, e indagar de manera sistemática y periódica por los usos que la comunidad da a estos medios de comunicación, las relaciones que se establecen y los diferentes roles que llega a jugar una emisora en el seno de una comunidad particular.

En función del anterior diagnóstico, la Política plantea cuatro objetivos específicos relacionados con la participación, la programación, la gestión integral y la capacidad del Estado frente a la Radiodifusión comunitaria. En la siguiente tabla se presenta una breve 
reseña de estos objetivos así como de las principales estrategias y herramientas que se proponen por cada uno de ellos.

Tabla 1: Tabla N¹. Objetivos, estrategias y herramientas de la Política Pública de Radiodifusión sonora comunitaria.

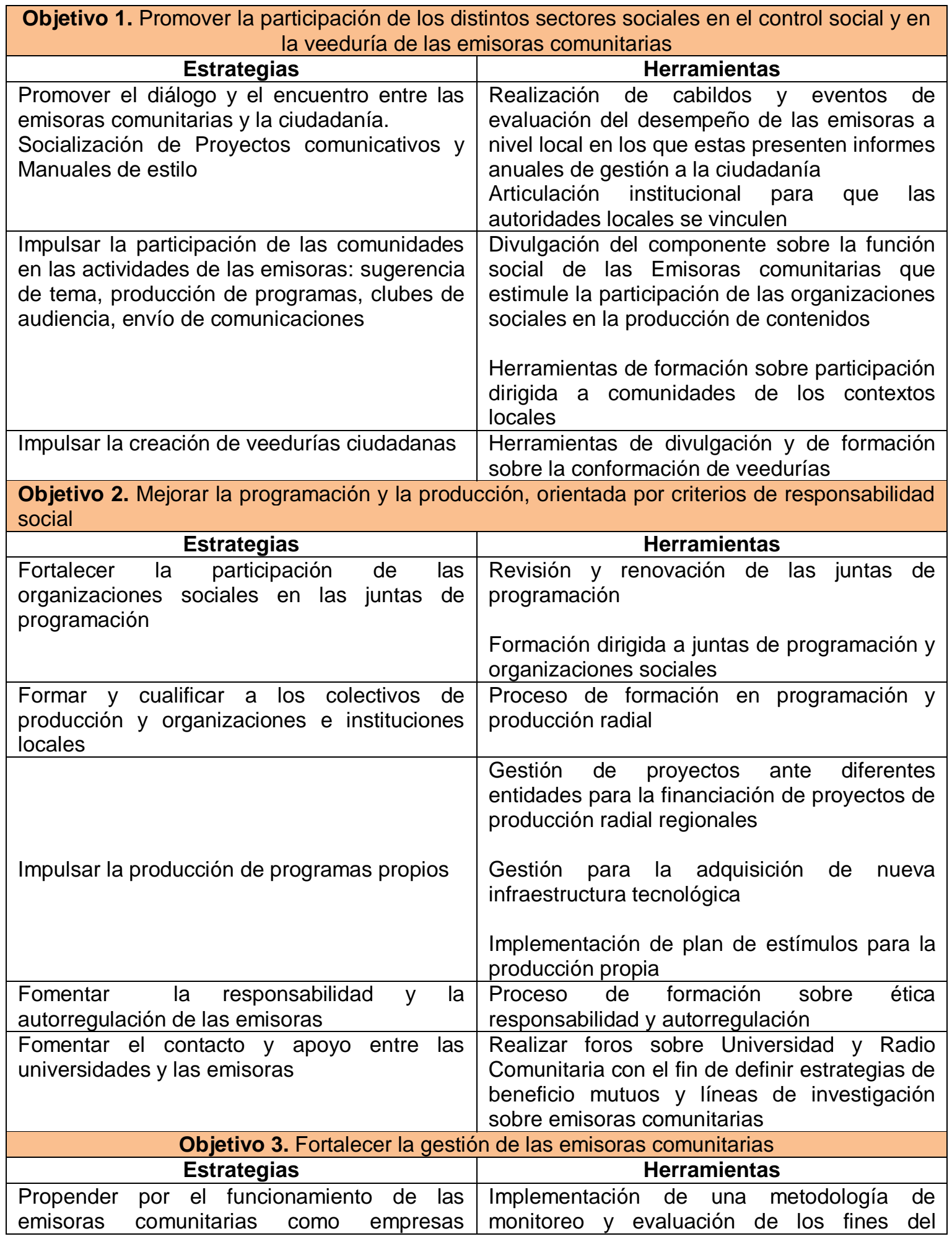




\begin{tabular}{|l|l|}
\hline sociales sostenibles & $\begin{array}{l}\text { servicio } \\
\text { Formación en temas de gestión y proyecto } \\
\text { comunicativo }\end{array}$ \\
\hline $\begin{array}{l}\text { Promover la organización de las emisoras } \\
\text { comunitarias }\end{array}$ & $\begin{array}{l}\text { Apoyar encuentros o mesas regionales y } \\
\text { nacionales de organizaciones y redes }\end{array}$ \\
\hline $\begin{array}{l}\text { Impulsar la presencia de los integrantes de las } \\
\text { emisoras en los consejos de planeación }\end{array}$ & $\begin{array}{l}\text { Divulgación sobre espacios locales de } \\
\text { planeación y participación }\end{array}$ \\
\hline $\begin{array}{l}\text { Impulsar la inclusión de las emisoras en los } \\
\text { planes de desarrollo }\end{array}$ & $\begin{array}{l}\text { Procesos de gestión con los gobiernos locales } \\
\text { y gobernaciones para que apoyen las } \\
\text { actividades de las emisoras comunitarias sin } \\
\text { que esto afecte su autonomía }\end{array}$ \\
\hline \multicolumn{2}{|c|}{ Objetivo 4. Fortalecer al Estado en su capacidad institucional } \\
\hline \multicolumn{2}{|c|}{ Estrategias } \\
$\begin{array}{l}\text { Ampliar y hacer más efectiva la capacidad del } \\
\text { Estado frente al sector }\end{array}$ & $\begin{array}{l}\text { Consolidación de información sobre el estado } \\
\text { real de las emisoras comunitarias } \\
\text { Desarrollo de herramientas de monitoreo y } \\
\text { acompañamiento }\end{array}$ \\
\hline
\end{tabular}

Fuente: (Ministerio de Comunicaciones República de Colombia, 2007, págs. 37-42)

En función de lo anterior, es posible identificar cinco tipos de herramientas: de información, de formación, de divulgación, de gestión institucional y de monitoreo y acompañamiento. Las herramientas de información incluyen dos elementos en primer lugar, la construcción de una base de datos sobre la actividad de las emisoras comunitarias desde un componente técnico, financiero, administrativo y de proyecto comunicativo. En segundo lugar, la construcción de un portal web para la interacción e intercambio de información entre las emisoras comunitarias.

Por su parte, las herramientas de formación hacen referencia a un plan integral de capacitación orientado a cualificar los procesos de participación, programación, producción, organización y gestión de las emisoras comunitarias, de acuerdo a ello incluye temas relacionados con ciudadanía, producción radial, evaluación de impacto, responsabilidad social de los medios, administración y organización. Sobre esta herramienta la meta planteada es "30 personas partícipes del proceso de formación" (Ministerio de Comunicaciones República de Colombia, 2007, pág. 50). Esta meta es irrisoria si se tiene en cuenta que en Colombia existen alrededor de 400 emisoras comunitarias (Ministerio de Comunicaciones República de Colombia, 2007, pág. 6).

Las herramientas de divulgación se orientan a partir de dos acciones fundamentales: la implementación de una campaña de sensibilización en radio, televisión y medios impresos y el posicionamiento de las emisoras comunitarias en los medios nacionales y regionales. En ese sentido se propone la celebración de cabildos y eventos de evaluación, la renovación de las juntas de programación.

De manera complementaria las herramientas de gestión institucional buscan apoyar la sostenibilidad integral de las emisoras comunitarias. Se incluyen en ese sentido, acciones como la gestión y presentación de proyectos ante entidades nacionales e internacionales, la gestión de infraestructura tecnológica y la celebración de mesas nacionales y regionales para una mayor articulación. Un elemento importante considerado en estas herramientas corresponde al desarrollo de un plan de estímulos para reconocer la labor en la producción propia. 
Por último, las herramientas de monitoreo y acompañamiento tienen el propósito de optimizar la labor institucional respecto al funcionamiento de las emisoras comunitarias, incluye entre otros aspectos, el desarrollo de una metodología de monitoreo y evaluación desde las direcciones territoriales y la conformación de un equipo técnico que coordine la implementación de la Política, así como el diseño de una metodología para que cada emisora adelante una evaluación de impacto.

Las herramientas en teoría son pertinentes, no obstante, se identifica una debilidad y es que no están planteadas de manera práctica y su éxito depende en gran medida de la eficiencia institucional del Estado y convoca muy poco a la autonomía de las emisoras comunitarias: desarrollar un portal web, consolidar una base de datos, llevar a cabo un plan de formación. Es claro el papel que el Estado debe jugar en la implementación de una Política Pública, sin embargo, una Política Pública para la Radiodifusión Sonora Comunitaria no puede quedarse mirando el ombligo de la institucionalidad, por el contrario, debe superar los esquemas asistencialistas y convocar a la acción en contexto de diferentes sectores.

Los siguientes testimonios dan cuenta no sólo del escaso avance que reportan las estrategias y herramientas antes planteadas, sino del poco conocimiento que las emisoras comunitarias del sur del Tolima tienen de la Política de Radiodifusión Sonora Comunitaria.

Bueno pues como tal si conocemos las normas generales que permiten la emisora esté en marcha, pero como tal, ese documento que usted dice que existe, ese sí no lo conocemos o por lo menos no así con tantas arandelas. Más bien es como poco contacto con el gobierno nacional, sólo una vez fui a Bogotá a un evento pero eso era del Alto Comisionado para la Paz y el tema era del papel de las emisoras comunitarias en el posconflicto, fue muy bueno. Pero sí sería bueno que uno conociera mejor esa propuesta y así haría un trabajo de más calidad. Sí de manera muy propia algunos colegas de otros municipios hemos querido hacer un evento más de nosotros y de eso sí se conversó con el alcalde Manios y le pareció muy viable (Rodríguez, R. 2017, 26 de noviembre, entrevistado por Álvarez, M., Natagaima)

Tengo entendido que cuando se hicieron las diligencias en Bogotá, al doctor Osorio le dieron una explicación de todas las normas y requerimientos que se deben cumplir que son muy importantes, porque o si no estaríamos en la ilegalidad y eso es bastante delicado. La Universidad la Gran Colombia sí nos ha ayudado, averiguando por ejemplo quien nos puede ayudar con lo de la antena, que es la situación que más nos agobia en este momento y parece que ya el alcalde nos va a ayudar. Lo que sí es que yo entro a la página web del Ministerio de Comunicaciones cada tanto y lo último que se publicó fue un documento que es una guía para mantener al día con el Ministerio de las Comunicaciones, sobre ese estamos trabajando ahora (Rojas, P. 2017, 30 de noviembre, entrevistado por Álvarez, M., Alpujarra)

Yo personalmente no conozco ese documento, ni tampoco que yo sepa hemos asistido a eventos o talleres. Lo único es que nosotros estuvimos hace poco en unos talleres con la Universidad del Tolima, con unos estudiantes de comunicación social que hicieron su práctica acá y fue muy interesante, nos enseñaron a manejar unos programas de edición y a un semillero de jóvenes también. Nosotros todo es por intermedio de la alcaldesa, porque para estar viajando a Bogotá es muy complicado y sin saber si a uno le van a parar bolas, no vale la pena gastar el dinero que es tan 
limitado. Sería bueno que el gobierno estuviera más pendientes de nosotros para ayudarnos y no sólo para caernos cuando pasa algo malo o cuando matan a los líderes (Romero, C., 2017, 3 de diciembre, entrevistado por Álvarez, M., Rioblanco).

En efecto, el documento al que hace referencia el profesor Plutarco se publicó el 2 de mayo de 2017 en la página web del MinTic. Este se plantea como una guía de obligaciones ${ }^{12}$ que deben tener en cuenta las emisoras comunitarias para estar al día con el Ministerio. Las obligaciones a las que hace referencia el documento son: solicitud de prórroga de la concesión, informar o solicitar autorización para la suspensión temporal de las transmisiones inferiores a 15 días, la no modificación de parámetros técnicos aprobados (frecuencia, potencia, centro de radiación de la antena, entre otros), organización de la programación y de la pauta publicitaria de acuerdo a fines del servicio, elaborar y dar a conocer el Manual de estilo, realizar proyectos y estrategias de comunicación a petición del MinTic, apoyar a las autoridades locales en caso de emergencia o calamidad pública (Ministerio de la tecnología, información y comunicación, 2017, pág. 1).

De igual manera, se plantean obligaciones que se deben cumplir anualmente: enviar documento con la composición de la junta de programación, presentar información de evaluación de los fines del servicio a la comunidad y los respectivos verificadores al Ministerio, pagar la contraprestación por concepto de uso del espectro, permiso para compartir infraestructura, paz y salvo por concepto de pago de derechos de autor, actualizar registro tic de radiodifusión sonora, atender visita de la Agencia Nacional de Espectro, presentar estudio de mediciones y declaración de conformidad de emisiones radioeléctricas, divulgar campañas de prevención de la corrupción (Ministerio de la tecnología, información y comunicación, 2017, pág. 2).

Las obligaciones planteadas en este documento retoman en muy bajo grado las estrategias de la Política de Radiodifusión Sonora Comunitaria, por el contrario, le otorgan especial relevancia a los asuntos técnicos, sin mencionar, que no se desagrega la ruta de acción o metodología que debería considerarse para su desarrollo, por ejemplo, se plantea que la emisora debe realizar una evaluación del servicio de acuerdo a sus fines, pero no se mencionan los criterios mínimos que dicha evaluación debería tener. De forma paralela, algunas de las obligaciones simplemente se enuncian sin indicar si existirá o no alguna retroalimentación por parte del MinTic.

\section{Un himno a la bandera}

A partir de esta revisión general no queda más que decir que la Política Pública de Radiodifusión sonora comunitaria tiene las mejores intenciones, pese a esto, su nivel de abstracción es tal que no pasa de ser un himno a la bandera. Si bien constituye un referente fundamental para la regulación de las emisoras comunitarias, hace falta la creación de un órgano independiente de regulación que asegure la transparencia y un acompañamiento integral y oportuno.

La Política privilegia la regulación estatal cuando debería promover la cultura de la autorregulación con el liderazgo de las emisoras comunitarias. En ese sentido, la elaboración de códigos de práctica a nivel regional en coherencia con las disposiciones

\footnotetext{
${ }^{12}$ En cada caso se indica el referente normativo que soporta la obligación.
} 
nacionales, se considera una herramienta pertinente que con la participación de las comunidades de los municipios serviría para fortalecer la toma de decisiones y la incorporación de lineamientos éticos a la práctica de las emisoras. Esta autorregulación debe aprovechar al máximo el capital humano de quienes participan cotidianamente en las dinámicas de producción de contenidos.

Ahora bien, la participación de la sociedad civil en el proceso de formulación e implementación de una política pública de comunicación constituye una variable determinante para asegurar su pertinencia y adecuada puesta en contexto. Lo anterior se debe a que el trabajo concertado entre estado y sociedad civil "facilita la adopción de decisiones de impacto social en ámbitos no adecuadamente representados por el sistema político" (De la Maza, 2007, pág. 152).

Precisamente la Política deja en evidencia una representación muy pobre de la situación actual de las emisoras comunitarias en el país y esta es una debilidad que abiertamente se reconoce en el diagnóstico. Las lógicas de funcionamiento de estas emisoras distan de ser homogéneas en el territorio nacional. Es probable que existan casos en los que las juntas de programación tengan un compromiso genuino para trabajar con la comunidad desde referentes locales y generar autorrepresentaciones colectivas con temas, contenidos y lenguajes propios, en otros, las comunidades organizadas a las que se les otorga la concesión estarán más interesadas en la satisfacción individual que en la realización colectiva.

Toda política pública apunta a la resolución o toma de decisiones frente a un tema que se reconoce como de interés público, en este caso, la radiodifusión sonora comunitaria que a su vez se ubica en el contexto de los medios de comunicación. A nivel nacional se identifican unas dinámicas sociales y estructurales que propician un sistema de medios poco democrático que se caracteriza por estar concentrado en grandes conglomerados económicos ${ }^{13}$, por ser homogéneo y excesivamente privatizado, ante este panorama, la toma de decisión estatal implícita en la Política de Radiodifusión Sonora Comunitaria es muy débil.

Por lo anterior, debe ser pensada de manera complementaria con un conjunto de políticas de comunicación y cultura capaces de promover una mayor democratización de la comunicación y de representar las aspiraciones de la ciudadanía que se moviliza en el paisaje mediático de los medios comunitarios. Se requiere superar el enfoque mediocéntrico y tecnológico para comprender y asumir desde la acción gubernamental que los medios comunitarios son expresión del desarrollo humano y comunitario y que ellos mismos tienen la capacidad de ser columna vertebral de los procesos de participación e incidencia ciudadana: "el rol de la comunicación en la toma de decisiones y el acceso va más allá de constituirse en instrumentos de difusión, para transformarse en agentes del proceso participativo (Del Valle, 2004, pág. 262).

La poca valoración y estímulo de los proyectos comunicativos de las emisoras comunitarias $\mathrm{y}$, en general, de los medios comunitarios, no ha sido solo un problema de visibilidad, de

\footnotetext{
13 Para el año 2010 en Colombia el sector de la comunicación mediática se logró oligopolizar en dos grandes grupos económicos nacionales Grupo Santo Domingo y Ardila Lule y dos trasnacionales españolas Grupo Planeta y Grupo Prisa. En el año 2012 la Casa El Tiempo pasó de manos de grupo español Planeta a ser del grupo Luis Carlos Sarmiento Angulo (Revista Semana, (17 de marzo de 2010) Sarmiento compra El Tiempo).
} 
que los gobiernos de turno no vean las demandas de estos medios, sino que obedece a una dinámica que pasa por la falta de condiciones sistemáticas para la participación de sus líderes y la ausencia de mecanismos públicos y reconocibles en los que la voz, la experiencia y los saberes de los medios comunitarios, sean reconocidos y considerados por las autoridades gubernamentales como agentes portadores de un conocimiento válido sobre el tema.

Es clara la casi completa invisibilización de las emisoras comunitarias en el debate sobre medios comunitarios o más aún en los diálogos sobre convergencia digital ${ }^{14}$. En definitiva, las emisoras comunitarias ocuparán un lugar relevante en el debate y regulación de la radio comunitaria, en la medida en que sus líderes y representantes puedan intervenir de manera activa y visible antes de su promulgación, así como en las siguientes fases de implementación, monitoreo y evaluación. Es necesario que parte de los objetivos de la intervención ciudadana en el diálogo sobre emisoras comunitarias se concentre en asegurar la apertura de este tipo de espacios de participación.

Se pone de manifiesto la incapacidad institucional para proponer una Política Pública coherente para mejorar la situación de las radios comunitarias. A este hecho ahora se debe agregar un tema emergente: la convergencia digital, proceso que complejiza aún más el diálogo sobre medios comunitarios en Colombia. Al respecto preocupa que el debate público no adquiera una perspectiva pública y civil sino que se centre sólo en lo tecnológico y empresarial.

Se identifican dos desafíos principales. En primer lugar, identificar las variables sobre las cuales tanto la ciudadanía en general como las emisoras comunitarias pueden incidir a través de su práctica para que sus posiciones consigan una mayor relevancia tanto en el debate público como en el debate legislativo. Se trata principalmente del desarrollo de sinergias y de trabajar en red, es decir, de una articulación entre proyectos comunicativos no necesariamente similares en todos sus aspectos, pero con capacidad de unirse por la defensa de la democratización de la palabra y el derecho a la comunicación. Es en esta capacidad organizativa donde se generarán posibilidades para que la radio comunitaria logre su inclusión en el ámbito de la política pública, no porque esta no exista ya, sino porque la que existe las mira de reojo.

En este punto conviene retomar la triple sustentabilidad a la que se refiere GumucioDagron: social, institucional y económica. La sustentabilidad social comprende la apropiación por parte de la comunidad en la cual está inserta el medio, esta es clave para que los medios comunitarios logren trabajar en pro de la sustentabilidad institucional la cual se relaciona con el marco legal y las políticas existentes. Por su parte la sustentabilidad financiera se refiere a los recursos que requiere el medio para su funcionamiento material (Gumucio Dagron, 2011, pág. 32). Si se considera que la precariedad del sector de radiodifusión sonora comunitaria se sitúa más en el plano institucional y financiero, y en menor medida en la dimensión social, la transición a un nuevo entorno tecnológico

\footnotetext{
${ }^{14}$ La convergencia tecnológica digital es "el proceso económico, político y cultural que está configurando un nuevo régimen de información y comunicación, bajo un modelo de negocio, reglas legales y prácticas sociales, en un conjunto de cadenas productivas de una industria cultural soportada en medios de comunicación electrónicos digitales (Dantas, M (2010) "Convergencia Digital: entre os Jardins Morados e a pracas públicas, en Sel, S. Políticas de Comunicación en el capitalismo contemporáneo, Buenos Aires, CLACSO). En Colombia, el proceso de convergencia digital se sustenta en la Ley Tic 1341 de 2009.
} 
constituye una oportunidad para el fortalecimiento de los proyectos comunicativos siempre y cuando se cuente con un adecuado impulso y articulación institucional.

En segundo lugar, es necesario fortalecer la articulación institucional y ciudadana en torno a las emisoras comunitarias desde una perspectiva de derecho a la comunicación y derechos culturales. En esta línea, no puede haber una despolitización de la política pública de radiodifusión comunitaria y en la democratización de la comunicación no puede tener más peso lo económico que lo político y lo cultural. El primer paso en esta dirección debe traducirse en la redefinición de las relaciones entre políticas de comunicación y política en general desde un enfoque radicalmente democrático que asuma la comunicación para el desarrollo como una experiencia vital de las comunidades en vinculación profunda con su propio texto cultural y los contextos institucionales que dan sentido a los territorios que habitan.

Lo anterior no quiere decir que se desestime lo económico, por el contrario, es necesario comprender que la importancia económica de la comunicación reside no en que sea un negocio rentable desde el punto de vista de las empresas mediáticas, sino que como categoría social es un factor que aporta al desarrollo de un país como lo advirtió en su momento el informe Mc Bride.

En lo que respecta a la concepción instrumental de las políticas de comunicación, desbordadas por valores normativos, institucionales y económicos, es necesario emprender un ejercicio participativo de construcción de política pública con incidencia de todas las regiones y asumirlo como una práctica de reflexión colectiva, de discusión pública democrática sobre los intereses, puntos de encuentro y contradicciones internas de los proyectos comunicativos de las emisoras comunitarias a nivel local, esto es, pasar de una regulación bien intencionada y teórica a una más comprometida y transformadora.

El telón de fondo de la transición descrita anteriormente debe ser la comprensión de la comunicación comunitaria como elemento fundamental de la democracia, en tanto representa el escenario social donde se vivencia el derecho a comunicar de manera diversa y plural. Las emisoras y, en general, los medios comunitarios deben ser fuente inagotable de esperanza para Colombia, pues ante la consolidación de los monopolios comunicativos nacionales e internacionales, encarnan de manera legítima la expresión de muchos actores sociales que hoy más que nunca están decididos a hacerse escuchar. 


\section{Capítulo 3. Breve marco histórico de las emisoras comunitarias del sur del Tolima}

En este apartado se planteará un marco histórico general de las emisoras comunitarias de los municipios de Natagaima, Alpujarra, Rioblanco y San Antonio, ubicados en el sur del departamento del Tolima. La información se recopiló a partir de entrevistas estructuradas personales realizadas en los municipios y envío de ampliación de información a través de correos electrónicos. Los datos obtenidos contribuyen al análisis en aspectos cualitativos y a conocer de manera más precisa el alcance de estos medios en sus territorios, su liderazgo en las comunidades en las que se ubican, sus logros y sus expectativas de futuro.

Las entrevistas se estructuraron en función de dos grandes ejes: información general y capital social. En el Anexo E es posible visualizar en detalle las preguntas abordadas en esta entrevista.

\subsection{Natagaima: Emisora Haca Yu Macu 106.0 FM}

\begin{tabular}{|l|l|}
\hline \multicolumn{2}{|c|}{ Ficha de identificación } \\
\hline Director & Roque Arcángel Rodríguez Prada \\
\hline Representante legal & Rubén Barrera \\
\hline Teléfono & 2264064 - 3202575770 \\
\hline Correo electrónico & hacayumacufm@gmail.com \\
\hline Enlaces de interés & $\begin{array}{l}\text { http://www.elanzuelomedios.com/index.php/historias/lo-mas- } \\
\text { leido/219-haca-yu-macu }\end{array}$ \\
\hline
\end{tabular}

En el municipio de Natagaima inicialmente existieron dos emisoras que funcionaban de manera ilegal: SanJuanera Estéreo y Pamina Estéreo. Cuando el Ministerio de las Comunicaciones reglamentó la radio a nivel nacional, desaparecieron las dos emisoras y surgió Haca Yu Macu 106.0FM, la emisora comunitaria del municipio. En lengua Pijao Haca Yu Macu significa "Bienvenidos Espíritus Buenos", de ahí que esta emisora comunitaria haya asumido el compromiso de destacar el valor de la cultura Pijao en los pobladores de la región, promoviendo espacios de participación de la comunidad en la programación radial.

Como misión esta emisora se propone trabajar "por la reconstrucción histórica de una región orgullosa de su identidad, comprometida en liderar la formulación de estrategias dirigidas a la construcción participativa de una cultura de comunicación a través de la radio, que incentive la identidad pijao".

Esta emisora empezó a funcionar mediante licencia $N^{\circ} 413$ otorgada por el Ministerio de Comunicaciones el día 24 de febrero de 2009. El 4 de agosto se empezaron a realizar algunas emisiones de prueba y finalmente el 4 de octubre del mismo año fue inaugurada oficialmente con la participación de 40 representantes de diferentes sectores sociales. Esta iniciativa nació de la Corporación Haca Yu Macu liderada por Israel Peña Ramírez y 
Germán Cortés Tocarema, acompañados de la Corporación Hombres y Mujeres. El proceso fue acompañado por líderes importantes para el departamento como Miguel Marín ${ }^{15}$ Q.E.P.D.

El 27 de septiembre de 2008 fue elegido en asamblea por los demás socios el señor Roque Rodríguez Prada como director de la Emisora. De igual manera, el proceso de consolidación del medio contó con el apoyo de diferentes sectores sociales, entre los que se destaca el Sindicato de profesores del municipio, la veeduría ciudadana a través del grupo de trabajo municipal permanente, en cabeza de la señora María Garzón. La adquisición de equipos técnicos para el montaje se dio gracias a la participación de algunas ONG que prestaron el dinero. Por su parte, la adecuación del lugar y el montaje de la torre que sostiene la antena fue obra del trabajo voluntario de los jóvenes del municipio. El primer programa que se realizó fue "Mundo Joven", el segundo fue "Mundo Infantil", el tercero fue la Radio Revista Ciudadana, los que se han mantenido vigente hasta la fecha.

El cuerpo de producción, dice don Roque, "está conformado por toda la ciudadanía y aunque algunos cuentan con poca experiencia técnica tienen mucho interés y entusiasmos y eso es lo que importa" (Rodríguez, R. 2017, 20 de octubre entrevistado por Álvarez, M., Natagaima). Por el momento el sostenimiento de la emisora corre por cuenta de la junta de programación, aunque se proyecta que mediante convenios interadministrativos que todavía no se concretan, podrá ser sostenible. Se quiere además lograr convenios académicos para formar a las personas y que estudiantes realicen su práctica profesional en la emisora. Se resalta el apoyo que han recibido por parte de la Universidad del Tolima y la profesora Marisol Mesa Galicia.

A continuación, una muestra de la programación vigente ${ }^{16}$ :

El despertar del gallo con aroma de café: narraciones sobre el trabajo de los campesinos en sus labores diarias.

Radio Revista Ciudadana: desde reporterías rurales se abordan distintos temas y problemas del municipio, alrededor del programa se consolida una agenda participativa.

De Mujer a Mujer: busca abordar temas relacionados con el papel de la mujer en un nuevo desarrollo comunitario.

Mundo Joven: se habla sobre temas del municipio que interesan o preocupan a la juventud

De regreso al rancho: pretende acompañar a los campesinos de vuelta a sus viviendas después de haber trabajado en la tierra, en esa medida, se abordan temas de producción, agricultura, entre otros.

Mundo infantil: incluye franja de música infantil, cuentos de autoría de los niños en las clases de español del colegio.

\footnotetext{
${ }^{15}$ Miguel Marín fue un líder social del Tolima que impulsó el trabajo de las emisoras comunitarias de la región. Fue director de la emisora comunitaria Café estéreo del municipio del Líbano. En su momento fue militante del M-19. Una vez reinsertado se dedicó a la defensa de la comunicación alternativa. Murió por causas naturales en el 2009.

${ }^{16}$ La programación también incluye franjas musicales.
} 
Aveki Mitos, leyendas y relatos ancestrales del municipio.

Esta emisora comunitaria además es reconocida por los cabildos y resguardos como la manera de acercarse a los gobiernos locales. A pesar de su importancia, en el 2012 se contempló la posibilidad de cerrarla porque no se contaba con el acompañamiento del gobierno municipal ni nacional. Con la administración del alcalde Jesús Alberto Manios, (2016-2019) se ha tenido mayor apoyo.

Cada día esta emisora intenta seguir el enfoque de fortalecer procesos sociales y culturales dentro del municipio, generar espacios de participación y acompañar procesos organizativos de gran relevancia local como es el caso de la escuela agroecológica Manuel Quintín Lame, y esto es gracias a que la emisora puede hablar abiertamente sobre ecología, minería, agua convirtiéndose en una intermediaria entre la institucionalidad y el pueblo.

A nivel técnico se resalta que la emisora funciona en la casa de uno de los integrantes de la Junta de Programación, la principal dificultad es que el espacio no está insonorizado y que los cortes de energía eléctrica han dañado algunos equipos.

\subsection{Alpujarra: Samán estéreo 102.5 F.M}

\begin{tabular}{|l|l|}
\hline \multicolumn{2}{|c|}{ Ficha de identificación } \\
\hline Directora & Cidia Aya Trujillo \\
\hline Representante legal & José Santos Soler \\
\hline Teléfono & 3125801946 \\
\hline Correo electrónico & cidiaya1964@hotmail.com \\
\hline Enlaces de interés & http://www.colradios.com/samanstereo \\
\hline
\end{tabular}

La emisora comunitaria Samán estéreo nació en mayo del año 2009 gracias al trabajo de la Asociación de Padres de Familia de la Institución Técnica Felisa Suárez de Ortiz y el trabajo del líder cívico Jaime Osorio, más conocido como el Mono Osorio. La cobertura es de 200 W y se ha propuesto como misión la promoción del arraigo cultural y el rescate de valores como la reconciliación, el perdón y el respeto. Algo que resultó inspirador para todas las personas que se vincularon en el proceso, fue que en el municipio de Dolores existía una emisora llamada Radio Altamizal en la que se abordaban muchos temas de interés para el municipio y en el que las personas podían expresarse frente a diferentes situaciones, incluyendo, el conflicto armado.

La propuesta se presentó a través de la asociación de padres de familia, pero se recibió el apoyo de muchas personas pues todo se hizo en una fecha muy próxima al vencimiento de los plazos. "Mientras un grupo de personas elaboraba el documento, otro se encargaba de visitar las veredas para conseguir certificaciones de trabajos comunitarios realizados. 
Cuando tuvimos la información viajamos a Bogotá un día antes de la fecha límite y quedamos entre los seleccionados y nos dieron la resolución" (Aya, C. (2017, 15 de septiembre) entrevistado por Álvarez, M., Alpujarra).

Después de que la Junta recibió la resolución se enfrentaron a la incertidumbre de no saber qué hacer pues no contaban con los equipos necesarios ni sabían cómo manejar una emisora. El Mono Osorio hizo un teletón y llamó a la generosidad de las colonias de Neiva y Bogotá, además, se presentó un proyecto al Ministerio de Cultura. Con los recursos recaudados y los aportes de la alcaldía de turno y del Ministerio de Cultura, se compraron algunos equipos y la antena de un Telecom que había quedado abandonada luego de ser derribada por las FARC en el año 2000, fue la que se usó para empezar a hacer las transmisiones.

Luego de haber resuelto lo de los equipos, debían definir dónde instalar la emisora. Fue entonces cuando el alcalde Víctor Manuel Martínez cedió un espacio ubicado en la anterior sede de la administración que fue afectada por la toma guerrillera de las FARC. En palabras del profesor Plutarco, en ese momento se cometieron dos errores graves: la antena quedó mal ubicada y los equipos no cumplían con los requerimientos técnicos solicitados (Rojas, P. (2017, 15 de septiembre) entrevistado por Álvarez, M., Alpujarra). Por lo anterior, la emisora ha sido sancionada con una multa que asciende a más de $\$ 12^{\prime} 000.000$.

La emisora empezó a funcionar gracias a que un joven del municipio, Ismael Rodríguez, estudió comunicación en Neiva con énfasis en producción audiovisual y empezó a trabajar en la emisora y a enseñar cómo editar audios a los integrantes de la Junta. Así, se empezaron a ofrecer cuñas a la Alcaldía, al Hospital y a la comunidad en general, con el dinero que se recibía se asumían los gastos de la emisora.

El profesor Santos Soler plantea que el apoyo que han recibido ha sido más de carácter local y en su momento del Ministerio de Cultura que otorgó un presupuesto de $\$ 12^{\prime} 000.000$ para la compra de equipos. De igual manera, han acudido a la Universidad Surcolombiana que esporádicamente envía estudiantes a realizar su práctica profesional (Santos, J. (2017, 15 de septiembre) entrevistado por Álvarez, M., Alpujarra).

Dentro de la parrilla es posible encontrar $\operatorname{programas}^{17}$ de convivencia ciudadana, culturales y espacios informativos. A continuación se mencionan algunos de ellos.

-Amanecer campesino: es un programa dirigido al campo, se abordan temas de actualidad y ocasionalmente se preparan especial sobre agroproducción limpia.

-Programa religioso: orientado por el párroco del municipio, ofrece reflexiones sobre valores y reflexiones bíblicas.

-Radio Revista Soplando el Caldo: en esta franja los ciudadanos pueden comunicarse a través de diferentes medios para hablar de temas de actualidad del municipio y denunciar problemáticas locales.

\footnotetext{
${ }^{17}$ La programación no tiene una continuidad, pues hay días, incluso semanas, en que la programación es netamente musical.
} 
-La media mañana: incluye consejos para el hogar, recetas de cocina y complacencias musicales.

-Tardes de locura: orientado por jóvenes, se privilegia principalmente la música y temas de interés para la juventud, entre ellas, la drogadicción, el embarazo adolescente, la adicción al celular. La Comisaría de familia municipal acompaña el desarrollo de algunos de estos temas.

-Convivencia ciudadana: liderado por la policía, se desarrollan temas variados enfocados principalmente a la prevención de problemáticas como las riñas, el abuso del alcohol, la contaminación del espacio público, el maltrato animal.

También hay programas como "Entre el amor y el despecho", "La media Naranja" y "Llegando a casa", en estos se privilegia la música con breves insertos de poemas y reflexiones cortas. Los sábados cada 15 días, la administración municipal tiene un espacio radial de rendición de cuentas. Sobre la programación, el profesor Santos plantea:

El principal problema que tenemos es la inconstancia, porque a veces no hay quien haga los programas si la junta de programación está ocupada, entonces lo que se hace es poner música que es lo más fácil. Digamos que cuando pasa algo en el municipio, pues ahí sí estamos muy pendientes para ponerlo a circular por los micrófonos de Samán estéreo. A esto hay que sumarle todos los problemas técnicos que tenemos, no sólo el de la antena, sino que como se va tanto la luz, cuando regresa quedamos fuera del aire no sabemos por qué y nos toca esperar que venga una persona de Neiva a ayudarnos. Una vez quedamos por fuera del aire como casi dos meses y cuando eso pasó recurrimos al perifoneo y parlantes de la iglesia para hacer el trabajo (Santos, J. (2017, 15 de septiembre) entrevistado por Álvarez, M., Alpujarra).

La emisora no cuenta con estudios de audiencia, sin embargo, han hecho sondeos informales para conocer a la gente qué le gustaría escuchar y se han encontrado que la gente prefiere la programación musical, así como espacios donde puedan opinar y hablar de temas de interés local. Al respecto, la Junta de Programación recalca la importancia de contribuir a rescatar los valores ciudadanos y familiares, por eso procuran que la música que se transmite no incluya vocabulario soez o que se denigre de la mujer. De forma paralela, siempre que se requiera, la comunidad cuenta con un espacio para proponer temas, plantear quejas o promocionar actividades: bazares, proyección de videos, ensayos del folclor. En época electoral se enlazan con la Red Pijao para hacer un informativo sobre los comicios en coordinación con la emisora universitaria Tu Radio de la Universidad del Tolima.

Se contaba con un documento con el reglamento interno y con la propuesta que se presentó para obtener la licencia con la misión y visión de la emisora, sin embargo, se perdió y no ha sido posible conseguir una copia. Tampoco se ha emprendido un ejercicio para actualizar el proyecto comunicativo y el Manual de estilo

Para el año 2018 la Junta de Programación está compuesta por la Asociación de padres de Familia de la Institución Técnica Felisa Suárez de Ortiz, el rector de la Institución, el párroco y representantes de Asociaciones productivas. La programación es principalmente de carácter musical, con franjas informativas y magazines en vivo o pregrabados sobre 
diferentes temas de interés local como el cultivo de café, celebraciones culturales, entre otros.

Como principal problema se identifica la ubicación de la antena en tanto fue ubicada al revés de manera que las ondas rebotan con la cadena montañosa e invaden el espectro del departamento del Huila. La principal fuente de financiamiento corresponde a cuñas radiales, avisos comunitarios y espacios radiales de la administración municipal, en ese sentido, los recursos económicos son muy limitados y por ello no ha sido posible hacer frente a la multa por invasión de espectro.

En el desarrollo de contenidos participan principalmente la Junta de Programación y en algunos casos los actores de la comunidad, para lo que previamente deben presentar una propuesta de lo que desean emitir.

\subsection{Rioblanco: Rioblanco estéreo 95.0 FM}

\begin{tabular}{|l|l|}
\hline \multicolumn{2}{|c|}{ Ficha de identificación } \\
\hline Director & Luis Enrique Ospina Gómez \\
\hline Representante legal & Luis Enrique Ospina Gómez \\
\hline Teléfono & $3115707073-3206996508$ \\
\hline Correo electrónico & rio95fm@yahoo.com \\
\hline
\end{tabular}

El municipio cuenta con dos emisoras, una de interés público, "Colombia estéreo" del Ejército Nacional y la emisora comunitaria Rioblanco estéreo 95.0 F.M. En los años 90 existió una emisora ilegal creada por la iglesia Pentecostal, que finalizó su trabajo cuando el Ministerio exigió la legalización de las emisoras en el territorio nacional.

Rioblanco Estéreo nació inicialmente en el corregimiento de Herrera ${ }^{18}$ como una iniciativa de la Asociación de Productores de Alto Saldaña, PROAS. No obstante, debido a la presión ejercida por las FARC, se tomó la decisión de trasladar la emisora a la cabecera municipal y aunque inició labores desde 1998, sólo desde el 2009 está legalizada ante el Ministerio.

La cobertura del medio es de 2 w lo que le permite llegar a municipios del sur del Tolima como Ataco, Chaparral, Planadas, San Antonio y sectores del norte del departamento del Huila. La población objetivo es la ciudadanía en general, con un énfasis especial en los campesinos y agricultores ya que la población rioblancuna está mayormente dispersa en la zona rural.

En los últimos años han participado de procesos de formación liderados por la Oficina del Alto Comisionado para la Paz, la Universidad de Antioquia, la Unidad de Reparación de Víctimas, la Universidad del Tolima, la Red Sipaz, el Programa de Radio ciudadanas y de

\footnotetext{
18 Durante muchos años este municipio del sur del Tolima, especialmente el corregimiento de Herrera, vio la luz de una etapa violenta que rompió la convivencia pacífica. La violencia arrasó por muchos años con cafetales, trapiches, animales y familias campesinas.
} 
ONG como OXFAM. El tema de estas capacitaciones ha sido principalmente en procesos de producción radial y del papel de los medios comunitarios en el posconflicto.

La programación aborda temas de opinión, salud, educación, secciones informativas y musicales, magazines agropecuarios y programas dirigidos por la mesa municipal de juventudes.

El principal problema que se identifica es los escasos recursos económicos y la carencia de infraestructura y equipos adecuados (no cumplen con exigencias técnicas del Ministerio) ${ }^{19}$ así como la falta de cobertura de Internet. Pese a estas restricciones la emisora goza de credibilidad en los pobladores por la labor comunitaria y de servicio que han prestado desde su nacimiento.

La principal fuente de ingresos son las cuñas locales y esporádicamente cuñas para el orden nacional, por ejemplo, sobre desminado humanitaria y erradicación manual. En la producción de contenidos participan diferentes representantes de la comunidad quienes se dividen las labores de locución, investigación y reportería urbana y rural. Al respecto, se cuenta con colectivos temáticos: de juventud, de salud, de liderazgo comunitario y planeación participativa, de medio ambiente, entre otros. Un representante de cada uno de estos colectivos hace parte de la Junta de Programación. Sobre la programación, su director plantea:

Lo principal que tenemos como emisora comunitaria es la vocación de servicio, por eso más que lo que se emite, lo importante son los procesos que nosotros promovemos: mingas ciudadanas, mesas de diálogo con el gobierno local y procesos de planeación participativa a partir de una capacidad instalada que nos dejó USAID con un proyecto de Cabildeo (Ospina, L. (2017, 19 de septiembre) entrevistado por Álvarez, M., Rioblanco).

Para el año 2018 está vigente un proyecto con el Ministerio de Cultura, y por el cual la emisora recibirá un incentivo económico, que tiene como objetivo adelantar actividades de producción, participación, emisión y circulación de contenidos que promuevan el diálogo público en torno a la construcción de una cultura de paz y convivencia. Este trabajo se realiza en el marco del Programa insignia "Voces de Resiliencia" que se emite todos los viernes en la mañana y en el que se resalta la inclusión del sector rural como factor clave para aprender de las personas y comunidades que han superado la violencia armada y que han encontrado alternativas para mediar sus conflictos.

\subsection{San Antonio: Tetúan estéreo}

\begin{tabular}{|l|l|}
\hline \multicolumn{2}{|c|}{ Ficha de identificación } \\
\hline Director & Eloy Aguiar \\
\hline Representante legal & Eloy Aguiar \\
\hline
\end{tabular}

\footnotetext{
${ }^{19}$ Para el año 2018 requieren renovar la consola y el sistema irradiante que resultó afectado por los continuos cortes eléctricos.
} 


\begin{tabular}{|l|l|}
\hline Teléfono & 3105644890 \\
\hline Correo electrónico & $\underline{\text { sanjosetetuan@yahoo.es }}$ \\
\hline
\end{tabular}

En la historia del municipio es posible identificar tres emisoras de radio que funcionaban ilegalmente en los años 90. Estas eran: San Antonio de Calarma, que fue creada por un sacerdote del pueblo, Calarma Estéreo, fundada por la familia Salcedo Aguiar y Aguiar Estéreo creada por los hermanos Eloy y Yesid Aguiar.

Cuando el Ministerio exigió la legalización de las emisoras, San Antonio de Calarma y Calarma estéreo desaparecieron, mientras que Aguiar Estéreo pasó a denominarse Tetúan Estéreo y se registró como comunitaria pese a que no nació como iniciativa de un proceso de organización social y comunitario. La cobertura otorgada por el Ministerio es de 200 vatios que no ha sido posible ubicar en su totalidad porque cuando se realizaron los estudios para el enlace, el lugar donde estaba ubicada la antena se deslizó y no se ha contado con los recursos necesarios para reubicar la antena. De acuerdo a esto, la emisora trabaja en el casco urbano con transmisor y antena ubicados en el mismo lugar, no es posible subir la potencia porque se afectaría la señal de televisión y la de otras emisoras.

La emisora tiene una orientación ideológica conservadora que se hace evidente en el sesgo político del equipo de producción que se caracteriza por ser de planta. (no hay participación de la comunidad). En el equipo participan Eloy Aguiar, Yesid Aguiar y Julieth Caicedo. Esto hace que se afecte la imagen de la emisora comunitaria porque la hace parecer como si perteneciera a un grupo político, el partido conservador.

El equipo de producción ha participado de procesos de capacitación con la Corporación Sipaz. De igual manera reciben el apoyo de la administración municipal que en el año 2017 asignó un espacio con mejores condiciones para su funcionamiento y asumió los gastos que la emisora no había logrado pagar. De igual forma, la alcaldía tiene destinado un recurso para la renovación de equipos por una suma de $\$ 10^{\prime} 000.000$.

En la producción de contenidos se privilegia el formato noticioso y el magazine en vivo. A pesar de que en constantes ocasiones se ha hecho un llamado a la comunidad para que participe, este llamado no ha tenido eco entre los micunos. 


\section{Capítulo 4: La tensión como encuentro}

A primera vista la palabra tensión puede significar conflicto, contradicción o punto de quiebre y por ello puede considerarse un término muy impreciso para enunciar un objetivo de investigación. Para efectos de este trabajo, abordar la pregunta por el relacionamiento entre la Política Pública de Radiodifusión comunitaria en Colombia y el funcionamiento de las emisoras comunitarias en el sur del Tolima en términos de "tensiones", es una decisión conceptual y metodológica al mismo tiempo; entendiendo que ninguno de estos dos asuntos es neutro. En tal sentido, se propone problematizar los límites y potencialidades de esta relación a partir de elementos concretos de análisis que están implicados desde la concepción misma de la Política y la dinámica de funcionamiento de las emisoras en los contextos en los cuales están insertas.

El concepto de tensión se utiliza en los campos de la mecánica, la física e, incluso, en el área de la salud. En este caso, se retoma la definición que se hace desde la física sobre este concepto, para entender el sentido con el que se utiliza en el contexto de este trabajo. En física, todos los objetos que están en contacto pueden ejercer fuerza entre sí, estas fuerzas se nombran de manera diferente de acuerdo a su naturaleza y al tipo de objetos que están en contacto. Si dicha fuerza es ejercida por un hilo, una cadena o un cable, se denomina tensión. Así pues, se plantea que un hilo o un cable pueden transferir una fuerza eficiente a una distancia significativa correspondiente a su propia longitud, es decir, la tensión es una fuerza de tracción y no de empuje. Empujar con una cuerda podría provocar que se afloje y se pierda la fuerza de tensión (Khanacademy, 2015).

Visto de esta manera, en el planteamiento de la pregunta que orienta el desarrollo del presente trabajo, los dos objetos en tensión son la Política Pública de Radiodifusión Sonora Comunitaria y, más que las emisoras comunitarias en sí mismas, las características y elementos que se concretan en su funcionamiento cotidiano. Dicha tensión, en primer lugar, enuncia una relación que, aunque es susceptible de problematizarse, no se agota en la existencia de un conflicto, todo lo contrario, se trata de una relación que se configura diariamente en la distancia a partir de diferencias de contexto y la creación permanente de campos de interlocución e interpelación. Las emisoras comunitarias recrean su funcionamiento en el seno de comunidades cambiantes ubicadas en contextos sociohistóricos de complejidad creciente, la Política, por su parte, intenta trazarles una ruta de trabajo en términos de participación y ciudadanía.

En segundo lugar, se trata de una tensión que se flexibiliza, y que por ello no busca resolverse sino enunciar desde otras coordenadas la relación que encarna, de modo que la Política Pública, en la lógica desde la que esté pensada, representa mejor las condiciones de los contextos y asuntos sobre los cuales intenta proponer una red de decisiones. Al respecto sería necesario revisar las formas y niveles de institucionalización que operan en esta relación, las historicidades particulares y comunes de los territorios donde están alojadas las emisoras comunitarias y, lo más importante, revisar formas y estrategias de legitimación de la Política Pública de comunicación a nivel regional y local.

Dicho lo anterior, el uso intencional del término tensión, busca que en los hallazgos de este trabajo emerjan elementos concretos para resignificar la relación entre la Política Pública de Comunicación en Colombia y las emisoras comunitarias en el contexto del departamento del Tolima. 
Los medios de comunicación comunitarios se han ido abriendo camino en distintos municipios del territorio nacional. Desde que el gobierno reglamentó la creación y funcionamiento de las emisoras comunitarias a mediados de la década del 90, se han creado y legalizado emisoras locales que antes funcionaban ilegalmente y que, a pesar de ello, habían adquirido reconocimiento en sus comunidades.

Con el Decreto 1981 de 2003 el Estado definió los fines que orientan a estas emisoras:

Satisfacer necesidades de comunicación del municipio o área objeto de cubrimiento; facilitar el ejercicio del derecho a la información y la participación de sus habitantes, a través de programas realizados por distintos actores del municipio, de manera que promueva el desarrollo social, la convivencia pacífica, los valores democráticos, la construcción de ciudadanía y el fortalecimiento de las identidades culturales y sociales.

A partir de este Decreto, y de la convocatoria realizada por el gobierno nacional en 2005 para radios comunitarias, distintas personas y organizaciones municipales se mostraron interesadas en participar para garantizar una emisora comunitaria en sus territorios, que les permitiera tener un medio de información y comunicación, promover sus costumbres y tradiciones, y ofrecer espacios de participación a las organizaciones.

Estos medios de comunicación deben facilitar que los ciudadanos habiten de manera colectiva y plural los territorios, toda vez que se han pensado como espacios para la discusión de los temas de interés que allí emergen, convirtiéndose así en escenarios genuinos para el ejercicio de la ciudadanía (EIGazi, 2011, pág. 38).

El ejercicio de caracterización de medios de comunicación implicado en este trabajo, tuvo el propósito de profundizar en las dinámicas de producción y proyecto comunicativos de cuatro emisoras comunitarias del sur del Tolima para a partir de allí, llegar a plantear e forma concreta tensiones entre estos medios de comunicación y la Política Pública de Comunicación en Colombia. Para llevar a cabo la caracterización, se tomó en cuenta un primer ejercicio de mapeo de medios de comunicación comunitaria del departamento, que sirvió como insumo para lograr un acercamiento a las dinámicas de producción de los medios que finalmente fueron seleccionados. El mapeo sirvió además para el diseño de la metodología a partir de la cual se llevó a cabo la caracterización, con la participación de los actores de los distintos medios de comunicación.

Las emisoras comunitarias priorizadas fueron las de los municipios de Alpujarra, Natagaima, Rioblanco y San Antonio como se muestra en la Figura $N^{\circ} 1$ 


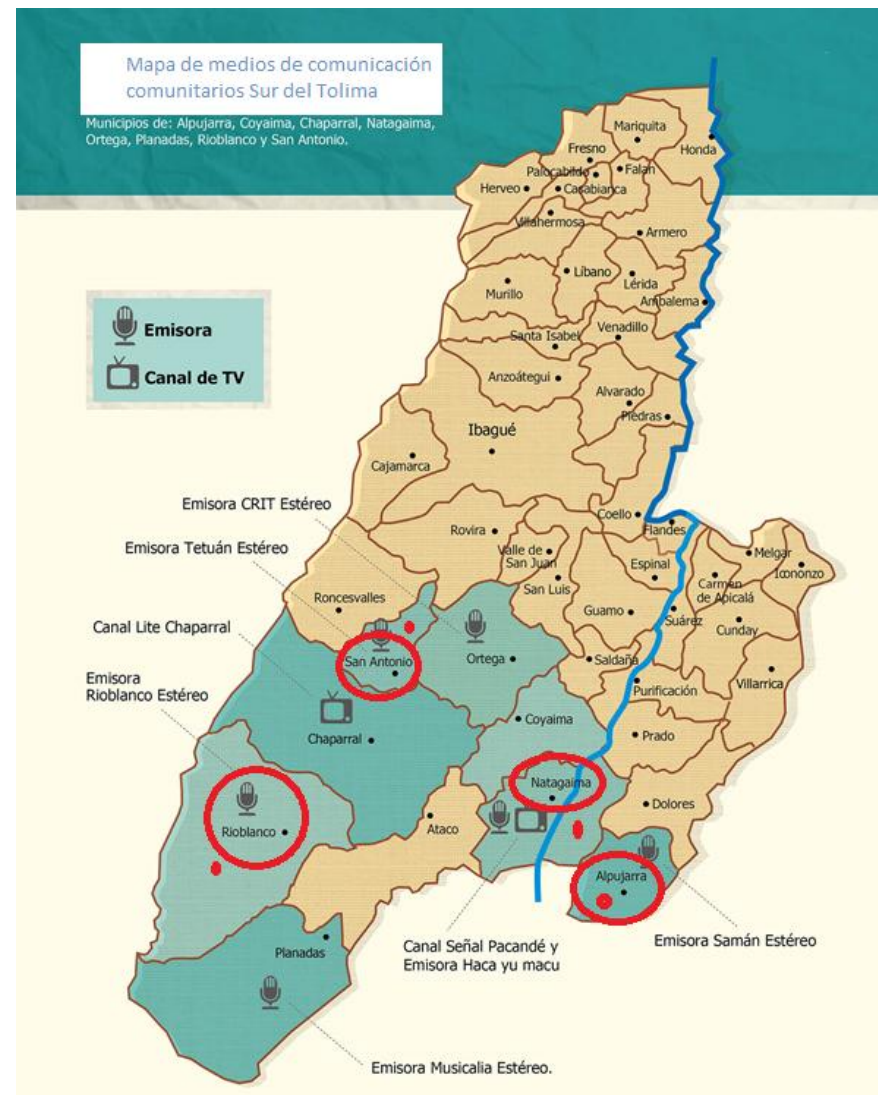

Figura 1: Ubicación geográfica de las emisoras comunitarias consideradas en el estudio

Hace más de cinco décadas que los medios comunitarios existen en Colombia, siendo considerado junto con Perú, Ecuador y Bolivia, como uno de los ejemplos en toda Latinoamérica y el mundo, en este tipo de experiencias de medios comunitarios, y más específicamente de la radio comunitaria. Estas, en algunos casos, son emisoras con enormes problemas de legitimidad, pero a la vez constituyen escenarios importantes de participación y construcción de ciudadanías, si mencionar que en el marco de la radio comunitaria es posible promover un pensamiento comunitario y planetario, anclado en un contexto sentido por las personas, pero universal en tanto se reconoce el planeta tierra como un territorio común. En las siguientes páginas se documentan cuatro tensiones identificadas a partir del análisis de la información recolectada.

\subsection{Tensión 1. El prisma de la participación}

Contrario a lo que podría pensarse, en el contexto de los municipios pequeños y rurales como es el caso de los municipios que alojan las emisoras comunitarias elegidas para este estudio, la globalización, sumado a otras condiciones históricas, no ha llevado a la 
homogeneización de las personas y las prácticas, sino, a un proceso acelerado de fragmentación social que conduce a que los sectores que empiezan a sentirse excluidos, promuevan su organización en el contexto local a partir de experiencias compartidas, en las que se gesta la re significación de las identidades y del territorio.

En el contexto de estos municipios, las emisoras comunitarias constituyen espacios geográficos importantes dentro de la cotidianidad de sus comunidades, en esa medida confieren cierto poder a quienes tienen la posibilidad de habitarlos. No hay un alpujarreño, un micuno o natagaimuno que no sepa dónde funciona su emisora comunitaria. Al respecto, es pertinente revisar la experiencia de diálogo e interacción que se legitima en cada una de ellas e interpelar las prácticas, símbolos y sentidos a partir toma forma uno de los rasgos de lo comunitario: la participación. En esta dirección, es necesario considerar el poder de agencia de los sujetos que confluyen en lo local, así como aquellos espacios donde surgen intereses distintos a los proyectos políticos y comunicativos que intentan encarnar las emisoras.

La Política de Radiodifusión sonora comunitaria en Colombia, plantea que una de las responsabilidades de las emisoras comunitarias es ampliar el acceso democrático a los medios por parte de diferentes sectores de la sociedad a partir de la participación pensada en tres niveles: la participación de las comunidades en las juntas de programación y definición de proyectos comunicativos; la participación de la ciudadanía en la producción de programas de acuerdo a sus intereses, y la participación desde la perspectiva de la audiencia en tanto la programación refleje narrativas propias de su territorio (Ministerio de comunicaciones, 2008, p.15).

En el diagnóstico, frente a la participación en las emisoras comunitarias, la Política de Radiodifusión comunitaria señala: "esta participación no siempre logra concretarse en muchas de ellas, ni reflejarse en la construcción de parrillas incluyentes que respondan a la diversidad de intereses y necesidades de comunicación de los ciudadanos" (Ministerio de Comunicaciones, 2008, p.16). Sobre esto añade:

Algunos de los problemas que aparecen señalados por quienes colaboraron en la consulta, pueden agruparse como: problemas relacionados con la participación de algunos sectores de la población o para el cumplimiento general de los fines del servicio, las emisoras no convocan a la participación ciudadana, ni sus programaciones reflejan los intereses y necesidades del municipio (Ministerio de Comunicaciones, 2008, p.16)

Lo anterior demuestra que a nivel institucional se reconoce que la participación está en la base de la razón de ser de la radiodifusión comunitaria y que de igual forma lo entienden los líderes que participaron en los foros y encuentros con fines diagnósticos convocados por el Ministerio como base para la formulación de la Política. Frente a esto, en el diagnóstico se concluye que "a pesar de que este discurso ha sido apropiado por la gran mayoría de personas que participan en estos medios, falta mucho para hacerlo efectivo de una manera sostenida y lograr que se traduzca en procesos de toma de decisión con efectos visibles en la programación" (Ministerio de Comunicaciones, 2008, p.15).

La anterior conclusión, al enunciarse en términos tan simples, no reconoce la riqueza de lo que la participación significa e implica en los municipios colombianos. Se la presenta como algo que funciona o no, que avanza o no y que, en especial, debe llegar a reflejarse en algo tan concreto como una parrilla de programación. La participación es un proyecto inacabado y de complejidad creciente al que se le da contenido de maneras distintas en los territorios. 
Frente a esto, Sandra Osses señala que no existe un consenso para entender la participación como esencia de lo comunitario, no obstante, esta puede entenderse como la capacidad de intervención en problemas colectivos a partir de una mediación entre los habitantes de un territorio y la institucionalidad, que puede valerse de diferentes lenguajes y plataformas. (Osses, 2002, pág. 142). A continuación, desde los hallazgos efectuados en cada emisora, se plantean cuatro maneras de darle sentido a la participación:

\section{Samán estéreo: la lógica de la pseudoparticipación}

La emisora comunitaria Samán estéreo nació en el año 2008. El líder cívico Jaime Osorio, más conocido como el mono Osorio relata que luego de dos tomas guerrilleras, el municipio de Alpujarra quedó incomunicado y la única alternativa de comunicación era un kiosko de Telecom en el que vendían minutos a celular y fijo. En medio de esta situación él conoció la convocatoria del entonces Ministerio de Comunicaciones para emisoras comunitarias en el país, inicialmente se quería una emisora escolar para la Institución Educativa Técnica Felisa Suárez, sin embargo, tal idea quedaba por fuera de los términos de la convocatoria. La propuesta se presentó a través de la asociación de padres de familia con el liderazgo de la presidente Cidia Aya y a finales de ese año empezó a funcionar la emisora, utilizando la antena que había sido de Telecom. Durante los ocho años de existencia de este medio, la iglesia católica y la Asociación de padres de familia, conformando la Junta de Programación han liderado tanto la gestión de su funcionamiento como su proyecto comunicativo.

La junta de programación ha logrado dar forma a un proyecto común que tiene como bandera la participación ciudadana a través de la radio, esto se ha hecho a partir de una mezcla de intereses individuales, pues antes que miembros de la junta, son maestros, padres de familia o fieles de la iglesia y los intereses que cada uno de estos roles supone, siguen presentes, aunque con distintas intensidades, en el rol que tienen como partícipes de la Junta. Frente a esto, Turner plantea que cada persona o integrante de un grupo tiene como característica principal la participación no sólo en un performance, sino que forma parte en una diversidad de los mismos y en cada participación tiene la capacidad de actuar o representar un papel dentro de las distintas tramas sociales, y es esto lo que le permite definirse ante el otro y reconocerlo, es decir, es a través de las representaciones como cada persona evidencia su participación en ellos (Turner, 1988, pág. 42).

La Junta de programación de la emisora, no ha cambiado a lo largo de estos ocho años, la razón principal tiene que ver, en primer lugar, con que todos sus miembros ocupan en la vida municipal un lugar importante, entre ellos, el párroco del pueblo, el rector del colegio, la presidente de la Asociación de padres de familia, esto les permite tener, no sólo reconocimiento, sino también credibilidad y autonomía para poner en la agenda del medio lo que se asume de interés general para la comunidad. En tal sentido, esta junta se ha encargado de consolidar tanto una imagen individual desde un rol específico que se asume al interior de la Junta, como una imagen colectiva hermética que hace que los demás piensen que no cualquiera puede hacer parte de la Junta "La labor que la junta hace en el municipio, es muy importante, ellos son gente muy preparada que conoce de qué se tiene que hablar y cómo se tiene que hacerlo, sobre todo que representan muy bien los inconformismos que aquí cada día son muy grandes, por eso siempre estamos de acuerdo en que la junta siga como está" (Londoño, V., 2016, 20 de octubre, entrevistado por Álvarez, M., Alpujarra). 
El reconocimiento del que goza esta Junta dista de ser por la gestión que han adelantado en la emisora, de hecho, no sólo ha estado cerrada y fuera del aire varias temporadas, sino que tiene una multa que asciende a los $\$ 12^{\prime} 000.000$ por invasión de espectro electromagnético como consecuencia de una antena puesta al revés. Pese a estas dificultades que revisten un componente técnico importante, sí se ha consolidado un proyecto comunicativo en función, principalmente, de la expresión de inconformidades y la denuncia de distintos problemas de la comunidad. Al respecto, es fundamental considerar que la comunicación se ubica en el campo de interacción del poder simbólico, el que hace posible la "(...) capacidad de intervenir en el transcurso de los acontecimiento para influir en las acciones de los otros sujetos y crear acontecimientos reales a través de los medios de producción y transmisión de las formas simbólicas de información" (Thompson, 1998, pág. 34).

La Junta de Programación desde la acción comunicativa ha posicionado el valor de la participación incluso al margen de lo que es o podría llegar a ser la emisora comunitaria, pero conservando los matices de un proyecto comunicativo que bien podría encontrar en ella su asidero. La comunidad en general es consciente de la importancia de participar en la construcción de un proyecto de sociedad común, y es precisamente esta premisa compartida la que ha hecho posible que se establezca una lógica en la que Cidia Aya y su equipo aparecen como voceros y defensores de los intereses individuales que al ser puestos en escena como mensajes que se comunican públicamente adquieren un sentido colectivo.

Los alpujarreños frecuentemente recurren a la emisora, más precisamente a la Junta de Programación para quejarse de incidentes que les ocurren. Tal es el caso de doña Betty y María, dos historias que muestran como cualquiera puede incluir un asunto en la agenda de la radio y a partir de allí sentir que participa:

Pues mire señorita como le comento, yo acudí con la señora Cidia para contarle lo que me pasó, resulta que el mes pasado yo fui víctima de maltrato por parte de las autoridades de este municipio, yo estuve esperando desde temprano en el juzgado a ser atendida de acuerdo a una cita que me dieron, pasó el tiempo y nadie me paró bolas, llegaron las 12 del día y el juez encargado dijo que ya se iba a almorzar, yo le mostré el papelito con la hora y la fecha de mi cita y fue tan descarado que me dijo que él no tenía la culpa de que yo tuviera un marido irresponsable al que había tenido que demandar por alimentos (Suárez, M., 2016, 21 de octubre, entrevistado por Álvarez, M., Alpujarra).

Yo veo que eso por lo de la multa ha estado como abandonado, pero de todas maneras la labor que hacen en la junta con el liderazgo de la profesora Cidia es importante porque la emisora ha estado fuera del aire algunas semanas pero ella sigue escuchando a la gente, buscando las historias como ella misma dice, mostrando los problemas de este lugar que pareciera tan tranquilo. Yo creo que eso es bueno, porque como ciudadano uno siente como que alguien lo respalda. Yo una vez tuve un problema de robo en el hotel, y pues gracias a que ese fue el tema durante una semana de los programas, ya no ha vuelto a pasar nada como eso (Betty, 2016, 20 de octubre, entrevistada por Álvarez, M., Alpujarra)

Una vez María y doña Betty hicieron pública su queja a través de la emisora, este tema se abordó, no sólo en la programación sino en las conversaciones de la vía pública, incluso el 
caso de María mereció un especial completo en la radio revista de la mañana del viernes que es cuando mayor sintonía se reporta. Estas historias permiten ver cómo en el caso de Samán estéreo, la participación se asume desde tres premisas.

En primer lugar, la participación es temática, es decir, tal como en el caso citado, cuando alguien es víctima de maltrato en el juzgado y lo enuncia a través de la emisora, en seguida el maltrato por parte de los funcionarios públicos deviene el tema en torno al cual la ciudadanía configura su participación y al hacerlo se siente parte de una colectividad que, en apariencia, está conectada por lazos frágiles, pero que a partir de relatos de esta naturaleza son una misma fuerza.

"Aquí todos pueden participar, venir a contar sobre problemas que pasan y ver cómo la gente cuando empieza a hablar de eso ayuda al que tiene el problema. Nosotros como junta de programación siempre hemos querido que la gente sienta que puede venir a contarnos sus cosas, y eso nos sirve mucho pues para armar los contenidos" (Aya, Cidia., 2016, 20 de octubre, entrevistada por Álvarez, M., Alpujarra.)

En segundo lugar, al ser temática, lo local es el referente de sentido por excelencia para participar: "Aquí en la emisora pues lo que yo veo es que se habla de lo que le pasa a la gente, en general este es un pueblo tranquilo, pero cuando a alguien le pasa algo, de eso es que se habla, y se le da la importancia que se merece. De todas maneras eso evidencia el compromiso que tiene la emisora con los habitantes de este pueblo, porque de qué otra cosa se podría hablar si no es de lo que pasa aquí a nuestra gente" (Osorio, J., 2016. 20 de octubre, entrevistado por Álvarez, M., Alpujarra)". El territorio genera las coordenadas en torno a las cuales debe constituirse el proyecto comunicativo aun cuando este no se expresa en un documento ni tampoco en una programación definida que incluya narrativas locales profundas, por el contrario, aquellas que se logran desarrollar, versan sobre asuntos cotidianos que afectan a alguien en particular, pero con los que otros se sienten fácilmente identificados.

Por último, se asume que la opinión amplificada en la radio se convierte automáticamente en participación, como si mágicamente los medios de comunicación, o sus representantes, fueran productores de ella, o por lo menos, los únicos capaces de legitimarla. Es así como afloran los relatos de pseudoparticipación, es decir, aquella participación que se agota en la queja, en la denuncia, en la enunciación del inconformismo pero que, como lo indica Winocur, de igual manera configuran una esfera pública: "podemos considerar que todas las formas de encuentro entre los miembros de diversos grupos y la radio que se realizan con cierta regularidad, como llamar para participar, hacer pública una demanda, denunciar un atropello a sus derechos, requerir asistencia o información, integrar una red de radioescuchas, formar un grupo de autoayuda, o pertenecer a una audiencia cautiva, pueden constituir eventualmente una esfera pública" (Winocur, 2000, pág. 39).

Así, en el caso de Alpujarra, el problema de la participación no es de acceso a la radio, sino que adquiere un cariz más complejo en tanto se trata de un problema político. La participación que se debería promover en la radio implica el paso de un actor social a un sujeto colectivo que busca la generación de bienes públicos. Sobre la participación en la radio, Winocur dice: "El desafío para los ciudadanos, las organizaciones civiles y los movimientos sociales no es cómo aparecer en los medios, tampoco cómo apropiarse de ellos, suena tan utópico como hacer de cuenta que no existen; el verdadero reto es 
aprender a servirse de ellos" (Winocur, 2000, pág. 37). En ese sentido, los alpujarreños aparecen en la radio, de alguna manera se han apropiado de ella, pero no se sirven de ella para consolidar una participación política, aquella que debería incidir en el mundo de lo público, que exige sujetos con capacidad para el trabajo en equipo y dispuestos a interlocutar y cooperar con otros.

\section{Haca Yu Macu: la participación del ciudadano diverso}

La emisora comunitaria Haca Yu Macu en el municipio de Natagaima, constituye un referente fundamental para la ciudadanía, no sólo por su capacidad de interlocución con diversos actores del contexto local, sino también por ser un escenario privilegiado para la deliberación pública, le negociación de significados y la capacidad para proponer y llegar a acuerdos colectivos en los que se representan los diferentes intereses de las identidades que confluyen en el territorio. Al respecto su actual director, Roque Arcángel Rodríguez plantea:

La premisa de la que hemos partido aquí en la emisora es que todos pueden hacer radio, que todos pueden crear y hacer que una determinada propuesta salga adelante y se haga realidad. Me interesa sobre todo que la gente cuente sus propias historias, de dónde viene, quién quiere ser. Si usted se fija tenemos una variedad de programas que hablan desde el agua, la minería, hasta la familia y el embarazo (Rodríguez, R., 2016, 25 de octubre, entrevistado por Álvarez, M., Natagaima)

Así, en el seno de esta emisora, la participación se teje desde la polifonía de voces, el sentido de la participación radiofónica en Haca Yu Macu es conectar todo aquello que en el territorio pareciera desligado, a partir de un proceso complejo de interacciones entre dinámicas culturales y sociales que permiten, por un lado, configurar una agenda del medio y por otro, consolidar un proyecto comunicativo bajo los principios de la diversidad y la inclusión. En oposición a una pretendida cultura globalizante que busca establecer una única manera de ver, sentir, disfrutar e interpretar el mundo, en esta radio se exploran los modos estéticos y narrativos de lo indígena, y de otras sensibilidades que habitan Natagaima desde valores diferentes: ser joven, ser mujer, ser anciano, y es desde aquí que se configura la creatividad del medio. Sobre esto el gobernador indígena de la vereda Yaví expresa:

Para nosotros como comunidad, como comunidad indígena, lo valiosos de Haca Yu Macu es que todos tenemos la posibilidad de ser escuchados y de proponer cosas que a nosotros como pueblo indígena nos interesa, nuestras raíces, nuestros planes de vida. Es valioso que para la emisora todos somos importantes y todos podemos participar y eso que nos da pena hablar por el micrófono pero eso también lo hemos superado (Pernía, L, 2016, 25 de octubre, entrevistado por Lezama, J., Natagaima).

En este medio se habla un lenguaje propio, se reivindica el derecho de todos los sujetos a ejercer la comunicación como una manera de afirmar su existencia y legitimar su resistencia simbólica frente a problemáticas que han visto la luz en este municipio, especialmente aquellas de carácter ambiental. En esa medida, la gente asume la emisora como una posibilidad de problematizar el territorio, pero también de divertirse, de soñar, de reconocerse y esto es participación.

Conforme lo anterior, de las cuatro emisoras a las que se tuvo acercamiento en el marco de este estudio, Haya $\mathrm{Cu}$ Macu, es donde más variedad de formatos y de narrativas se 
identificaron. Desde noticieros, programas en vivo, radio revistas, hasta adaptaciones de mitos, historias y reporterías rurales, como su junta de programación las ha bautizado, las cuales consisten en que una vez a la semana uno de los reporteros voluntarios se desplaza a zona rural del municipio para dialogar, construir y producir piezas comunicativas a propósito de un tema en particular que sea de interés en la zona: la agricultura, el deporte, el cambio climático, el rol de las matronas tradicionales entre otros. Es posible afirmar entonces que el medio es usado para narrar, reinventar formatos y contar historias y en ese sentido hay una propuesta estética propia. En esa propuesta estética, las ciudadanías están presentes con su identidad, sus gustos y sus necesidades.

En este medio se configura la participación del ciudadano diverso, se nutre del diálogo intercultural de territorialidades de lo local con lo universal, así lo señala el alcalde municipal de Natagaima, Jesús Alberto Manios Urbano:

Vea, lo que a mí personalmente me aterra del trabajo que hace don Roque en la emisora es que ha rescatado mucho de la cultura indígena, todos esos saberes que nosotros como comunidad podemos brindar, pero eso no ha hecho que se dejen de reconocer y darles importancia a otros temas de Natagaima, por ejemplo se visibiliza mucho todo lo relacionado con el distrito de riego del triángulo del Tolima, que es algo fundamental para el sur del departamento, pero de la misma manera, se habla de la consulta minera de Cajamarca, del problema de Monsanto, entonces como que igual la emisora es local pero muestra temas de país (Manios, J.A., 2017, 05 de febrero, entrevistado por Álvarez, M Natagaima).

De esta manera, es posible afirmar que la agenda que se propone desde la emisora es incluyente y diversa, en esa medida, es una multiplicadora de experiencias que construye ciudadanías en tanto tiene en cuenta diferentes sensibilidades del mundo y esa mirada está presente tanto en el espíritu de su junta de programación, la parrilla de programación, y los relatos que se construyen sobre el territorio.

Por lo anterior, en los diálogos con el director Roque y con ciudadanos que participan y conocen la trayectoria del medio, se identifica una radio que intenta la enunciación otra del relato colectivo, que construye afectos y cercanías, no en vano, su lenguaje privilegiado es el de la ficción, a diferencia de las otras emisoras estudiadas en las que el formato noticioso es el más utilizado, en este caso, priman los cuentos, los perfiles de lugar, de personajes importantes en la escena local, crónicas, reportajes y la construcción de paisajes sonoros en los que en pocos minutos y a partir de mezclas sonoras se recrea por ejemplo: cómo suena la plaza de mercado un domingo en la mañana.

Una emisora como Haca Yu Macu reafirma la importancia de que existan medios locales en la medida en que "[...] ofrecen la posibilidad de reafirmar y reelaborar las propuestas culturales, proponer alternativas comunicativas viables, que permitan oír todas las voces que constituyen la vida regional de nuestros pueblos [...] donde se conozcan y reconozcan las voces y los planteamientos de quienes de otra manera seguirían siendo excluidos" (EIGazi, 2011, pág. 37).

En Haca Yu Macu, se tejen redes, se tienden puentes siendo la participación el sostén más importante y al respecto se le otorga sentido al carácter local y público de la comunicación de cara a un contexto particular. Como plantea María Cristina Mata, en estos casos la radio comunitaria es una "relación comunicativa" por cuanto es al mismo tiempo "práctica significante y experiencia cultural", es decir, en ella tiene lugar la difusión de mensajes, pero 
a la vez se dota de sentido aquello que se enuncia y que tiene su raíz en la cotidianidad y en la cultura (Mata, s.f).

La participación en este caso se asume como la posibilidad de poner a circular la diversidad cultural, diferentes opiniones y perspectivas de vida, intereses colectivos y las necesidades del municipio.

\section{Rioblanco estéreo: el altavoz de la oposición política}

El principal rasgo de esta emisora comunitaria tiene que ver con un proyecto comunicativo inclinado a la oposición política de los gobiernos locales, no desde la mera denuncia, sino desde la promoción de propuestas alternativas para el municipio con respecto a procesos de planeación participativa para el desarrollo. En ese sentido, la participación se entiende como una mirada otra sobre lo local y sobre los temas que se consideran de interés colectivo.

En primer lugar, se debe considerar que la oposición política es necesaria para garantizar que la democracia se consolide como una forma legítima de gobierno, no en vano, ha sido objeto de estudio y reflexión en diferentes contextos históricos, especialmente desde la ciencia política. En segundo lugar, la oposición en sí misma como práctica social no necesariamente va acompañada del adjetivo política. ¿Qué es lo que hace entonces que se considere que la oposición que se plantea desde la emisora comunitaria Rioblanco estéreo tenga el carácter de política y que desde allí se entienda y se asuma la participación en la radio?

Para entender el sentido de la anterior pregunta, debe considerarse que la oposición política no es algo que se da en el vacío, sino que se produce en un contexto concreto y está atravesada por los valores desde los cuales históricamente se ha entendido lo político en general. Lo político, a su vez, no es algo que esté dado, por el contrario, consiste en una práctica, una expresión cultural que se construye socialmente. En la vida cotidiana, el ciudadano asocia lo político con lo institucional, específicamente, con aquellas instituciones que gobiernan y detentan legítimamente el poder. En dicho escenario, la conflictividad se sataniza, se la relaciona con la violencia, que es sin duda, una vía desacreditada para plantear un disenso. El consenso es el valor opuesto al disenso, en función de ello, se esperaría que la vida política de un municipio, expresada de manera tangible en la puesta en escena de un gobierno local, se acompañe del consenso de los ciudadanos o por lo menos de una mayoría.

Para Mouffe (2007), el hecho de que se le otorgue mayor valor al consenso y se le dé un valor tan negativo a lo conflictivo y por ende al disenso, dificulta que se piense políticamente. De acuerdo con esto, ella propone la siguiente distinción entre lo político y la política:

"concibo "lo político" como la dimensión de antagonismo que considero constitutiva de las sociedades humanas, mientras que entiendo a "la política" como el conjunto de prácticas e instituciones a través de las cuales se crea un determinado orden, organizando la coexistencia humana en el contexto de la conflictividad derivada de lo político" (Mouffe, 2007: 16-17)

Siguiendo el planteamiento de Mouffe, el hecho de que los miembros de una comunidad política se asuman como adversarios, hace posible que se piense lo político como un ámbito que no lleva necesariamente a la liquidación del otro, sino que admite e diálogo y la 
expresión diversa del disenso. Lo anterior cobra mayor sentido si se reconoce que lo que está en juego en lo político son los encuentros y puntos de quiebre propios del vivir juntos, del vivir con otros en el que se configura el poder de unos sobre otros y el empoderamiento de quienes no ejercen formalmente el poder.

Las formas de ejercer y disputar el poder, o de pronunciarse acerca del poder pueden estar cercanas a la violencia o, como en el caso del municipio de Rioblanco, cercanas al diálogo, la discusión y la negociación, tres elementos presentes en la apuesta de la emisora comunitaria, tal como lo expresa su director:

"Uno ve que hay mucha inconformidad y nuestra propuesta es hacerle frente a ese descontento, pero no desde la queja y la denuncia amarillista, sino dando cabida a un diálogo en este caso con la alcaldía. Si usted escucha nuestros programas se da cuenta que cada uno busca proponer cosas, ganar un espacio, capacidades y un equilibrio con el poder y las instituciones locales" (Romero, C., 2016, 21 de septiembre, entrevistado por Álvarez, M., Rioblanco)

Cuando se plantea que la participación en Rioblanco estéreo se asume desde la oposición política, no se hace referencia a un partido político, organización, asociación o movimiento que, al no pertenecer a la coalición de un gobierno, se mantiene en contra de él, por el contrario, se hace alusión a una ciudadanía que ejerce vigilancia, control y modos de resistencia sustentados en un diálogo público e incluyente que interpela a gobernantes y gobernados.

Así pues, en este caso, la oposición política alude a un modo de participar en el ámbito político en el que los ciudadanos se reconocen como sujetos comunicativos, con el deber y la capacidad para participar en la enunciación colectiva del mensaje de lo público. La puesta en escena de Rioblanco estéreo permite que los asuntos privados se conviertan en asuntos públicos, o mejor, en asuntos de intervención colectiva, de igual forma, promueve el disenso a partir de la negociación y la discusión política, aumentando las posibilidades de dialogar, discutir y negociar por medio de la palabra. El anterior planteamiento se hace evidentes en testimonios como los del señor Toro, ciudadano participante en el Programa "Rioblanco te saludo"

"Desde que arrancamos el primer programa que es Rioblanco te saludo, lo que nos interesa es que la gente piense, se cuestione sobre lo que pasa aquí en el municipio y desde ahí que se movilice con un proyecto y una ilusión nueva para las comunidades, las organizaciones, el pueblo. Esto tiene una reflexión profunda porque no se trata de decir no me gusta y ya, sino de ver uno qué puede hacer y la radio es una oportunidad para eso" (Toro, J., 2016, 21 de septiembre, entrevistado por Lezama, J., Rioblanco).

La participación entonces se erige como camino para concretar un proyecto colectivo de municipio y se sustenta en sujetos ricos en experiencia política y narrativa. Discutir y negociar constituye un poder que usualmente está sujeto a la posesión de otros poderes en el orden social, por ejemplo, económico, que sitúan al sujeto en un lugar de enunciación desde el que es posible hablar o discutir y que, de alguna manera, asegura el ser escuchado y tomado en cuenta. En tanto no todos los lugares de enunciación ofrecen iguales oportunidades para hablar y ser escuchado, desde el proyecto comunicativo de Rioblanco estéreo se ha asumido el compromiso de configurar escenarios de enunciación en los que todos pueden participar, entrar en el diálogo de lo público y trascender la opinión 
falaz y momentánea por la incidencia política y la planeación participativa, muestra de ello, es el plan de cabildeo que se construyó con la participación de varios líderes comunitarios con el fin de incidir en el plan de desarrollo municipal "Todos somos Rioblanco".

"Como gobierno local consideramos que la emisora comunitaria del municipio es un aliado de la de administración pública, por un lado, se han aumentado y cualificado los espacios de rendición de cuentas y en ese trabajo la emisora ha sido fundamental, pero al mismo tiempo que nos acercan a la ciudadanía, les dan una voz y los llevan a ser críticos, a tener argumentos, a gestar las propuestas que como comunidades empoderadas todas tienen porque conocen el territorio mejor que uno. Uno pues como gobernante de todas maneras tiene una mirada muy institucional de los asuntos, hay Programas que igual se sabe que hay que desarrollar, pero los conocedores del territorio son ellos, por eso aplaudo personalmente toda esa, digamos, pedagogía ciudadana que se propone desde la emisora, y a pesar de las diferencias en opinión, la considero una aliada y me siento orgullosa como Rioblancuna de decir que en mi municipio, cuna del conflicto armado en el sur del Tolima, los fusiles se cambiaron por la palabra en la radio. (Isaza, D. (2017, 07 de febrero) entrevistado por Lezama, J., Rioblanco)

No se trata de cualquier participación, sino de una participación política, no sólo porque se considera legítima, sino porque los rioblancunos se ven y se asumen como sujetos políticos y desde allí se construyen como ciudadanos que ejercen una oposición política que no se criminaliza, y que tampoco se da en términos de disputa por el poder, sino una práctica en la que predomina el diálogo y el reconocimiento del otro como actor válido para interlocutar. Al ser Rioblanco uno de los municipios cuna de la violencia en el Tolima, la manera en que hoy se configura la oposición política se considera disruptiva, en tanto lo que medió por mucho tiempo dicha configuración fue la confrontación violenta y la aniquilación del otro.

Atendiendo las anteriores consideraciones, se evidencia la generación de distintos espacios y temporalidades de participación para los ciudadanos, esto es posible no sólo porque el gobierno y las instituciones locales reconocen la oposición, la presentan como legítima e incluso le garantizan espacios de visibilización y de ejercicio del disenso y la discusión, sino porque la misma oposición ha trascendido dicho reconocimiento y se ha construido un poder propio en clave de proyecto colectivo, representando de este modo un lugar versátil para enunciar reivindicaciones sociales y económicas de los rioblancunos.

\section{Tetuán estéreo: el lugar de la no participación}

La emisora comunitaria Tetuán estéreo, ubicada en el municipio de San Antonio al sur del Tolima, representa el relato de la no participación, en ella los ciudadanos, que ni siquiera son reconocidos como tal, no participan en los procesos de enunciación del medio ni tampoco se sienten identificados en los mensajes que esta pone a circular. En esta emisora comunitaria la participación es un desafío, un reto que aún no está planteado, o por lo menos no de manera explícita.

La participación ciudadana es un desafío que está condicionado por las características de la sociedad civil, la existencia de espacios de articulación y la construcción de diversidad de actores que con su interacción ponen en juego fuerzas y conflictos de acuerdo a la naturaleza de los contextos dentro de los cuales se ubican. Adicional a esto, se debe considerar que la categoría de ciudadanía no es un atributo predeterminado, ni un simple 
adjetivo para calificar los sujetos sociales, sino que constituye una práctica en construcción que va más allá del reconocimiento y la ampliación de derechos no obstante, su conquista por parte de sectores sociales históricamente excluidos, constituye un aporte significativo para enriquecer el concepto de ciudadanía.

En esta emisora comunitaria, no se identifica una propuesta ni una alusión visible al fortalecimiento de la ciudadanía ni mucho menos a la participación ciudadana, de modo que esta pareciera agotarse en el ejercicio electoral y el derecho a organizarse en partidos políticos. Lo anterior tiene que ver con la asepsia desde la que se asume el ejercicio radiofónico y el propósito mismo que se le ha atribuido: servir a la institucionalidad ${ }^{20}$, en palabras de su director, Hernando Alzate:

"Aquí hemos conservado la tradición e idiosincrasia con la que se fundó Tetuán estéreo. Tendiendo un puente entre la administración municipal y la ciudadanía, para que la gente esté enterada de lo que pasa y hace la alcaldía. No hemos querido cambiar el hilo conductor porque consideramos que de esta manera se conservan las buenas costumbres de hacer radio" (Aguiar, E., 2016, 24 de octubre, entrevistado por Álvarez, M., San Antonio).

Un efecto de lo anterior es la anulación de los sujetos y de las posibilidades para participar. Los micunos quieren hacer parte del proyecto de la emisora pero no se les permite por cuatro tipos de censuras: la estética pues se considera que la gente del común no puede estar en la radio; la de autor, no cualquiera puede hacer radio; tecnológica, hacer radio es difícil y requiere de capacidades técnicas específicas y la más evidente de todas, la censura política en tanto la puesta en escena de voces diversas es inadmisible de manera que la emisora, en palabras de la señora Blanca Cobos, oriunda de Cundinamarca pero San Antoniana de corazón, se ha convertido en el Comité de aplausos de los gobiernos locales.

Vea, hemos llevado propuestas para que se pueda transformar lo que se hace allá, y con el respecto del señor Hernando, uno ve que eso están es como vendidos, porque de una vez cierran las puertas, se han dedicado es a ser el comité de aplausos de los gobiernos de turno. Vea yo tengo una asociación de producción de café artesanal, y el año pasado que hubo todo el tema de pérdida de cultivos yo quise proponer un espacio para hablar sobre cómo era manejo de eso, sobre todo porque quedamos a la deriva, nadie nos asistió con ese problema, vea eso era algo que interesaba a muchas familias, pero no fue posible. ¿Y ahí uno que hace? No puede hacer nada, como ciudadano a llorar al mono de la pila porque no se sabe quién responde por eso (Cobos, B, 2016, 25 de octubre, entrevistada por Lezama, J., San Antonio)

Lo que aquí se observa es una resistencia a la posibilidad de ampliar la participación ciudadana, en ese sentido se cuestiona el que un ciudadano común y corriente pueda y tenga las condiciones y las capacidades para influir en asuntos públicos. Con este argumento se elude la responsabilidad del Estado y de quienes han institucionalizado la radio para promover y facilitar la construcción de sujetos sociales como recurso para la

${ }^{20}$ Este servicio a la institucionalidad no se traduce en una contribución a la gobernabilidad, pues al anular expresivamente al ciudadano, se limita también el proyecto de un gobierno local legítimo. 
superación de la exclusión y se genera aceptación frente a la exclusión social como una realidad insuperable, no en vano, se expresa que no hay más remedio que ir a llorar al mono de la pila.

Como resultado de lo anterior, no se observa ni se promueve una participación reflexiva que se integre a la narración de contenidos y construcción de relatos que podrían encontrar su lugar de enunciación en Tetuán estéreo, de forma paralela, no hay una representación social de ciudadanía o por lo menos, aunque sea arriesgado afirmarlo, no se identifica una identidad ciudadana. Con esto no se quiere decir que los sujetos dependan de la existencia de una emisora comunitaria legítima en términos sociales para ser considerados ciudadanos, pero es indudable que un medio de esta naturaleza podría apadrinar, como se ha visto en distintas latitudes de Latinoamérica, un proyecto sólido de ciudadanía.

En este caso, la ciudadanía se erosiona por la exclusión y a su vez, el no reconocimiento de los ciudadanos dificulta la participación. Al respecto llama la atención que el derecho de acceso a la participación y a la información de los ciudadanos para hacer efectivos sus derechos colectivos, no tienen la misma apertura que los derechos civiles o políticos. Así, se propicia la pasividad complaciente del ciudadano por el temor de quienes ejercen el poder público a la asociatividad, la conformación de grupos o movimientos que dispersen o cuestionen su poder así como la visibilización de posiciones contestatarias.

Un aspecto que llama la atención sobre Tetuán estéreo obedece a que se privilegia el informar sobre el contar siendo el formato noticioso el predilecto para el desarrollo de la programación, de igual manera, se privilegia el lenguaje rebuscado, quienes hablan detrás del micrófono lo hacen para impresionar y excluir, de ese modo, "las palabras quedan vacías de sentido, se hace reverencia al lugar común y se empobrece la comunicación" (López Vigil, citado por Pérez, J. 2012, p.23). El siguiente testimonio permite sustentar este planteamiento:

Creemos que nos hemos ganado un lugar en el pueblo porque siempre mantenemos bien informadas a las personas desde que se levantan hasta que se acuestan. Eso es un aporte importante para que la gente se culturice y se alfabetice que fue el primer propósito con el que nació la radio en este país y pues eso no se puede perder" (Rojas, G., 2016, 24 de octubre, entrevistado por Lezama, J., San Antonio).

Si bien se observa un atisbo de intencionalidad pedagógica y educativa, que fue uno de los pilares en los que se erigió la radiodifusión comunitaria en Colombia, resulta un intento fallido en tanto se asume lo educativo a partir de una distinción entre lo culto y lo vulgar, satanizando lo autóctono y negando el surgimiento de relatos y narrativas del territorio. Así por ejemplo, existe una sección de efemérides en la que se recrean líneas de tiempo acerca de sucesos acontecidos en la historia en la misma fecha, también, antes de terminar la emisión, hay un programa que habla de escritores y artistas del mundo aunque con pocos recursos sonoros, es una voz que de principio a fin cuenta la historia del personaje en cuestión.

Prácticas como la censura, la exclusión de actores y de formatos radiofónicos diversos, son limitantes de la participación ciudadana. Por un lado, hay una mirada empobrecida de esta en tanto se la asume exclusivamente desde lo electoral y por otro, se generan procesos de cooptación de organizaciones y líderes de distintos sectores sociales por parte del gobierno local y de las élites políticas del territorio. Así, es posible hablar de cuotas de poder que, en primer lugar, configuran la ciudadanía como un momento en la vida democracia y no como lo que es, un continuo en la vida social y, en segundo lugar, favorece un ambiente de 
desafección política, en el que se multiplican las expresiones de inestabilidad y de falta de credibilidad en la institucionalidad sin que ello redunde necesariamente en una mayor cohesión social o fortalecimiento del tejido comunitario.

La radio comunitaria tiene todo el potencial para constituirse como un motor de cohesión ciudadana en la esfera pública local de los municipios colombianos, en donde los actores sociales se sientan representados, se puedan informar, reflexionar, discutir problemas y soluciones. Pese a este panorama esperanzador y fecundo, radios comunitarias como Tetuán estéreo representan el relato de fracaso de los medios comunitarios si no movilizan, si no interrogan, si no crean.

En suma, la participación ciudadana en la radio no se puede analizar en forma aislada, como si cada persona representa un número más que engrosa las cifras del rating y cuya participación se traduce en más publicidad y más ganancias. Los ciudadanos no son consumidores, y por esto hablar de participación en la radio debe pensarse en función de los significados que producen y de la forma en que representan su territorio y al mundo desde un discurso propio.

\subsection{Tensión 2. La construcción de lo público: Un juego con muchas caras}

De acuerdo al Banco Interamericano de Desarrollo, lo público se relaciona con lo que es de incumbencia de todos, como aquellos lugares que se encuentran disponibles para todos sin importar su edad o su afinidad política (BID, 2011, pág. 24). Desde la comunicación, "lo público viene de pueblo", y desde sus inicios se relaciona con la inclusión social, para Rincón, lo público se entiende como el encuentro de todos y el reconocimiento de las minorías, la pluralidad y la diversidad (Rincón, 2015, pág. 45)

Para la construcción de lo público, los líderes de las comunidades deberían ejercer su liderazgo en espacios de deliberación, debate, concertación y diálogo en torno a agendas que sean de interés colectivo. Uno de los espacios en los que ha tomado fuerza la discusión y construcción de lo público, son los medios de comunicación en la medida que tienen potencial para convocar más actores sociales, y servir de escenario al diálogo plural. Un rasgo característico de estos nuevos actores se relaciona con el tránsito que están haciendo de la esfera privada a la esfera pública, entre ellos es posible mencionar el liderazgo naciente de las mujeres y de los presidentes de Junta de Acción Comunal.

Por lo anterior, las emisoras comunitarias se consideran lugares privilegiados no sólo para discutir, sino para construir lo público en distintas coordenadas de acuerdo a las propuestas que emergen en los contextos locales. Desde la Política Pública de Radiodifusión Comunitaria se contempla como uno de los principios de las emisoras comunitarias la responsabilidad social para la construcción concertada de lo público, la equidad y protección de intereses de sectores vulnerables. Al respecto plantea:

"La participación ciudadana en la construcción de convivencia plural y dialogada requiere del ejercicio autorregulado y responsable de la información y la comunicación para configurar agendas públicas y los procesos de debate y concertación que reconozcan la diferencia", más adelante se añade [...] La labor de las emisoras comunitarias, su función de servicio es la de contribuir en forma responsable y consecuente a la configuración de una conciencia social, sensible a 
las necesidades y proyectos de futuro colectivos" (Ministerio de Comunicaciones, 2008, p. 24).

De esta manera, se espera que las emisoras comunitarias tengan la capacidad de hacer visibles distintas relaciones sociales y comunicativas entre los sujetos que habitan un territorio y que de forma paralela, sirvan como plataformas para reconocer conflictos y construir a propósito de ellos acciones colectivas. En esta aspiración de colectividad están implícitos los intereses individuales, pues al asumir que lo común es algo susceptible de ser construido, se deben reconocer las expectativas particulares para pensar en dinámicas de relacionamiento que posibiliten la construcción de lo público.

Al igual que la participación, la construcción de lo público no se configura de la misma forma en las emisoras comunitarias abordadas en este trabajo. A continuación, se reseñarán los principales rasgos identificados en las emisoras estudiadas a propósito de este asunto.

Uno de los rasgos identificados tiene que ver con que los intereses particulares se ponen en juego en propuestas colectivas. Para ello se establecen diferentes tipos de relación comunicativa entre los actores del territorio y la puesta en escena de las emisoras comunitarias. Por ejemplo, en el caso de Alpujarra, se observa que el sistema político del municipio se ha recompuesto, en especial, gracias a la emergencia de nuevos liderazgos como los de Cidia Aya (presidente de la Junta de Programación) que gozan de mucha popularidad, en este caso, el proceso se debe a la capacidad ganada para reconstruir desde la emisora la trama de lo comunitario y ocupar desde allí el espacio dejado por otros actores para la conducción política de la oposición y la apertura de espacios de participación que irónicamente se gestan desde los intereses que transitan en la esfera privada. Es decir, la participación que hoy en día se promueve desde Samán estéreo, no se da en clave de esfera pública, sino de la coincidencia de compartir problemas que se dan a nivel individual, y que al repetirse en distintas subjetividades cobran legitimad como asuntos de interés colectivo y por ello merecen hacer parte de la agenda del medio. Al respecto, uno de los oyentes menciona:

De pronto lo que yo veo es que siempre hay temas que de pronto no son tan generales, ¿me entiende? Me refiero que lo que más se acostumbra es que si de pronto se habla de algo que no es muy cercano a la vida de uno pues como que no interesa tanto, pero ya cuando uno ha vivido algo parecido, la sensación es diferente, ahí si uno se siente interesado (Lozano, C., 2016, 20 de octubre), entrevistado por Álvarez, M., Alpujarra)

De esta manera se construye una identidad colectiva, sobre este asunto George Mead, citado por Giménez plantea: "La identidad subjetiva emerge y se afirma sólo en la medida en que se confronta con otras identidades subjetivas durante el proceso de interacción social, en el interjuego de las relaciones sociales" (Giménez, 1993, pág. 25). En este punto se hace referencia a la construcción de identidades que emergen a partir de la interlocución y puesta en común de los actores de un colectivo.

La relación entre lo público y lo privado han sufrido diversas transformaciones a lo largo de la historia, incluso se han considerado categorías con límites difusos. Para autores como Habermas (Habermas, 1986) y Norberto Bobbio (Bobbio, 1998), lo público se refiere a un mundo político, y lo político es una dimensión de la vida en comunidad en la que convergen múltiples horizontes individuales con apertura a la pluralidad, el diálogo y la negociación. De manera particular, Habermas hace énfasis en la comunicación como base para la 
deliberación en el espacio político y la transición de las convicciones individuales a una voluntad común. Por su parte, Bobbio propone la dicotomía de lo público y lo privado como una manera de entender la relación entre lo local y lo nacional, así como la acción gubernamental en contextos específicos

Por lo anterior, ser parte de un colectivo con el que se posee algo en común es definitivo en la identidad ciudadana. En el caso de la emisora comunitaria de Alpujarra se identifica, por una parte, que cada vez sus habitantes están más interesados en la esfera privada que en la pública, de modo que tal como se planteó anteriormente, lo común se termina construyendo en términos de lo privado, y por ende de los intereses particulares.

Cabe preguntarse, ¿Qué sentido tiene lo colectivo cuando uno de los referentes de la configuración de lo público pareciera ser la asociación de subjetividades, en palabras de Bauman, "[...] frustrante(s), e insatisfactoria(s), que en nada se asemeja(n) a lo que podría considerarse una "verdadera comunidad" (Bauman, 2002, pág. 57).

Pues bien, por irónico que resulte, lo público no se agota en lo que debe ser visto y oído por ser de interés colectivo. Lo público nace de manera legítima de la puesta en común de los mundos privados y ello permite el encuentro de múltiples perspectivas que se pueden compartir, que participan de un mundo común que dejaría de serlo si se considera como válida una única voz y se emprendiera la búsqueda de un consenso sin sentido.

Desde el trabajo que realiza la emisora comunitaria Samán estéreo el tránsito de los mundos privados a la esfera pública está atravesado por juegos de poder entre la junta de programación y la comunidad en general. Sobre esto, uno de los oyentes plantea:

La junta de programación es algo importante para el pueblo, ellos se han ganado el lugar que tienen y por eso tienen el respeto y apoyo de todos, sobre todo la profe Cidia que ha estado desde que empezó Samán. De todas maneras, no cualquiera tiene como el perfil para ser de la junta, figúrese usted, uno que anda tan ocupado no tiene tiempo para estar pendiente de todo lo que pasa aquí mientras que ellos si le sacan tiempo a eso (Rojas, P, 2016, 20 de octubre, entrevistado por Álvarez, M., Alpujarra)

Este testimonio deja ver el poder que la comunidad ha conferido a la junta de programación, reconociéndola como un actor importante de la escena local, con un lugar privilegiado para enunciar lo que se considera de interés colectivo. En ese sentido, la junta de programación de la emisora comunitaria Samán estéreo detenta un poder que le confiere un margen más amplio para la acción en tanto es menos dependiente para adquirir y mantener recursos, tiene menos interferencia y restricción y, así, el margen que tiene para actuar se amplía.

En ese juego de poder, el ciudadano se asume y se representa en el relato radiofónico como una víctima que necesita ser defendido y que además requiere ayuda para lograr su propia enunciación:

Aquí como en todas partes hay atropellos de muchas clases, por eso tan importante es la presencia de la emisora y de la labor de la junta porque ellos lo defienden a uno o por lo menos se muestran interesados y así es más fácil tratar ciertos temas, hablar de lo que pasa y lograr que por fin alguien esté pendiente de nosotros los ciudadanos que siempre estamos tan desprotegidos (Díaz. G. (2016, 20 de octubre) entrevistado por Lezama, J., Alpujarra). 
Esta manera de asumir el ciudadano otorga mayor validez al poder de la junta, poder que es a la vez construido y ganado a partir de unas rutinas. Gabriel Gaitán en su artículo "Distancia de poder y autoridad", define las rutinas como "estructuras previsibles y regulares de comportamiento, conducen a esquemas repetitivos de actividad, formando la memoria organizacional: el depósito de conocimiento que orienta las decisiones de la organización. También conducen a un patrón de dependencia. Las rutinas se constituyen en mecanismos de ejercicio de autoridad y gobierno." (Gaitán García, 2010, pág. 140).

Así, en la denuncia amplificada que se vuelve rutina, la emisora moldea hábitos y cualidades en los ciudadanos frente a su manera de relacionarse con la institucionalidad y, en general, con el entorno cercano, desde allí se promueve un ejercicio de toma decisiones colectivas sin que por ello deje de mediar una distancia de poder entre ciudadanos y emisora.

\section{Construcción de lo público e identidad}

Lo público implica una puesta en escena colectiva que puede apreciarse en distintos grados. Al respecto, se identifica el papel de la identidad como un elemento cohesionador que fortalece y cualifica el proceso de construcción de lo público. En la emisora comunitaria Haca Yu Macu del municipio de Natagaima, es posible apreciar que la construcción de esta esfera se da en términos de la inclusión de diversidad de sujetos que no suelen estar representados en ningún otro escenario o instituciones. Así lo plantea el joven líder Sergio Leal:

Actualmente las instituciones están muy desgastadas y uno como ciudadano no se siente muy representado, entonces cuando eso pasa y uno se da cuenta que hay una propuesta para pensarnos todos como Natagaimunos con todos los matices que eso tiene pues llama la atención. Si yo me pongo a ver hoy la emisora nos representa no en el sentido en que todos pensamos lo mismo o tenemos las mismas opiniones sino desde todo lo que nos hace distintos pero que en el fondo también es de todos, compromiso de todos (Leal, C. (2016; 25 de octubre) entrevistado por Lezama, J., Natagaima).

En este sentido, en palabras de Rodríguez Villasante, hay una revinculación por parte de los ciudadanos a un proyecto colectivo. "Los sujetos, individuales o colectivos, tenemos unos vínculos que nos conectan, que nos pueden paralizar o que nos pueden potenciar. Y nosotros podemos intentar analizar, elegir o cambiarlos según las condiciones existentes y lo que podamos atrevernos a hacer. Re-vincular es cambiar en lo cotidiano, unos lazos o vínculos, por otros" (Villasante, 2002, pág. 125).

La amplitud de recursos narrativos de los que se sirven en la emisora Haca Yu Macu, permite que lo público se construya en torno a lo identitario. Cada narración que pasa por las ondas sonoras, sobre la cultura ancestral, la comida típica de la región, o los problemas ambientales de los bosques secos tropicales, representa un sentido de lo público en tanto re-configura el mundo común y la acción política como una acción que también es estética. Así, en la narración y la riqueza de la palabra confluye tanto lo subjetivo como una pluralidad de perspectivas sobre el territorio y las relaciones con los otros, a partir de allí nace la construcción de lo público. 
Haca Yu Macu hace parte del tejido social del municipio, allí, en palabras de Barbero, hay un re-conocimiento sobre el conocimiento (Barbero J. M., 1987), en especial sobre el conocimiento diverso, sobre el otro diverso. Así, las subjetividades que comparten Natagaima están abiertas al mundo, a la acción, a la acción con otros como una posibilidad que nunca se cierra. En este punto, se considera pertinente traer a colación a Arendt a propósito de su mirada performativa de la política desde la que plantea la categoría de subjetividad política y pública para referirse a que los individuos se muestran, se ponen en escena a partir de lo que hacen y dicen. Acción y discurso entonces, están íntimamente ligados, a partir de ellos cada persona logra que las experiencias de la esfera privada se desindividualicen hasta convertirse en formas de aparición pública (Arendt, La condición humana, 1993, pág. 39). Al respecto agrega: "La más corriente de dichas transformaciones sucede en la narración de historias y por lo general en la transposición artística de las experiencias individuales" (Arendt, La condición humana, 1993, pág. 59).

A partir de la constante puesta en escena de los ciudadanos que en otros contextos pertenecen al anonimato, se producen una reapropiación del espacio público y de la capacidad para actuar en sociedad desde un ejercicio en el que convergen distintas sonoridades y con ellas nuevos modos de experiencia social y, por su puesto, de cuestionarla y otorgar valor al saber local. En este contexto, la práctica comunicativa constituye una producción significante que permite comprender y contar el territorio. Retomando las palabras de Rincón, las ciudadanías en esta emisora se celebran, se les alimenta el ego, se convierten en celebrities (Rincón, 2015, pág. 54). Son celebrities no tanto por el reconocimiento que ganan en el espacio público, como por su acción política, su capacidad para actuar en público, en común con otros y hacer surgir lo nuevo.

\section{Lo público como el lugar del diálogo colectivo}

Ya se ha planteado que lo público se piensa y se vive de diferentes modos. Desde la mirada moderna, se le concibe como el lugar para la construcción de la ciudadanía y el encuentro social. Lo público también es el lugar donde el poder se expresa y se ejerce sin que este sea apropiado por completo por el poder, siempre hay lugar para la disputa, un margen para la resistencia social a ese poder fundada en el diálogo, la participación y la confianza, con intención de empoderamiento, para mejorar las condiciones de bienestar en situación de igualdad en la toma de decisiones, de acuerdo a las expectativas e intereses propios.

La emisora Rioblanco estéreo plantea la potencialidad de todos los ciudadanos para constituirse como una red contra la fragmentación, capaz de promover el diálogo interinstitucional y con ello aportar a la construcción de la unidad del municipio, especialmente, en lo correspondiente a la planeación para el desarrollo, así se puede identificar en el siguiente testimonio:

El año pasado, por ejemplo, se hizo un proceso muy importante con el consejo territorial de planeación sobre la emisión de concepto sobre el Plan de Desarrollo Municipal, se hizo mucha pedagogía pero sobre todo diálogo discusión y alrededor de eso, y a partir de ahí se hacen cosas que van más allá del estudio de la emisora como mesas de trabajo, foros y pues se dinamizan con la emisora, entonces ahí hay unos frutos para el control social y veeduría ciudadana de esas decisiones en las que uno como que en principio como rioblancuno no está incluido pero sí puede 
incluirse (Romero, C., 2016, 21 de septiembre, entrevistado por Álvarez, M., Rioblanco)

Es posible afirmar que en esta emisora quizás, la figura más representativa de lo público es la opinión pública, que se ejerce como un derecho ciudadano que ofrece la posibilidad de generar debate político para articular la sociedad civil con el gobierno local, y así plantear consensos, conflictos e incidencia. En tal sentido, la puesta en escena comunicativa de esta emisora moviliza recursos políticos, organizacionales y estratégicos que entienden el medio más allá de un estudio de producción o de la emisión de contenidos por la radio. Desde la agenda comunicativa se ha incidido en la agenda pública del municipio, muestra de ello, es el liderazgo que durante el 2016 se ejerció para la construcción de un plan de cabildeo para organizaciones comunitarias del municipio de Rioblanco. En ese sentido, los ciudadanos reconocen la labor de Rioblanco estéreo frente a la planeación participativa y la generación de capacidades comunitarias para la gestión de lo público.

Uno al principio piensa que como que todo lo del municipio le corresponde a la alcaldía, que los que trabajan allá son los que tienen la última palabra frente a lo que pasa o frente a la manera en que se hacen las cosas, y resulta que no. Nosotros como comunidad hemos despertado a ese letargo y hemos asumido una actitud más activa y responsable frente a las decisiones en el municipio, frente a cómo soñamos este municipio donde tenemos nuestras vivencias buenas y malas. La emisora como que nos ha ayudado a despertar en ese sentido, nos ha formado para conocer sobre temas que son asunto de todos (Martínez, F, 2017, 15 de junio, entrevistado por Álvarez, M. Rioblanco)

Se reivindica lo público como el espacio de producción de las prácticas sociales y al respecto, Rioblanco estéreo se erige como un escenario en el que se consolida el diálogo de lo público y se concretan aspiraciones colectivas de desarrollo para el territorio. Lo anterior se logra en la medida en que esta radio comunitaria dinamiza la interacción entre la ciudadanía y la administración municipal, de forma paralela, al participar en temas de comunidad, los ciudadanos asumen una postura política y conductas relacionadas con el interés público.

Esta manera de interactuar en la vida pública permite que se establezcan nodos y redes de información que se integran de manera natural a la vida en colectivo, de igual forma, la deliberación y los consensos empiezan a verse como productos sociales que se alimentan cotidianamente y no como productos ya acabados que parecieran imponerse a manera de decisiones o conclusiones finales. Todo lo contrario, constituyen una ventana siempre abierta, una posibilidad latente para motivar el desarrollo y la inclusión.

En este marco, se entiende que, si bien las personas tienen un actuar individual, se ven motivadas por las acciones colectivas. En esa medida, al ciudadano se le reconoce con su capacidad de actuar, interactuar y decidir de manera autónoma, características que lo adhieren a grupos que intervienen en la vida pública. Así pues, del mismo modo como se emite música, campañas sociales, programas con contenido educativo, y promoción de valores. En estos casos, la emisora comunitaria también genera espacios de participación, veeduría, inclusión $\mathrm{y}$, en general, se constituye en expresión de la vida social en comunidad.

Más allá de los procesos técnicos de producción y emisión de mensajes, la radio comunitaria se constituye en un conjunto de procesos sociales y culturales de construcción y pertenencia a lo local, de recreación y fortalecimiento de memorias 
colectivas y un importante instrumento de las comunidades para construir imaginarios de su futuro; razón por la cual las emisoras deben entenderse en su naturaleza de medios de comunicación, instancias de representación y participación ciudadana y de creación social y cultural (DNP, 2008, P. 4)

En esos términos, el sentido de la radio comunitaria va más allá de la difusión de mensajes, son articuladores de la vida política y social de una comunidad de manera que su proyecto se da en función de lo colectivo, a partir de ello, se generan escenarios de comunicación, diálogo y participación.

Contrario a lo que se puede observar en las dinámicas de Samán estéreo, Haca Yu Macu y Rioblanco estéreo, en la emisora Tetuán estéreo del municipio de San Antonio, lo público se agota en lo institucional, es decir, su comprensión se agota en el poder ejecutivo que representa la alcaldía municipal. Al ser esta una emisora comunitaria que limita la construcción de relatos diversos limita también la construcción de lo colectivo y la puesta en común de los ciudadanos.

En función de lo anterior, se puede decir que Tetuán estéreo reivindica y privilegia una democracia de electores, es decir, encuentra en el régimen electoral un elemento fundamental que desborda las distintas dimensiones de lo que es un genuino ejercicio ciudadano y una democracia participativa. Los ciudadanos de San Antonio no validan el trabajo de Tetuán estéreo como legítimo, pues entienden que responde a intereses privados y deja de lado los públicos y no se tiende un puente entre uno y otro. Resulta irónico que lo público, en este caso la puesta en acción de la alcaldía se termine asumiendo como un asunto privado.

Realmente uno ve que en la emisora lo que hace todo el tiempo es hacerle como propaganda a la alcaldía, al alcalde y por eso se siguen dando como unos conflictos políticos como en años pasados, donde uno tiene que declararse de un bando o de otro, saber quién está con uno y quién no, porque se supone que si no es de la misma corriente de uno pes entonces es enemigo político. Eso hace que uno ya ni escuche esa emisora porque para qué si uno ahí no tiene cabida. (Laverde, R (2017, 15 de marzo) entrevistado por Lezama, J. San Antonio).

Un testimonio como el de la señora Rosalba, deja ver que la legitimidad de un gobierno, o de una emisora comunitaria, no depende tanto de un apoyo social mayoritario como de un cambio social con respecto al tipo de relaciones que se establecen y del bienestar ciudadano que se promueve, no como producto de la acción estatal, sino como resultado y propósito de una cierta forma de organización social. El poder público que detenta la alcaldía municipal queda vaciado de sentido cuando el ciudadano queda excluido y sólo se le reconoce una vez cada cuatro años cuando asiste a las urnas.

De acuerdo con esto, es posible afirmar que las emisoras comunitarias en su puesta en escena no sólo contribuyen a la construcción de lo público, sino que tienen la posibilidad de promover el diálogo sobre lo público y de generar valor sobre lo público. De acuerdo con los términos y lugares de enunciación desde los que se configura su funcionamiento, estos tres aspectos pueden o no concretarse, llegando en ocasiones a desvirtuar en parte el papel que se espera que cumplan en los contextos sociales dentro de los cuales se ubican.

Samán estéreo, Tetuán estéreo y Haca Yu Macu representan tres puestas en escena diferentes de las emisoras comunitarias con respecto a lo público. A pesar de las diferencias identificadas, es posible mencionar tres elementos que inciden en dicha puesta 
en escena.1) la participación. Si bien no se cuenta con estudios de audiencia, es posible afirmar que los niveles y modalidades de participación de los ciudadanos en el medio resultan decisivos a la hora de dar sentido y dirección a lo público, cuando se excluye la participación o se le imponen fronteras de algún tipo, se limitan de manera considerable las posibilidades para pensar en lo público. 2) La agenda del medio. Aunque en ninguna de estas tres emisoras se identificó un proyecto comunicativo documentado en papel, es claro que cada una sí tiene una agenda a partir de la cual adquiere una identidad y plantea su funcionamiento cotidiano. Al respecto, se aprecia que no existe un lenguaje común frente a lo que, por lo menos en términos de la Política Pública, es e implica la radio comunitaria, esto tiene que ver con los marcos cognitivos y culturales desde los que en cada territorio se dio vida a las emisoras. 3) Lo estético. Una mirada amplia sobre lo estético, los relatos y los recursos sonoros, favorece la construcción colectiva de lo público en términos de diversidad e inclusión, al limitar la creatividad o asimilar lo estético con lo estilizado, la radiodifusión comunitaria se reviste de una asepsia que excluye y niega lo diverso y que por ende desvirtúa los sentidos de lo público.

\subsection{Tensión 3. La radio comunitaria como experiencia política}

El uso de la comunicación en asuntos políticos y de poder ha estado presente desde los inicios de las civilizaciones humanas. El papel de la comunicación en la construcción de las realidades sociales cobra cada vez mayor importancia, así lo refiere Raquel Salinas cuando plantea "Actualmente, la comunicación ya no está más en la pura esfera de la cultura e ideología sino en el centro de la economía y de la organización política (distribución del poder)" (Salinas Bascur, 1984, pág. 52).

Sobre lo político y la comunicación, el crítico Francés Dominique Wolton plantea lo siguiente: "por un lado, que se trata de un lugar de enfrentamiento de discursos de desenlace incierto, pero también que ese enfrentamiento se realiza partiendo de tres discursos que se expresan legítimamente en una democracia: la información, la política y la opinión pública. (Wolton, 1998, pág. 35). En este sentido, la comunicación además de emitir públicamente asuntos de Estado y mediatizar la política, crea espacios para el encuentro de diferentes discursos políticos, en los que no sólo intervienen los políticos, sino, la opinión pública y la ciudadanía.

De esta manera, se plantea una comprensión más amplia de la comunicación política, que tradicionalmente se relaciona con el marketing político y se asume como una plataforma desde la que los líderes políticos refuerzan o generan técnicas de persuasión para posicionar y preservar su imagen en el escenario político y social con el fin de mantener el ejercicio del poder

En la actualidad, el carácter político de la comunicación va más allá de sustentar la emergencia y posicionamiento de figuras públicas o de facilitar la interacción entre los ciudadanos y los políticos de turno. Hoy tiene que ver con la emergencia de nuevos liderazgos, así como con el hecho de que cualquier ciudadano puede hacerse visible en los asuntos públicos.

La comunicación política fomenta la visibilidad no sólo de personas, sino de asuntos de interés colectivo en el ámbito comunicativo, de forma paralela, conforme lo plante José Luis Exeni, la comunicación política no se concentra sólo en el espacio público, sino en la 
relación del sistema político, los medios de comunicación y los actores de la sociedad (Exeni, 2005, pág. 226). Sobre esto, Exeni propone dos líneas en las que tiene lugar lo político: la sectorial y la territorial. La primera se refiere a la relación del sistema político, la sociedad y el espacio público, así como a la interacción del sistema político con los medios de comunicación, por su parte, la segunda línea se define por las interacciones a nivel local y regional y la relación del Estado con los territorios en el marco de interacciones sociales concretas, en este caso, se privilegia el papel de la ciudadanía y se reconoce que en el fondo todo proceso comunicativo tiene un cariz político.

Así, la comunicación política no es sólo un puente de relación entre gobernantes y gobernados, constituye un rasgo de la apuesta comunicativa que se define en términos de experiencias políticas y culturales construidas para y por los ciudadanos. Dichas experiencias no son neutrales y están abiertas a distintos juegos de poder que se sustentan en el diálogo permanente, la puesta en común de las problemáticas de un territorio y la incidencia social. Para Norbert Elías los juegos de poder hacen referencia a la manera en que algunos participantes limitan con sus jugadas y estrategias los movimientos de otros para acceder a recursos y funciones valoradas en determinadas configuraciones sociales. De este modo, las diferentes caras del juego terminan por mimetizar las formar violentas de exclusión del poder (Elías, 1994).

De acuerdo con esto, se entiende que cotidianamente las emisoras comunitarias tienen una puesta en escena, no sólo comunicativa sino también política y de poder. Cabe preguntarse entonces, ¿cómo se concreta o se hace explícito el carácter político de la comunicación en el funcionamiento de estas emisoras comunitarias? A continuación, se plantearán tres características que se identificaron sobre este aspecto en las emisoras abordadas en este estudio, se aclara que cada emisora representa una de ellas.

\section{La comunicación para interpelar el poder: Samán y Rioblanco estéreo}

Las emisoras Samán y Rioblanco estéreo permiten que el ciudadano viva cotidianamente la conexión con lo local, esto hace que se conserve el carácter colectivo de la experiencia comunicativa y que se haga explícito el interés de estos medios por el papel que deben desempeñar las personas en la configuración de su propio entorno sociopolítico, económico y cultural.

En estos dos casos se observa una comunicación vinculante que incorpora en su quehacer cotidiano el acceso y la participación de una ciudadanía que se siente convocada a través de distintos relatos y contenidos que los representa y escucha. Así lo plantea el profesor Soler quien hace parte de la Junta de programación de la emisora Samán estéreo:

De todas maneras a pesar de todos los inconvenientes por los que hemos pasado durante estos años, confiamos en que hacer radio es una oportunidad que tenemos de que se escuchen otras voces, de que hablemos sobre lo que nos interesa a todos y no que sean los mismos de siempre. Tal vez nos falta explotarla mucho más, de pronto mirar que otras cosas se podrían hacer pero lo importante es que ahí vamos (Soler, F., 2016, 20 de octubre, entrevistado por Lezama, J., Alpujarra)

Por su parte la ciudadana Marina Chacón plantea sobre la emisora Rioblanco estéreo:

Vengo ya hace como dos años participando de algunos programas de la emisora Rioblanco estéreo y pues lo que yo veo es que uno, por lo menos hablo por mi proceso, empieza a tener más sentido de pertenencia, a dejar la apatía y la pereza 
por las cosas del pueblo. Yo antes nunca me interesaba por conocer lo que era un Plan de desarrollo y ahora ya entiendo muy bien sobre qué se trata y esto a uno de verdad lo ayuda a ser un ciudadano y a recobrar la esperanza en la política, entender que la política no es cosa de politiqueros sino de todos, o sea, que yo también cuando me levanto a hacer mi programa soy política de Rioblanco y todos de alguna manera lo somos. (Chacón, M., 2017, 15 de febrero de 2017, entrevistado por Mónica, A. Rioblanco)

Estos testimonios dejan ver dos asuntos. Primero, para que la comunicación política trascienda un mero tipo de comunicación debe sustentarse en la polifonía de voces y en los relatos de la localidad sin que por ello dejen de existir vínculos con relatos más universales o globales. En segundo lugar, las emisoras comunitarias, como en el caso de Rioblanco estéreo, favorecen una apertura en la comprensión de lo político, favorecen su reconocimiento como un ámbito de la vida cotidiana en el que todos confluyen desde las coordenadas de los territorios que habitan y que no se restringe únicamente a la filiación a un partido político y al hecho de ser adeptos a un candidato en particular

De forma paralela, se debe considerar que la cultura política de una comunidad se ve reflejada también en la manera en que funcionan los medios de comunicación de los cuales dispone. La cultura política hace referencia al conjunto de orientaciones políticas de una comunidad, que incluyen conocimientos y creencias sobre la realidad, sentimientos y compromiso con la política. Para Almond (1990), el contenido de la cultura política es producto de la socialización, la educación, la exposición a los medios de comunicación y la experiencia de las personas de todo lo que ocurre en el ámbito político. Constituye un elemento fundamental de la vida social que termina por condicionar desde a actuación de los gobiernos locales, hasta la misma estructura política de un gobierno. (Almond, 1990, pág. 144)

Así, el contexto en el que dialogan los actores sociales, la forma en que los líderes o actores referentes de la comunidad tratan los asuntos públicos, el vínculo que la sociedad establece con sus instituciones y los canales por los que se informa, tienen directa relación con variables políticas y culturales. En este contexto, suele suceder que los líderes, más específicamente los gobernantes y representantes de la institucionalidad, encuentren difícil conectarse con los ciudadanos, que logren comprender sus inquietudes, temores, expectativas y que trabajen sobre ellas existiendo casos en los que ni siquiera reconocen como válida la representación que de ellos hacen en la opinión pública.

En el caso de Samán estéreo, el poder se interpela de forma indirecta y el carácter político de la comunicación está en el hecho de que se meten en las ondas de la radio otros discursos y otras voces, adicional a ello, se erige como un escenario privilegiado para resolver conflictos de diversa naturaleza y esta es una característica por la que está atravesada la ciudadanía política. Por su parte en Rioblanco estéreo, la comunicación se asume y se concreta como una posibilidad para interpelar y dialogar con las representaciones formales del poder (el alcalde, la alcaldía, los secretarios de despacho, entre otros), de esta manera, la emisora se consolida como un espacio en el que se piensa, se habla y se interroga el modelo de hegemonía política en el que se vive.

Así, es posible afirmar que la función social de una emisora comunitaria se logra en parte por la naturaleza de los contenidos que pone a circular, pero especialmente por la importante ampliación de las fronteras de la discusión pública, de modo que todo empieza a ser admisible en esta esfera. Butler (2009), plantea: 
La política del Estado, incluida la política exterior, pretende a menudo impedir que la esfera pública quede abierta a ciertas formas de debate y de circulación mediática. Un modo de lograr una comprensión hegemónica de la política es por medio de la delimitación de lo que es y no es admisible en la esfera pública (Butler, 2009, pág. 22).

Desde la puesta en escena de estas emisoras se supera esta comprensión hegemónica de la política y se le empieza a asumir como un terreno maleable, de fronteras porosas en el que todo ciudadano tiene cabida con sus experiencias individuales y sus aspiraciones colectivas de futuro. En particular Rioblanco estéreo es un escenario político con sujetos ricos en opinión pública que ejercen resistencia desde la comunicación y en función de ello plantean, no solo una disputa pública del poder, sino que proponen la discusión colectiva de las agendas públicas y sobre las maneras en que los rioblancunos están juntos. Samán estéreo por su parte no goza de una agenda tan clara pero no por ello sus aportes son menos importantes, pues de alguna manera para los alpujarreños la junta de programación en cabeza de la profesora Cidia Aya, encarna un proyecto colectivo que sirve de alter ego al poder que detenta el gobierno local.

\section{Comunicación política como la diputa simbólica por el sentido}

Haca Yu Macu en el municipio de Natagaima se caracteriza por ser una emisora comunitaria que cuenta desde lo local, miran de cerca aquellas experiencias con el potencial de producir otro tipo de narrativas. El efecto de diversificar las representaciones es que se producen nuevas visibilidades políticas y se reivindica el la comunicación como acto político por el potencial que ofrece para que los sujetos se enuncien desde los lugares que ocupan y con respecto a aquellos que quieren ocupar.

Sobre esto el líder indígena de Natagaima Alberto Silva plantea sobre la emisora Haca Yu Macu:

Hemos hecho un esfuerzo para innovar, no rebuscando cosas sino recurriendo a toda la imaginación de los natagaimunos, pero no sólo para pasar el tiempo y ya, sino que empieza a reflejarse un compromiso para pensar, hacer y decir diferente" (Silva, A (2016, 25 de octubre) entrevistado por Álvarez, M., Natagaima)

Ese hacer y decir diferente al que hace referencia el líder indígena, tiene que ver con la posibilidad de encontrar nuevos sentidos y darles forma en la producción de relatos propios. A partir de explorar distintas estéticas, narrativas y formatos se promueve el encuentro entre diferentes y la configuración de tejido y capital social. Esta fortaleza del medio en parte se sustenta en la tradición de la cosmogonía indígena de la cual se alimenta su gestión desde que se le dio origen hace algunos años.

Esta emisora propone una nueva enunciación política y cultural tanto de quienes participan de forma directa en las rutinas de producción del medio como de la ciudadanía en general. En relación con esto se plantea una disputa simbólica por los sentidos de lo público y lo comunitario y se abren nuevas coordenadas a través de los relatos diversos. La noción de relato es antigua, no obstante, teóricos de la modernidad empezaron a usarla para referirse a que la percepción y consideraciones que se generan frente a cada momento histórico, depende de cómo se describe, y que quienes logran imponer su relato sobre otros relatos posibles tienen una ventaja y es que los demás leerán los acontecimientos a través de esa manera de ver el mundo. Ese gran relato a su vez está conformado por una multitud de 
relatos pequeños o fragmentados, esto es, la forma en que se cuenta la realidad todos los días (Caparrós, 2011, pág. 259).

Así, en la propuesta de esta emisora se potencia la construcción de un tejido comunitario fuerte en términos de diálogo y del intercambio genuino de experiencias que tienen lugar en lo local. Por eso allí se habla de lo que se considera importante: de la memoria, de los derechos humanos, del agua, de la contaminación, de los bosques secos tropicales, del distrito de riego del sur del Tolima. El siguiente testimonio de uno de los líderes de la vereda Yaví da cuenta de esto:

Una de las primeras cosas que nosotros nos preguntamos cuando llegaron aquí con los aparatos de la emisora fue bueno y uno ¿de qué habla? Y más nosotros tan ignorantes, digamos tan aislados no sólo por la vía sino por ese aislamiento al que hemos sido condenados por los gobiernos nacionales, departamentales, y municipales, era una pregunta difícil, pero después nos dimos cuenta de que la tierra misma nos dice de qué hablar y sólo sobre qué hablar sino con qué palabras que es lo importante. La palabra es para todos, le emisora es una ventana bien grande para todos los natagaimunos. (Chiniscué, H. (2017, 20 de junio) entrevistado por Álvarez, M. Natagaima).

Podría decirse que la exclusión y el aislamiento a los que hace referencia don Héctor, son un sentimiento generalizado de la ciudadanía y estos terminan siendo sentimientos donde germina con mayor facilidad y potencia la comunicación en dirección desde abajo hacia arriba, replanteando el sentido del poder e interpelando constructivamente los gobiernos locales. En casos como este, la emisora comunitaria muestra su capacidad para defender una cosmovisión común y para fortalecer el papel de la interlocución y mediación cultural y política en una propuesta en la que el ciudadano de a pie está incluido y reconocido, la cual reivindica la comunicación no como un recurso para sino como la esperanza en acción. (Osorio \& Rubio, 2007, pág. 58).

En otras palabras, cuando se plantea que la comunicación en una emisora comunitaria es política en la medida en que pone en juego una disputa simbólica por el sentido, se hace referencia a que la emisora no es un objeto externo con un papel ya determinado, sino que representa una construcción social desde la que se propone cómo podría ser la política y deviene, en palabras de Escobar y Osterwel cuando se refieren a los movimientos sociales,: "una esfera de acción en la que la gente puede soñar con un mundo mejor y contribuir a realizar ese sueño, por la experimentación con formas sociales alternativas que podrían no cambiar el mundo actual, sino hacer visibles las posibilidades de nuevos ordenamientos o imaginarios de lo social" (Escobar \& Osterweil, 2009, pág. 150) y, por qué no, de lo político.

\section{Tetuán estéreo: cuando la comunicación no tiene relevancia política}

Contrario a lo que ocurre en Samán, Rioblanco estéreo o Haca Yu Macu, en Tetuán estéreo del municipio de San Antonio, la comunicación se considera política sólo cuando la voz de las figuras políticas se escucha (el alcalde, los secretarios de despacho, los concejales). En ese sentido, se asume que para ser sujeto político es necesario tener autoridad y ser un representante formal del poder, de forma paralela, se imponen restricciones sobre los actos políticos de los individuos en tanto se cree que la estabilidad política exige que los miembros de una sociedad autorregulen su comportamiento de acuerdo a cierta estructura cuya característica principal es la rigidez. 
Tres rasgos de Tetuán estéreo sustentan la afirmación del subtítulo: 1) la concentración de las rutinas de producción del medio en pocas manos, desde que inició han sido las mismas personas las que han estado al frente del medio y esto hace que empiecen considerarse figuras de autoridad en la materia; 2) una alta dependencia del medio a la información proporcionada por el gobierno, por las empresas, y por los expertos; 3) la pauta oficial como mecanismo de control del medio.

Así, se observa que la participación y el acceso a la comunicación son un peligro para los intereses creados por la emisora, intereses que hacen justificable el uso de la información como propaganda política. Muestra de ello es que con frecuencia se organizan entrevistas por razones de oportunismo político y aunque otorga cierta fluidez a la programación, los resultados enriquecen poco a los ciudadanos en la medida en que no se atienden los verdaderos intereses y necesidades de la población, por el contrario, se da respuesta a unas necesidades institucionales.

Políticamente estas puertas cerradas de la emisora constituyen un peligro, pues cuando un pequeño núcleo de personas toma todas las decisiones frente a qué comunicar y cómo hacerlo, se incluyen sólo ciertos puntos de vista, los de una minoría selecta y se concede tiempo solo a los temas que favorezcan a dicha minoría. De ahí que Tetuán estéreo es un medio institucionalizado, tiene un contrato comunicativo con la institucionalidad que opera en el plano simbólico pero que se concreta en el plano expresivo privilegiando un formato noticioso acartonado, así como otros formatos de homenaje a las cabezas visibles en los que la palabra es solemne y no es para todos.

Aquí no hay comunicación para ni desde el sujeto colectivo, tampoco se contribuye a configurar un tejido social fuerte, se trate de un escenario de comunicación cooptado por completo por un interés gubernamental que nada le interesa abrir el diálogo con la ciudadanía ni tener en cuenta sus aspiraciones o su identidad. Como se mencionó en otro de los apartados de este texto, Tetuán estéreo representa el relato de fracaso de una emisora comunitaria. 


\section{Conclusiones}

Estas conclusiones inician con un recordatorio, este es, que todo proceso de investigación más allá de sus limitaciones epistemológicas y metodológicas debe asumirse con compromiso social y político. En ese sentido, es fundamental una apertura del saber experto a uno situado y experiencial que se nutre del diálogo de saberes y de la reflexión sobre y desde la experiencia. En función de esta consideración se resalta el carácter dialógico que tuvo este estudio en tanto todos los sujetos sociales con quienes se llevó a cabo el proceso de indagación tuvieron la ocasión de reconocer sus jugadas (puesta en escena) a lo largo del tiempo en las emisoras comunitarias estudiadas, el rol ocupado por sí mismos y por los otros dependiendo de las coyunturas, el tipo de relaciones construidas, los intereses en juego y los diferentes escenarios en los que dichos intereses pueden confluir o entrar en conflicto.

Dicho entramado de relaciones e intereses es lo que otorga densidad al conocer, en este caso, la circunstancia, la espacialidad y temporalidad de las emisoras Samán estéreo, Haca Yu Macu, Tetuán estéreo y Rioblanco estéreo, constituyen experiencias locales que se conectan entre sí desde distintas aristas que a su vez están en relación constante con los marcos cognitivos y culturales de los contextos dentro de los cuales se insertan.

Como se plantea en el capítulo tres las emisoras comunitarias abordas en este trabajo fueron constituidas inicialmente por grupos sociales, (asociaciones productivas o redes de ciudadanos). Las cuatro nacieron inicialmente en el seno de otra organización social, en algunos casos, dichas organizaciones sociales no lograron proyectar su legitimidad social y política en el tiempo, en otros casos, al carecer de un proyecto propio, se empezaron a debatir en luchas internas y conflictos de intereses que llevaron a su disolución. Por lo anterior, las emisoras que apadrinaron en un inicio optaron por la autonomía de su dinámica, dejando de interlocutar con los sujetos sociales que les dieron vida para concentrarse en la consecución de sus propios recursos políticos, organizacionales y 
estratégicos; la generación de relaciones particulares y en general, la producción de una lógica de vida propia.

Las trayectorias propias marcaron derroteros diferentes por cuanto cada medio responde a las lógicas contextuales que les permiten existir. A través de una mayor reflexión y acción crítica es posible humanizarlos y lograr la armonía entre las dinámicas de sus contextos y los objetivos por los que deberían trabajar en su puesta en escena cotidiana, volviéndose más sensibles y abiertos a la construcción del bien común en un sentido genuino y no solo desde la pseudo-participación. En el seno de estas emisoras comunitarias es posible compartir formas de vida, creencias, ideas, sentimientos, imaginarios, deseos y sueños colectivos.

Como se advirtió en el Capítulo cuatro, una tensión no se agota en el conflicto, por el contrario, enuncia la relación entre dos objetos desde distintos puntos de vista, y a partir de la convergencia de elementos propios de una espacialidad y temporalidad particular. En este trabajo se enunciaron tres tensiones fundamentales entre la Política Pública de radiodifusión sonora comunitaria y el funcionamiento de cuatro emisoras comunitarias del Sur del Tolima: la participación, la construcción de lo público y la comunicación política. A continuación, se plantea una reflexión final frente a cada una de ellas.

\section{La participación como verbo y adjetivo}

Frente a la participación lo primero que hay que decir es que las múltiples identidades que confluyen en lo local tienen unas necesidades estéticas particulares, esto es, la estética de lo local en contraposición a un esquema institucional que aunque pone la participación como columna vertebral de la Política de Radiodifusión comunitaria, busca al mismo tiempo el desarrollo de la demanda de las tecnologías de la información y la comunicación, a partir de una política de espectro radioeléctrico que favorece el desarrollo de redes y servicios inalámbricos en su afán de responder a la convergencia tecnológica neoliberal a la que hoy se ve abocado el país.

En este contexto, la participación tiene tantas caras como se quiera, llegando incluso a desdibujar su sentido primigenio, especialmente, cuando se trata de intereses o status sociales en conflicto. La participación legítima que encarna la radio comunitaria se presenta como una lucha simbólica e inagotable por otros lugares de enunciación, como la búsqueda de otros relatos y sensibilidades que abonan la emergencia de nuevos actores y ciudadanos empoderados en su palabra y en sus acciones.

Ya lo han dicho los grandes teóricos y precursores de la radio, esta encarna una experiencia viva en la que el sujeto no sólo participa al tomar la palabra sino también al reconocerse en los relatos y discursos que esta pone a circular. La participación en la radio comunitaria, más allá de una Política Pública pensada en clave de participación, requiere ciudadanos con condiciones para participar, es decir, que hagan parte de una cultura política en la que se articulen los intereses propios, los comunes en el plano de lo público. Pero que en ese juego ganen todos: el individuo, las familias, las organizaciones y la sociedad en conjunto.

Así, en el seno de la radio comunitaria, la participación adquiere tantos sentidos como caras, por esta razón existe una necesidad creciente de analizar y establecer con mayor claridad de qué manera las dinámicas sociales, culturales y económicas de los contextos influyen en la capacidad de acción y participación de los sujetos al mismo tiempo en que 
ejercen influencia en la práctica y puesta en escena de la política de radiodifusión comunitaria a nivel local.

De acuerdo con los casos estudiados, en la radio comunitaria la participación puede abordarse como un adjetivo o como un verbo. Cuando es un adjetivo, se presenta como cualidad de la radio, "Radio participativa" y cuando se pide a sus gestores que citen ejemplos concretos de porqué la definen de esa manera, usualmente plantean que es participativa porque la gente puede ir a denunciar atropellos de los funcionarios públicos o a quejarse. Por el contrario, la participación como verbo, implica repensar la radio comunitaria como algo más que un simple vehículo conductor de mensajes y considerarla como una institución social que brinda a los ciudadanos comunes oportunidades para expresarse, articular sus preocupaciones y participar en la deliberación pública y la crítica social.

Si bien es cierto que son los ciudadanos quienes finalmente le dan sentido a la participación en la radio, es innegable el hecho de que cada emisora comunitaria propone unas condiciones y reglas de juego que pueden favorecer o no la participación. En algunos casos, como en el caso de Tetuán estéreo, las prácticas comunicativas de las emisoras comunitarias resultan ser procesos que desempoderan en lugar de empoderar. Estas limitaciones, por lo menos en los contextos estudiados, permanecen inexploradas debido a que el interés natural de las juntas de programación en autoevaluarse y de las evaluaciones a pedido de las instancias gubernamentales, reside en documentar todos los resultados positivos del medio.

Sin duda, para que la participación como verbo trascienda la participación como adjetivo, se requiere de intencionalidad por parte del medio comunitario y de quienes configuran su funcionamiento cotidiano, no basta con que sea una feliz coincidencia o un resultado fortuito y esporádico. La intencionalidad frente a la participación, eso es lo que diferencia una emisora como Haca Yu Macu en la que se encarna la participación del ciudadano diverso, de una como Tetuán estéreo, a la que se le denominó en este trabajo el lugar de la no participación. Cuando no media una intención explícita frente a la promoción de la participación, la emisora comunitaria termina siendo una fuerza social pobremente explotada. Ocurre lo contrario cuando sobre la base de principios como el acceso abierto, la multiplicidad de voces, la cualificación de los espacios para el diálogo y la expresión de diferencias de opinión, la radio comunitaria se convierte en una importante fuerza social en el desarrollo de trayectorias ciudadanas orientadas a fortalecer o reconstruir el tejido social. Este planteamiento remite a la necesidad de una visión y una ambición social más explícita en lo que respecta a los procesos de participación anclados al proyecto comunicativo de los medios comunitarios y constituye un argumento a favor de la teorización desde la experiencia y del compromiso que por ende, la práctica debe tener con la teoría.

Un elemento interesante y actualmente muy relevante tiene que ver con la acción conectiva de la que es capaz la radio comunitaria, esa que permite que el sujeto pase de la esfera individual a formar parte de un proyecto colectivo inacabado que se nutre de nuevas formas de movilización social y por supuesto, de aspiraciones colectivas. Lo anterior es posible a partir de la mediación que el proyecto comunicativo del medio comunitario propone al ciudadano en su subjetividad, desde el encuentro cotidiano con el vecino en torno a un tema en común que hace parte de la agenda del medio, hasta la inclusión de su identidad en relatos alternativos que lo narran y narran su territorio de manera diferente.

Poner la participación en el centro de la política pública de radiodifusión comunitaria requiere de nuevas conceptualizaciones, así como de una reflexión profunda sobre las prácticas a partir de las que las emisoras comunitarias concretan dicho ideario. La 
participación como categoría central, debe permear los modos de gestión y de organización de estas emisoras, es decir, la participación debe impregnar el conjunto de prácticas sociales que permiten su existencia.

\section{Emisoras comunitarias: ¿Faros para la construcción de lo público y la comunicación política?}

En casos como los de las emisoras Haca Yu Macu, Rioblanco estéreo y Samán estéreo, las emisoras comunitarias constituyen activos sociales porque son importantes para la gente, porque en ellas reconocen un proyecto expresivo local y una oportunidad para dialogar acerca de temas que son de interés común. Además de dialogar es posible incidir en lo público desde la acción colectiva.

El diálogo e incidencia en lo público que se logra en cada contexto refleja la cultura política, el grado de participación cívica de los ciudadanos, la capacidad de las emisoras comunitarias para ser accesibles a la gente. Refleja también quiénes son los individuos y las instituciones más respetados, cuáles son considerados confiables y cuáles no, qué papel cumplen los actores en la comunidad y qué deudas tienen individuos e instituciones para con la sociedad.

En los casos estudiados se identificó que la ficción tiene mayor potencial expresivo y narrativo que lo informativo para aportar a la construcción de lo público. Los formatos que se proponen en una y otra emisora no son neutros, cada uno propone una ideología, una manera de aproximarse al mundo y de narrarlo. Su principal riqueza es cuando se piensa en función de lo local, de los elementos que lo local ofrece y no rencauchando formatos ajenos a las lógicas del contexto.

De esta manera, cuando se cambian los lugares desde los cuales se enuncia, se cambia también el lugar del sujeto político y las emisoras comunitarias cobran relevancia política y perceptiva en tanto des-ubican y re-ubican a los ciudadanos en una amplia gama de experiencias comunicativas, políticas y culturales. El lenguaje de lo local ve nacer al ciudadano celebritie, lo local no es otra cosa que expresión de la cultura bastarda: "Y para ejercer las ciudadanías celebrities hay que localizarse en las culturas bastardas: comunicarnos y enunciarnos desde los referentes que tenemos. Y somos hijos de culturas bastardas, ilegítimas, ambiguas, sucias, barrosas" (Rincón, 2015, pág. 55).

Cuando las emisoras comunitarias se desarrollan de manera plena como pasa en Haca Yu Macu, configuran nuevas opciones para reagrupar y experimentar lo social y esto, en palabras de Santos, se debe a que se expande el campo de las experiencias sociales posibles (Santos, 2005, pág. 171). Estas experiencias sociales se amplían en la medida en que se reinventa lo expresivo de modo que la conciencia crítica está también en lo narrativo, la resistencia y la emancipación en la palabra cotidiana. En otras palabras, los contenidos producidos por estas emisoras comunitarios no son sólo periodísticos, realizan aportes en materia de producción de conocimiento sobre lo local, en visión de mundo, en instalar una mirada socialmente significativa y renovada sobre lo público. Los nuevos relatos que se fundan en el seno de estas emisoras activan el saber-decir, el saberescuchar, el saber-reconocer y el saber-hacer situado en colectivo.

Así pues el carácter político y la construcción de lo público en la radio comunitaria se tejen con los hilos del diálogo de saberes y de las relaciones interculturales, aquellas que interpelan, que confrontan al individuo en su esfera privada y le dejan ver que está llamado a hacer parte del intercambio colectivo de la palabra y de la experiencia. En colectivo se 
comprende que las diferencias y desigualdades de poder y conocimiento son experiencia transformadora en la comunicación comunitaria.

Las emisoras comunitarias pueden iluminar la construcción de lo público y la re-significación del carácter político de la comunicación en tanto generan aportes concretos a la ampliación del derecho a la comunicación a partir de prácticas donde distintos actores conjugan experiencias, habilidades y expresiones para dar forma a "un discurso entramado de la cultura y fundamento de la historia de vida de una comunidad" (Barbero J. , 2002, pág. 234). Los hechos recolectados en las entrevistas y talleres grupales reflejan que los ciudadanos se identifican con el trabajo de sus vecinos a través del acompañamiento a expresiones, reclamos, articulación de esfuerzos, convocatoria de acciones que coinciden con las necesidades, pensamientos y sentimientos de los habitantes del territorio donde el medio tiene cobertura.

En este punto es fundamental que cada emisora y medio comunitario se cuestione acerca de quiénes participan en la producción de sus contenidos y que atendiendo a los espacios reducidos con los que cuentan, promuevan el trabajo de corresponsales veredales o rurales que puedan dinamizar desde distintas latitudes y formatos la programación y que de manera voluntaria y cooperativa asuman las tareas que se requieren para el adecuado funcionamiento del medio. Allí es donde aparece viva la democratización de los medios, en el hecho de que el ciudadano de a pie sea capaz de generar información, hechos y relatos de interés que promueven la extensión de la democracia a todos los aspectos de la vida (Mosco, 2006, pág. 73).

Es posible que así como ocurre en Tetúan estéreo, en otras emisoras comunitarias del país reine un monólogo incesante de poder, ciego ante la polifonía de voces y entregado a favorecer intereses particulares. En esos casos el medio debe interpelar su propia práctica, y permitir que otros también lo interpelen para recordar que su aporte debe ser socialmente distinto al de los medios comerciales que privilegian valores de mercado y de alto consumo masivo. Al respecto, se considera determinante la existencia de redes en las que las emisoras comunitarias del departamento puedan articular esfuerzos e intercambiar sus buenas prácticas y sus desaciertos. Incluso, emprender de manera conjunta el desarrollo de contenidos que respondan a un proyecto de identidad regional en clave de paz y reconciliación, visibilizando las victorias tempranas y los retos de trabajo común. Institucionalizar espacios de estas características facilitaría que las emisoras comunitarias tengan memoria sobre sus trayectorias individuales y sobre los asuntos que las intersectan y por los cuales deberían plantear agendas colectivas susceptibles de abordarse en distintas temporalidades.

Hay un aspecto que en particular favorece el que las emisoras comunitarias aporten a la construcción de lo público, esto es, mantener una agenda independiente a la gestión municipal bien sea que le dé o no pauta publicitaria, de otro modo, se echaría por tierra la confianza que la gente tiene en ellas y se caería en el juego perverso de dejar sin voz a los sin voz. Lo anterior no quiere decir que los gobiernos locales queden excluidos del diálogo de lo público, todo lo contrario, también son actores importantes llamados para participar y a fortalecer, no sólo los procesos de rendición de cuentas, sino también, sus relaciones con la ciudadanía desde una mayor apertura a la incidencia política y al control social. Este diálogo amplio constituye un importante aporte a la superación de la desafección política que caracteriza nuestros contextos, en los que los ciudadanos suelen aparecer más como demandantes de derechos por parte del Estado que como gestores de cambios a partir de las preocupaciones genuinas que tienen por la vida de sus territorios. 
Un punto pendiente de trabajo en la gestión de estas emisoras comunitarias son los estudios de audiencia, lo que genera una carencia de conocimiento sobre el tipo de ciudadanos que integran su audiencia, y sobre lo que ellos piensan, desean y opinan. Este hecho hace que la afirmación de Canclini no pierda vigencia "Necesitamos estudiar el consumo como manifestación de sujetos, donde se favorece su emergencia y su interpelación, se propicia o se obstruye su interacción con otros sujetos" (García Canclini, 2001, pág. 28). Es de aclarar que tres de las cuatro emisoras abordadas en este estudio trabajan con sus audiencias, aunque sin una regularidad consolidada, en una relación dialógica, participativa y afectiva. Al realizar estudios de audiencia estas emisoras también podrían medir el grado de incidencia que tiene su trabajo y su agenda comunicativa en la comunidad, de este modo, se favorecería la contextualización de "las políticas culturales en ciudades, radios o centros culturales independientes, en la esfera de lo micropúblico" (García Canclini, 2001, pág. 28).

\section{Ciudadanía, la categoría que lo conecta todo}

En la definición radical democrática la ciudadanía no es sólo un conjunto de derechos y deberes conferido por el estado, sino una práctica social multidimensional que se refiere a las identidades y acciones de las personas como colectivos y no como individuos. (Mouffe, 2005). Para el caso de las emisoras comunitarias y los medios comunitarios en general, los ciudadanos no son sólo audiencias o receptores. ¿De qué manera se ha reconfigurado la noción de ciudadanía en la trayectoria de las emisoras comunitarias y qué tipo de ciudadano se legitima en su práctica cotidiana? ${ }^{21}$

En la época contemporánea, la categoría de ciudadanía juega -o debería jugar- un papel fundamental en la configuración de la identidad de las emisoras comunitarias. Desde la perspectiva de la Política Pública de radiodifusión comunitaria, dicha relación se enuncia de manera explícita, no obstante, desde las prácticas estudiadas, se producen cuatro rupturas fundamentales:

1) El diseño de la Política de Radiodifusión comunitaria deja de lado los saberes locales, los cuales constituyen los referentes concretos de los modos expresivos de las emisoras comunitarias. Al asumir una homogeneidad territorial que no existe, los rasgos identitarios de la radio comunitaria que se describen en la Política están enunciados desde la teoría y no desde la práctica.

2) Cuando la Política Pública plantea que el enfoque de la radio comunitaria debe ser participativo, en algunos casos, los gestores locales producen en distintas medidas una tajante separación entre el discurso de la participación y la práctica de la participación. Se reconoce, sin embargo, que desde el plano expresivo se generan posibilidades para acceder a status desde los que participar es más factible.

3) Cuando los ciudadanos se encuentran en las emisoras comunitarias con planteamientos sobre la naturaleza democrática y participativa del medio y contradictoriamente con prácticas autoritarias, confusas y discriminatorias por parte de sus gestores, se da origen a una existencia fragmentada de lo comunitario.

4) El ingreso paulatino de las emisoras comunitarias a la era de la sociedad del conocimiento y de lo digital, se basa más en la transformación del pensamiento

${ }^{21}$ En este caso la práctica cotidiana incluye las dinámicas de producción de contenidos, así como las acciones propias de gestión para la subsistencia del medio 
digital en pensamiento analógico que en una introducción genuina del pensamiento digital. Las implicaciones que esto tiene en la configuración de la ciudadanía y la participación en los medios comunitarios, tienen que ver con que la convergencia digital a la que invita la Política, no se asume como algo necesario, especialmente, cuando se carece de los medios económicos que dicha convergencia exige.

¿Qué ciudadanía se privilegia en el funcionamiento cotidiano de las emisoras comunitarias con esta confusa mezcla de prácticas e intereses? La pregunta queda abierta, no obstante, de manera preliminar, podría afirmarse que se trata de una ciudadanía culturalmente mestiza que desvirtúa por completo tres de los reproches con los que tan duramente la sociedad interpela al ciudadano contemporáneo.

\section{Reproche $\mathrm{N}^{\circ}$ 1. El peor defecto del ciudadano actual es su desafección política}

Incluso en las emisoras comunitarias que desvirtúan el sentido de lo comunitario y lo participativo, es posible encontrar ciudadanos con un alto interés y gran capacidad para vincularse a lo político y esto obedece a que se ha logrado una comprensión enriquecida de la política más allá de los rituales propios del régimen democrático. El ciudadano del común se describe como desafecto a la política porque en su imaginario esta equivale a las figuras públicas de la política y a la corrupción con la que dichas figuras y algunas instituciones hacen política.

Contrario ocurre con el ciudadano de la radio comunitaria, este ha entendido que la política es acción colectiva, es interés genuino por proyectos compartidos de territorio en los que confluyen las comunidades y la institucionalidad. Resulta muy pertinente en este caso traer las palabras de Hannah Arendt cuando plantea que lo político se construye en el ámbito de la palabra, del consenso de las relaciones de solidaridad que prosperan en el seno de un tejido social con profundo arraigo por el bienestar común. Desde esta perspectiva, es claro que lo político está en íntima relación con el poder el cual se manifiesta, no como fuerza coactiva sino como capacidad para actuar concertadamente (Arendt, ¿Qué es la política?, 1997, pág. 71).

\section{Reproche $\mathbf{N}^{\circ} 2$. El ciudadano contemporáneo no participa}

Una de las principales conclusiones de los estudios de percepción ciudadana suele ser que los ciudadanos ya no participan, o por lo menos no, a través de los mecanismos tradicionales. La revisión de la práctica de las emisoras comunitarias deja ver que esto no es cierto, y que el ciudadano contemporáneo es artífice de nuevas formas de participación que incluyen desde la apertura de escenarios alternativos que dan voz a los sin voz, hasta ejercicios colectivos que logran permear los escenarios tradicionales.

Desde el punto de vista expresivo, la participación se convierte en una estética, es decir, en una manera particular de enunciar lo subjetivo en interacción con otros. Participar entonces, no es algo protocolario o eventual, constituye una práctica cotidiana al alcance de todos, con potencial de reinventarse a partir de los referentes que cada uno encuentre más pertinentes y cercanos a su experiencia vital.

Además, el ciudadano de la radio comunitaria participa en colectivo y esto favorece los procesos de incidencia e interlocución con la institucionalidad. Esta manera de participar da lugar a una esfera pública mediada, es decir, un espacio que contiene tanto las posibilidades como las limitaciones para el cultivo de la acción para el cambio. 
De acuerdo a los casos estudiados, es posible identificar que uno de los aportes fundamentales de la radio comunitaria obedece a la construcción de oportunidades para la participación en la esfera pública, aspecto que cualifica la ciudadanía y genera un proceso de desarrollo inclusivo. Lo anterior es posible gracias al desarrollo de estrategias discursivas propias y a la apertura de espacios en los cuales las personas pueden articular sus opiniones, expresarse respecto a cuestiones que les preocupan y leer historias en clave territorial.

\section{Reproche $N^{\circ} 3$ El ciudadano prefiere estar distanciado de la institucionalidad}

La desconfianza es quizás uno de los atributos desde los cuales los ciudadanos contemporáneos se refieren a su relación con las instituciones, esto conduce entre otras cosas, a justificar el escepticismo por lo político y los bajos niveles de participación. Pese a esta actitud generalizable, es posible hablar de dos aperturas. En primer lugar, los gobiernos suelen entender la participación como un proceso social estrictamente vinculado con ciclos programáticos de agendas de desarrollo y ejecución de proyectos, ante la puesta en escena de las emisoras comunitarias, la institucionalidad complejiza su comprensión de lo que significa participar y está, al menos en el nivel local, más abierta a escuchar y tomar en cuenta a los pobladores de los territorios.

En segundo lugar, si bien la movilización social que promueve la radio comunitaria ocurre, en principio, por fuera de las arenas institucionales y políticas formales, logra que los procesos de deliberación, crítica social y política y acción colectiva terminen por acercar a los ciudadanos a la institucionalidad y viceversa.

\section{Hablemos de la política de radiodifusión comunitaria}

Es un hecho que la radiodifusión comunitaria tiene el potencial para ser portavoz de la pluralidad y de la diversidad que hoy caracteriza a las sociedades. La configuración de nuevas identidades en el marco de un discurso renovado, que se nutre de lo local, pero que reconoce la existencia de otros horizontes, es el caldo de cultivo perfecto para lograr un pensamiento comunitario y planetario (Morin, 2001). Hoy se necesitan medios más reflexivos, comprensivos y con conciencia planetaria para abordar la complejidad creciente de esta época, en este sentido, se deben considerar no sólo los marcos sociales y culturales en los que se insertan los objetos que se estudian, sino también, su puesta en escena a partir de la configuración de nuevos sentidos.

La radio es finalmente un medio en el cual se crean significados, en donde se reproduce la identidad y la cultura más allá del dinero. Excepto por el caso de la emisora Tetuan estéreo del municipio de San Antonio, las emisoras exploradas son comunitarias porque: a) expresan las voces de sus colectivos, b) responden a los intereses, y problemas de los ciudadanos y de acuerdo a ello diseña y produce una programación en clave local, c) reconocen y rescatan los sonidos y voces propias, juegan con la geografía cultural de la diversidad del territorio, las músicas y experiencias locales, d) promueven la convivencia y el diálogo local de manera ética y equitativa, e) acompaña a distintos actores en la búsqueda de formas organizativas y estéticas propias. En suma, estos medios son expresión desde un patrimonio que cuidan todos y una extensión de las necesidades y ganas de formar comunidad.

En este sentido, cotidianamente hay una puesta en escena no sólo comunicativa sino también política y de poder gracias a lo que cada emisora significa para los municipios que 
las acogen. Estas emisoras no sólo narran y descubren los territorios de manera diferentes, sino que logran conectar sus relatos con otros más universales, en palabras de Barbero:

[...] lo que está en juego es una nueva sensibilidad hecha de una doble complicidad tecnológica y expresiva: es en sus relatos e imágenes, en sus sonoridades, fragmentaciones y velocidades que ellos encuentran su idioma y su ritmo. Estamos ante la formación de comunidades hermenéuticas que responden a nuevos modos de percibir y narrar la identidad, y de la conformación de identidades capaces de amalgamar ingredientes de universos culturales muy diversos (Barbero J. , 2002, pág. 22).

Sin duda, son múltiples las virtudes de los medios comunitarios, no obstante, las emisoras comunitarias en el contexto del departamento del Tolima, oscilan entre la esperanza y la desesperanza, por este motivo, es urgente una Política de radiodifusión comunitaria para la esperanza. A continuación, se esbozan algunas reflexiones que pueden iluminar el camino.

Se considera importante construir sobre lo construido y de acuerdo a esto se reseñan algunos aspectos positivos de la actual Política Pública:

1. Ubica el tema de la comunicación en función del desarrollo social

2. Reconoce que la comunicación plural y diversa contribuye a la democracia y la participación ciudadana

3. Legaliza la función social de las emisoras comunitarias como tercer sector

4. Propone reglas y posibilidades a las emisoras para el desarrollo de actividades de formación y evaluación

5. Considera el monitoreo de la esfera pública con alternativas para el control social y la instalación de veedurías ciudadanas y nacional

6. Contempla escenarios de diálogo y debate a nivel regional

7. Plantea, aunque sea en un nivel consultivo, estrategias para que las organizaciones sociales y los líderes de las emisoras comunitarias accedan a espacios para opinar sobre la toma de decisiones y definición de planes de trabajo

Lo que se pone de relevo es un estancamiento de la Política, aspecto que genera incertidumbre y eventualmente inconformidad entre las emisoras comunitarias. Este estancamiento puede leerse desde una tensión que nace por el divorcio entre los intereses sociopolíticos e institucionales y las lógicas neoliberales y capitalistas presentes en el actual contexto de país que conciben los medios comunitarios como una práctica que debe institucionalizarse de forma instrumental. En contraposición a esta tensión inconclusa, se identifica el interés creciente de la ciudadanía para insertarse en la esfera pública y la necesidad de las instituciones para que los medios comunitarios favorezcan la gestión pública y la gobernabilidad.

La Política Pública de Radiodifusión Sonora Comunitaria es sin duda un avance político que debe ser fortalecida. En un contexto de país donde políticamente siempre se han tomado decisiones para favorecer los grandes medios, es muy positivo que, al menos en el papel, se asuma la comunicación como un escenario para la democracia. De manera general, se plantean algunas recomendaciones, tanto para las emisoras comunitarias como para el gobierno, a partir de las que se podría fortalecer el proceso de implementación de la Política: 
1. Promover entre las emisoras comunitarias formas organizativas propias, independientes de los gobiernos locales de modo que se favorezca su poder político y expresivo.

2. Las emisoras comunitarias a nivel regional, en articulación con la academia, deben promover escenarios de diálogo con los candidatos a cargos de elección popular para el periodo 2020-2023 a nivel departamental y municipal, de manera que logren incidir programáticamente en los programas de gobierno y posteriormente en los planes de desarrollo. Para ello se requiere previamente de un ejercicio de construcción de agenda compartida de emisoras comunitarias en el ámbito regional.

3. El gobierno es débil en cuanto al proceso de planeación, especialmente en lo que respecta a estudios de caracterización y levantamiento de líneas base. Es difícil subsanar esta brecha desde la capital, por lo que se sugiere promover una metodología de autodiagnóstico para que cada emisora revise en funcionamiento actual. En esta evaluación se debe considerar la participación de líderes comunitarios a nivel local y representantes de la institucionalidad.

4. Una política de radiodifusión sonora comunitaria sin suficiente visibilidad carece de sentido. El proceso de implementación y la Política en sí misma requiere de promoción y mayor visibilidad.

5. Es necesario definir estrategias que mitiguen al máximo los problemas que representa el cambio de prioridades presupuestales y programáticas de la transición de gobiernos para la continuidad de la Política.

6. Los escenarios de control social en la gestión de la radio comunitaria que propone la Política deben hacerse realidad, incluyendo la participación de sus representantes en los Consejos Territoriales de Planeación.

Ahora bien, el funcionamiento cotidiano de una emisora comunitaria constituye un saber social no confrontado, en esa medida, no sólo se requiere de una Política más abierta a conocer los contextos locales de Colombia, que difieren en mucho del territorio capitalino, sino de una que promueva programáticamente la articulación de esfuerzos y redes entre las emisoras comunitarias y que tenga en cuenta los siguientes aspectos:

Una Política que considere lo económico. En la actualidad es posible visualizar una serie de oposiciones simbólicas y materiales a la democratización de la palabra. La democratización de la palabra no es rentable, como si lo es la concentración de los medios en manos de los grandes conglomerados económicos, en tanto, resulta más fácil hablar de consumidores que de ciudadanos con derechos y de política como clientelismo, corrupción y marketing que de política como transformación y poder comunitario. Para mitigar estas disyuntivas es necesario que también se analice desde un punto de vista económico el funcionamiento de las emisoras comunitarias y que desde la Política se definan estrategias para que se asegure su sostenibilidad. Es claro que las emisoras comunitarias no pueden ser con ánimo de lucro, pero tampoco pueden ser con ánimo de pérdida y aunque por su perseverancia casi siempre encuentran una salida para los limitantes económicos en forma de bazares y bingos, es un tema que no puede quedar a la deriva pues se corre el riesgo de que la solución provenga de algo tan indeseable como la cooptación de las emisoras comunitarias por parte de intereses privados y comerciales.

Una política que renueve su mirada sobre el ciudadano. Conviene partir de un interrogante, ¿Cuál es la concepción de ciudadano implícita en la política pública? Es una visión del ciudadano como objeto pasivo beneficiario de la política o por el contrario se le 
aborda como sujeto activo de sus procesos y ciclos. No es posible hacer todo por la radiodifusión comunitaria, pero sin la radio comunitaria, es decir, es necesario contar con la ciudadanía organizada en este sector para asegurar no sólo la pertinencia sino la viabilidad de la Política.

Cambiar el enfoque de la intervención al del acompañamiento. En Colombia, el principal ente de control de las emisoras comunitarias es el Estado, esto configura un ambiente de dependencia irónico en el que el gobierno aparece para otorgar licencias e imponer sanciones -como el caso de la multa de la emisora Samán por invasión de espectro electromagnético- pero es poco visible en un proceso global de acompañamiento, o al menos no en el contexto tolimense. Un acompañamiento integral podría promover la sostenibilidad y legitimidad de los proyectos comunicativos y componentes técnicos de estas emisoras, de igual manera, se facilitaría la sistematización de los aprendizajes que se derivan de sus experiencias.

Tejer puentes. Incluir estrategias para superar rutinas productivas de carácter individual entre las emisoras comunitarias. Al respecto se sugiere construir y consolidar propuestas más allá de proyectos generales de corto plazo, y plantear desde el componente programático líneas de desarrollo epistemológico, y metodológico que contribuya a fortalecer el campo de la comunicación comunitaria, esto permitirá nutrir tanto la práctica como la reflexión de los medios comunitarios en Colombia. De igual manera, es necesario articular redes de formación para poner en común los diferentes procesos de aprendizaje y diálogo que tienen lugar en lo local y que terminan invisibilizados por lógicas institucionales.

Aprovechar el papel de la comunidad. La Política Pública de Radiodifusión comunitaria no se puede seguir haciendo únicamente donde hay aire acondicionado, se debe consolidar el rol activo y transformador de las comunidades y gobiernos locales de cara al diseño, ejecución y evaluación de la Política. De este modo se podría superar la visión y práctica difusionista e instrumental que produce la brecha entre la práctica y la teoría.

Alentar la producción de conocimiento desde la práctica. Se considera pertinente que en cada territorio se emprenda una cartografía histórica y crítica de las emisoras comunitarias, para situar y proyectar trayectorias, hitos y contribuciones comunes, así como diferencias principales, que permita recuperar la memoria y trazar nuevos itinerarios a partir de referentes concretos que alimenten la toma de decisiones desde la Política. Este ejercicio de producción de conocimiento debe revisar con rigurosidad las formas y niveles de institucionalización que operan en la puesta en contexto de la Política, las historias particulares y comunes, las formas y estrategias de legitimación tanto en el interior de la comunidad como en la relación con las instituciones de cada territorio. Este conocimiento que nace de la práctica debe asumirse desde las preguntas vitales sobre los saberes propios que definen o deberían definir el quehacer de estos medios.

Reflexionar también sobre lo comercial. Revisar en forma crítica y constructiva las condiciones que impone en nuestro país el modelo privatizador de la comunicación. Con el lucro en primer lugar se amenaza el ethos de la comunicación comunitaria y para el desarrollo, así como la cultura organizacional de la radio comunitaria y el valor de la conciencia crítica que debe acompañar su camino.

Una Política Pública de radiodifusión comunitaria de estas características requiere de la unión de muchos esfuerzos, tanto académicos como institucionales, y con una dosis importante de trabajo en red que ayude a que se superen las excusas y las barreras territoriales que tienen su origen en elementos culturales. Las breves reflexiones que aquí 
se han propuesto pretenden servir de invitación para trabajar por un modelo concreto de cooperación en la comunicación y la cultura.

Se considera necesario tener una mirada no sólo cultural sino también política y económica de la comunicación para el desarrollo y el cambio social. Esta nueva racionalidad debe defender la diversidad cultural con el protagonismo de la ciudadanía y de nuevos actores políticos y promover el diseño de políticas locales de comunicación. No se trata entonces de romper las tensiones, sino de tener una perspectiva adecuada que permita asegurar un marco normativo más pertinente para nuestros contextos.

\section{Recomendaciones}

Se propone siguiendo la línea del estudio realizado, incursionar en investigaciones que aborden un análisis contextual de las dinámicas sociales, culturales y económicas que inciden en la gestión de las emisoras comunitarias desde el punto de vista técnico, financiero y de producción de contenidos y de acuerdo con ello construir una ruta metodológica pertinente para que las emisoras comunitarias emprendan procesos de autodiagnóstico. Una de las líneas que debería incluir el autodiagnóstico, corresponde a los estudios sistemáticos de audiencia que permitan un mejor conocimiento de los hábitos, gustos y preferencias sonoras de los radioescuchas por parte de las emisoras comunitarias de manera que su programación y contenidos respondan de manera pertinente a estas expectativas.

De forma paralela, se considera pertinente abordar un ejercicio de cartografía histórica y crítica de las emisoras comunitarias que haga explícita la relación entre el tipo de proceso organizativo en el seno del cual surgieron y su situación actual. Se considera que un abordaje de este tipo podría conducir a dos resultados principales, primero, la actualización de los criterios que se tienen en cuenta para el otorgamiento de licencias de funcionamiento por parte del MinTic, segundo, la proyección de rutas de trabajo colectivas con componentes de trabajo individual.

Es posible seguir perfeccionando este estudio y plantear nuevas perspectivas de análisis, como, por ejemplo, profundizar en los procesos de autogestión de las emisoras comunitarias, la configuración de ciudadanías e identidades locales y las estrategias de relacionamiento con las comunidades. En ese sentido se abren nuevas preguntas como: ¿Qué características de los contextos municipales favorecen la legitimación de las emisoras comunitarias como escenarios para la participación y la democratización de la comunicación?, de acuerdo a los contextos regionales ¿qué diferencias y elementos comunes existen entre el funcionamiento e historia reciente de las emisoras comunitarias 
de cada región? y de acuerdo a ello, ¿qué aprendizajes y buenas prácticas se pueden compartir?, ¿De qué manera se ha reconfigurado la noción de ciudadanía en la trayectoria de las emisoras comunitarias y qué tipo de ciudadano se legitima en su práctica cotidiana?, ¿Cuáles son los modelos de gestión que se pueden inferir y caracterizar a partir del análisis del funcionamiento de las emisoras comunitarias?

Una de las conclusiones del estudio se refiere a la necesidad de analizar desde el punto de vista económico el rol de las emisoras comunitarias, es pertinente indagar en ese sentido por el aporte de estos medios a las dinámicas de desarrollo local desde la perspectiva de la planeación participativa del desarrollo y el posicionamiento de problemáticas susceptibles de abordarse en agendas de desarrollo territoriales.

En función de lo anterior se requiere de una producción de conocimiento comprometida con la práctica y la experiencia, que a su vez retome en su desarrollo los saberes de los representantes del sector de la radiodifusión sonora comunitaria en Colombia. En lo que respecta a la Política, se podrían abordar estudios que desarrollen un análisis de la Política Pública en sentido estricto que reconstruya la memoria de su etapa de formulación y proponga líneas de acción para su evaluación y actualización.

\section{Bibliografía}

Alboan, Instituto de derechos Pedro Arrupe y Hegoa (2004). La sistematización, una nueva mirada a nuestras prácticas. Guía para la sistematización de experiencias de transformación social. Consultado el 20 de septiembre de 2014 en: http//www.alboan.org/archivos/portindice.pdf

Aguiló, A. (2009). Los derechos humanos como campo de lucha por la diversidad humana: un análisis desde la sociología de Boaventura de Sousa Santos. Universitas Humanística, 180-205.

Alcántara Sáez, M. (2004). Gobernabilidad, crisis y cambio. México: Fondo de Cultura económica.

Almond, G. (1990). The study of political culture. En G. Almond, A discipline divided: school and sectors in political science (págs. 130-150). New Port. 
Alvarado, O. (1998). El plan de ajuste: orden en la casa . En C. N. Televisión, Canales regionales de TV: una mirada estatal (págs. 25-32). Bogotaá: Convenio Andrés Bello-Fundación Antonio Restrepo Barco.

Arendt, H. (1993). La condición humana. Barcelona: Paidós.

Arendt, H. (1997). ¿Qué es la política? Barcelona: Paiidós.

Barbero, J. (1987). La comunicación desde la cultura. Crisis de lo nacional y emergencia de lo popular. Estudios sobre las culturas contemporáneas, 45-69.

Barbero, J. (2002). Oficio de cartógrafo. Travesías latinoamericanas de la comunicación en la cultura. Santiago de Chile: Fondo de Cultura Económica.

Barbero, J. M. (1987). De los medios a las mediaciones. Barcelona: Gustavo Gili.

Barbero, J., Rey, G., \& Rincón, O. (2002). Televisión pública cultural de calidad. Gaceta Ministerio de Cultura, 50.

Bauman, Z. (2002). En busca de la política. México: Fondo de cultura económica.

Becerra, M. (2008). Information society policies: the digital divide after the world summit. En A. Fernandez, M. Moragas, \& (eds.)), Communication and cultural policies in Europe (págs. 123-150). Barcelna: Lexikon.

Benedetti, A. (1995). La televisión del futuro. La nueva Ley de televisión. Bogotá.

BID. (2011). Cadenas de valor en lo público.

Bobbio, N. (1998). La gran dicotomía de lo público y lo privado. En Estado, Gobierno y Sociedad. México: Fondo de Cultura Económica.

Bresnahan, R. (2003). Los medios y la transición neoliberal en Chile. Promesa democrática incumplida. Perspectivas latinoamericana, 39-68.

Butler, J. (2009). Vida precaria. Buenos Aires: Paidós.

Califano, B. (2011). Políticas públicas de comunicación. Un acercamiento conceptual para su análisis. . Obtenido de Instituto de investigaciones Gino Germani.

Canclini, N. (1987). Ni folklórico ni masivo ¿Qué es lo popular? Revista Diálogos de la Comunicación. Perú: Felacs.

Caparrós, M. (2011). Argentinismos. Buenos Aires: Planeta.

De la Maza, G. (2007). Actores y asuntos públicos. En M. Erazo, P. Martín, \& H. Oyarce, Políticas públicas para un Estado social de derecho: el paradiigma de los derechos universales (págs. 149-168). Santiago de Chile: LOM. 
Del Valle, C. (2004). Comunicación, participación y el dilema existencial del Estado frente a las nuevas lógicas democráticas y ciudadanas: discursos y experiecias participativas en Chile. En J. Encina, J. Pino, \& F. Sierra, Participación, comunicación y desarrollo comunitario, Democracias participativas (págs. 229-273). Sevilla: Instituto europeo de comunicación y desarrollo.

EIGazi, J. (2011). La experiencia de las emisoras ciudadanas y comunitarias. En J. Pereira, A. Cadavid, \& (eds), Comunicación, desarrollo y cambio social (págs. 36-45). Bogotá: Pontificia Universidad Javeriana.

Elías, N. (1994). Conocimiento y poder. Madrid: La Piquete.

Escobar, A., \& Osterweil, M. (2009). Movimientos sociales y la política de lo virtual. Tabula Rasa, 123-161.

Espinel Torres, Y. R. (2011). Entre el optimismo y la incertidumbre. Estudio sobre la Política Distrital de comunicación comunitaria PPDCC (2003 -2009). Bogotá: Universidad Inpahu .

Exeni, J. (2005). Metamorfosis: Comunicación Política e ingobernabilidad en democracia. Bolivia: FOADO.

Fox, E., \& Anzola, P. (1989). Política y televisión regional en Colombia. En E. Fox, \& P. Anzola, Medios de comunicación y política en América Latina. La lucha por la democracia (págs. 107-118). España: G.Gili.

Gaitán García, A. (2010). Distancia de poder y autoridad: algunas evidencias empíricas para Colombia. En F. Rojas, I. Pérez, \& H. Gil, Comunicación y Comunidad (págs. 127-157). Bogotá: Universidad Externado.

García Canclini, N. (2001). La globalización imaginada. Argentina: Paidós.

Giménez, G. (1993). Cambios de identidad y cambios de profesión religiosa. En G. Bonfil Batalla, Nuevas identidades (pág. 25). México.

Gómez, R. (1994). Perspectivas. La tv comunitaria en Colombia. Signo y pensamiento N²4, 25-32.

Guerrero, V. (1990). Coyuntura legal y uso de la comunicación. Gaceta, 27-28.

Gumucio Dagron, A. (2011). Comunicación para el cambio social: clave del desarrollo participativo. En J. Pereira, \& A. Cadavid, Comunicación, desarrollo y cambio social (págs. 27-38). Bogotá: Pontificia Universidad Javeriana.

Habermas, J. (1986). Historia y crítica de la opinión pública. México: GG Massmedia. 
Harvey, E. (2000). Régimen legal de los medios en Legislación cultural de los países del Convenio Andrés Bello. Obtenido de Unesco: http://unesdoc.unesco.org/images/0005/000507/050705so.pdf

Kaplún, G. (2007). La comunicación comunitaria en América Latina. En B. Díaz, Mdios de comunicación: el escenario Iberoamericano (págs. 311-342). Madrid: Fundación Telefónica.

Kaplún, M. (1987). El comunicador popular. Buenos Aires: Humanitas.

Khanacademy. (2015). Khanacademy. Recuperado el 26 de Septiembre de 2017, de https://es.khanacademy.org/science/physics/forces-newtons-laws/tensiontutorial/a/what-is-tension

Londoño, J. (1999). La nueva Ley de Radiodifusión Sonora Comunitaria en el proceso de democratización de las comunicaciones en Colombia. Encuentro Nacional de Radios Comunitarias En la Onda de la Paz (págs. 36-49). Bogotá: Ministerio de Cultura-Red Recorra.

López de la Roche, F. (1999). Las relaciones entre comunicación y cultura y la formulación de políticas culturales. Seminario distrital Políticas culturales para Santafé de Bogotá. Bogotá: Fondo Mixto de Cultura y las Artes.

Mata, M. C. (s.f). Obtenido de La radio, una relación comunicativa: https://archive.org/stream/LaRadioUnaRelacionComunicativaMataMCristina/La\%20r adio\%20Una\%20relacion\%20Comunicativa\%20Mata\%20M\%20Cristina_djvu.txt

Mc Bride, S. (1980). Un solo mundo, voces múltiples, comunicación e información en nuestro tiempo. México: Unesco.

Ministerio de Comunicaciones República de Colombia. (2007). Raio y Pluralismo Política de Radiodifusión Sonora Comunitaria. Bogotá.

Ministerio de la tecnología, información y comunicación. (02 de mayo de 2017). MinTic. Obtenido de https://mintic.gov.co/portal/604/w3-article-8921.html

Morin, E. (2001). Los siente saberes necesarios para educación del futuro. . México: El correo de la Unesco.

Mosco, V. (2006). La economía politica de la comunicación: Una actualización diez años después. Cuadernos de información y Comunicación, 57-79.

Mouffe, C. (2005). The return of the political. Londres: Verso.

Osorio, J., \& Rubio, G. (2007). La cualidad. Reflexividad, Investigación-acción y Enfoque Indicial en Educación. Santiago: Escuela de Humanidades y Política. 
Osses, S. L. (2002). Nuevo sentido de lo comunitario: La radio comunitaria en Colombia. Facultad latinoamericana de Ciencias Sociales.

Paiva, R. (2003). El espíritu común: comunidad, medios y globalismo.

Piquero V, F. (1995). Aspectos jurídicos de la prensa en Colombia. En E. Castillo, \& (Comp), Libertad de expresión en los países andinos. Lima: Fundación Konrad Adenauer.

Presidencia de la República. ( 1990). Obtenido de http://www.suin.gov.co/viewDocument.asp?id=1754184

Presidencia de la República. (1995). Decreto 1445. Obtenido de http://www.suinjuriscol.gov.co/viewDocument.asp?id=1288368

Presidencia de la República. (1995). Decreto 1447. Obtenido de http://legislaciontelecomunicaciones.weebly.com/decreto-1447-de-1995.html

Rincón, O. (2015). La creación de las ciudadanías celebrities en las culturas bastardas. En J. M. Pereira, Televisión y construcción de lo público (págs. 41-59). Bogotá: Universidad Javeriana.

Roth, A. (2002). Políticas Públicas. Formulación, implementación y evaluación. Bogotá: Aurora.

Salinas Bascur, R. (1984). Política y comunicación: el estilo que falta en la iglesia. Quito: UNDA-AL.

Sánchez, J. (1995). Los monopolios y la censura en tv. Bogotá.

Santos, B. (2005). El Milenio Huérfano. Madrid: Trotta.

Serrano A, L. (1983). Legislación sobre prensa. Prensa escrita, radiodifundida y televisada. Bogtotá: Derecho colombiano.

Sierra, F. (2005). Políticas de comunicación y educación crítica y desarrollo de la sociedad del conocimiento. Barcelona: Gedisa.

Surel, Y. (2006). Relación entre la política y las políticas públicas. En R. Franco, \& J. Lanzaro, Política y políticas públicas en los procesos de reforma de América Latina (págs. 43-73). Buenos Aires: Naciones Unidad.

Thompson. (1998). Los media y la modernidad: una teoría de los medios de comunicación. Barcelona: Paidós .

Turner. (1988). El proceso ritual. Madrid: Taurus.

Unesco. (2003). Legislación sobre radiodifusión sonora comunitaria. Estudio comparativo de legislaciones de trece países. 
Unesco. (2005). Unesco. Obtenido de Convención sobre la protección y promoción de la diversidad de las expresiones culturales:

http://unesdoc.unesco.org/images/0014/001429/142919s.pdf

Villasante, T. R. (2002). Sujetos en movimiento. Redes y procesos creativos en la complejidad social. . Montevideo: Nordan.

Vizcaíno, M. (2005). La legislación sobre tv en Colombia: del Estado al Mercado". Historia Crítica(28), 127-152. Obtenido de

http://revistas.uniandes.edu.co/doi/pdf/10.7440/histcrit28.2005.05

Winocur, R. (2000). La participación en la radio, una posibilidad negociada de ampliación del espacio público. Diálogos de la comunicación, 37-46.

Wolton, D. (1998). La comunicación política: construcción de un modelo. En D. Wolton, \& Ferry, El nuevo espacio público (págs. 28-46). Barcelona: Gedisa. 


\section{Anexos:}

Anexo A: Guía de entrevista semiestructurada con actores de los municipios del Tolima

Esta guía contiene las preguntas a partir de las cuales se llevaron a cabo las entrevistas con actores de los municipios de Natagaima, Alpujarra, Rioblanco y San Antonio. Esta guía se estructura a partir de tres ejes de indagación: perspectiva histórica, proyecto comunicativo, y procesos de producción de contenidos.

\section{Guía entrevista semiestructrurada con actores de los municipios del Tolima}

\section{Perspectiva histórica:}

4. ¿Quiénes fueron los pioneros, y qué motivó el surgimiento del medio de comunicación?

5. ¿Cuál es la historia de los primeros años del medio? (indagar por los hitos que permitieron el nacimiento del medio, participantes etc.)

6. ¿Cómo fue el acompañamiento que recibieron en el proceso de creación del medio? (particulares, instituciones, otros)

\section{Proyecto Comunicativo:}

5. ¿Cuál es el enfoque del medio de comunicación? (Se está haciendo referencia en esta pregunta al proyecto comunicativo)

6. ¿Cómo se ve reflejado en la parrilla de programación este enfoque?

7. ¿De qué manera la comunidad y las organizaciones locales participan en la producción de contenidos y a qué tipo de públicos van dirigidos? (Es importante profundizar en el tipo de formatos y contenidos que se privilegian en el medio de comunicación)

8. ¿Existe un documento en el que esté consignada la información que define la identidad del medio de comunicación? ¿Las personas vinculadas conocen el documento-particularidades? ¿Cómo se llevó a cabo la construcción de este documento? ¿Quiénes participaron? ¿Qué dificultades se han presentado en el desarrollo del proyecto comunicativo, como se podrían superar?

\section{Procesos de producción:}

5- ¿Quiénes están vinculados a la producción técnica del medio y con qué experiencia cuentan? 
6- ¿Qué dificultades técnicas presenta el medio de comunicación y cuáles son las debilidades en el proceso de producción de contenidos?

7- ¿Qué espacios de capacitación existen quienes están vinculados en la producción?

8- ¿De qué manera se da a conocer el medio de comunicación?

\section{Cierre:}

¿Cuáles son los aportes que genera el medio de comunicación al contexto local a nivel económico, político, social?

Anexo B: Guía para el desarrollo del taller con actores del territorio.

Esta guía presenta de manera detallada las distintas actividades previstas en el desarrollo del taller con el fin de construir una reflexión colectiva con los participantes acerca del papel de la emisora en el contexto local así como su rol como audiencia y gestores de contenidos.

Anexo C: Política Pública de radiodifusión sonora comunitaria

Esta Política Pública se expidió en el año 2007. Contiene cinco apartados: Fundamentos conceptuales, diagnóstico, principios, objetivos, estrategias con cajas de herramientas por objetivos. Es el documento de Política al que se hace referencia en el apartado número dos.

Anexo D: Guía de obligaciones que deben tener en cuenta las organizaciones concesionarias de las emisoras comunitarias para estar al día con el MinTIC

El documento se publicó el 2 de mayo de 2017 en la página web del MinTic. Este se plantea como una guía de obligaciones que deben tener en cuenta las emisoras comunitarias para estar al día con el Ministerio. Algunas de las obligaciones a las que hace referencia el documento son: solicitud de prórroga de la concesión, informar o solicitar autorización para la suspensión temporal de las transmisiones inferiores a 15 días, la no modificación de parámetros técnicos aprobados (frecuencia, potencia, centro de radiación de la antena, entre otros), organización de la programación y de la pauta publicitaria de acuerdo a fines del servicio, elaborar y dar a conocer el Manual de estilo, realizar proyectos y estrategias de comunicación a petición del MinTic, apoyar a las autoridades locales en caso de emergencia o calamidad pública, entre otras.

Anexo E: Guía de entrevista estructurada con líderes representantes de las emisoras comunitarias.

Esta entrevista se llevó a cabo de manera inicial con los líderes representantes de las emisoras comunitarias con el fin de identificar el contexto histórico de origen de las emisoras, así como el capital social en el que se apoya el funcionamiento cotidiano del medio. 
Anexo F: Documento resumen de relatorías taller de identificación y caracterización de medios comunitarios de comunicación

El documento recoge una relatoría general de los talleres llevados a cabo en los cuatro municipios con la participación de actores de la comunidad y líderes de las emisoras. 